\title{
VARIATION IN FLORAL FRAGRANCES AND POLLINATORS IN THE Gongora quinquenervis COMPLEX (ORCHIDACEAE) IN CENTRAL PANAMA
}

\section{By}

WILLIAM MARK WHITTEN

A DISSERTATION PRESENTED TO THE GRADUATE SCHOOL OF THE UNIVERSITY OF FLORIDA IN

PARTIAL FULFILLMENT OF THE REQUIREMENTS FOR THE DEGREE OF DOCTOR OF PHILOSOPHY

\section{UNIVERSITY OF FIORIDA}




\section{ACKNOWLEDGEMENTS}

I am deeply grateful to my parents for their continued encouragement and support during my graduate career. I especially grateful to Norris williams for his encouragement and for his help in obtaining funding, materials, and equipment for my work, and for introducing me to orchid biology. I thank the members of my committee for their advice and help with various aspects of my work, and for sharing their enthusiasm for tropical botany. The Department of Botany provided assistantships and generous greenhouse space and supplies. The Florida state Museum provided me with financial support and with lab space. I am grateful to the University for the purchase of the GC/MS system that was used so heavily during my work. This study was funded in part by NSF grant DEB-8116538.

I have relied heavily on the help and advice of many chemists during this study. I wish to thank Ralph Dougherty, Merle Battiste, Dave Carlson, Niels Linquist, Lucjan Strekowski, Gregg McClure, and John walradt for their generous help in chemical analysis and data interpretation. I especially wish to thank Terry Davis for advice on chemical synthesis and for the synthesis of elemicin. 
Robert Dressler provided invaluable help during my field work in Panama and at the Smithsonian Tropical

Research Institute (STRI). He provided numerous plants used in this study and assisted in the identification of bees and plants. Both he and Kerry Dressler provided unfailing hospitality whenever I was at STRI.

Two individuals deserve special thanks. Ron Determan devoted many hours to the care of the orchid collection and prevented the demise of many of my research plants. He also taught me much about orchid culture and taxonomy. I wish to thank Mark Elliott for his help during two seasons of field work and for many hours spent catching bees. 
TABLE OF CONTENTS

Page

ACKNOWLEDGEMENTS $\ldots \ldots \ldots \ldots \ldots \ldots \ldots \ldots \ldots \ldots \ldots \ldots \ldots \ldots \ldots \ldots \ldots \ldots$

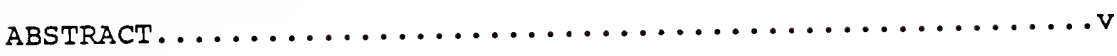

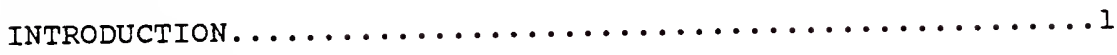

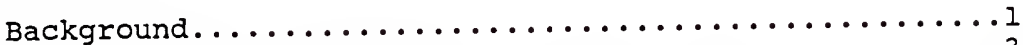

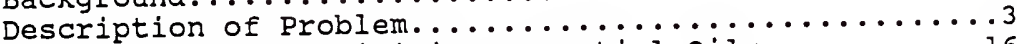

Phenetic studies Utilizing Essential oils..........16

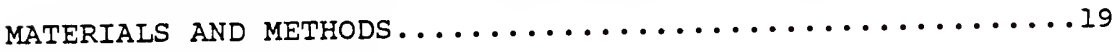

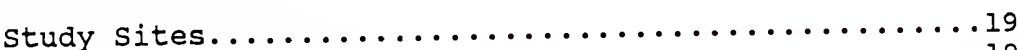

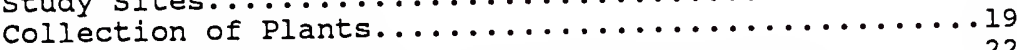

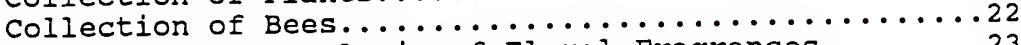

Collection and Analysis of Floral Fragrances........23

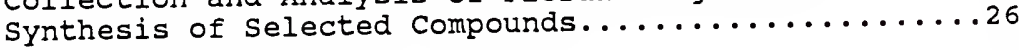

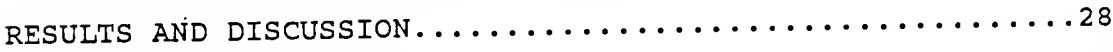

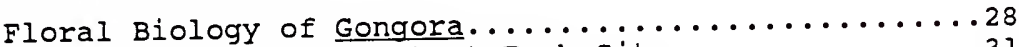

Gongora Species Present at Each Site..............

Compounds Present in Floral Fragrances.............

Reproducibility of Fragrance Samples............

Variation in Floral Fragrance composition.........44

Bee Species Present at Each Site.............. 82

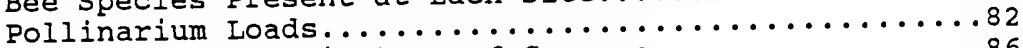

Visitors and Pollinators of Gongora............86

Bees Attracted to Synthetic Fragrance compounds.....89

Alternative Fragrance Sources...............95

Floral Morphology of $G$. quinquenervis and $G$. gibba...95

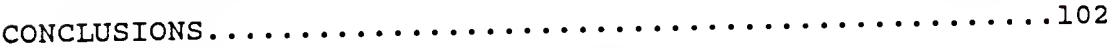

SPECULATION ON THE ORCHID/EUGLOSSINE INTERACTION

AND SUGGESTIONS FOR FUTURE STUDIES................ 109

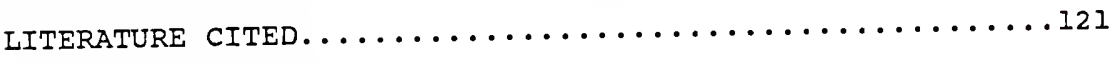

BIOGRAPHICAL SKETCH....................... 
Abstract of Dissertation Presented to the Graduate School of the University of Florida in Partial Fulfillment of the Requirements for the Degree of Doctor of Philosophy

\section{VARIATION IN FIORAI FRAGRANCES AND POLIINATORS IN THE Gongora quinquenervis COMPLEX (ORCHIDACEAE) IN CENTRAL PANAMA}

\section{By}

\section{William Mark Whitten}

$$
\text { August, } 1985
$$

Chairman: Norris H. Williams Major Department: Botany

Species of the genus Gongora (Stanhopeinae: orchidaceae) are pollinated by fragrance-collecting male euglossine bees (Apidae: Euglossini). The $\underline{G}$. quinquenervis complex contains many species and varieties that differ mainly in flower odor, color, Iip morphology, and pollinators. Floral fragrances and pollinators of Gongora quinquenervis, G. tricolor, and $\mathrm{G}$. gibba were studied at several sites in central Panama. Pollinators were observed in the field. Floral fragrances of 144 plants were analyzed using gas chromatography/mass spectrometry. Each morphological species produces a qualitatively distinct fragrance that attracts a unique set of pollinators. Variation also exists within species. Principal component analysis and cluster analysis reveal two fragrance taxa within both $\mathrm{G}$. tricolor and within $\mathrm{G}$. quinquenervis. Both taxa of $\underline{G}$. tricolor attract the same pollinator. The two taxa of $G$. quinguenervis attract different pollinators and 
appear to be reproductively-isolated sibling species. Floral fragrances are useful characters in distinguishing ethologically-isolated sibling species of euglossinepollinated orchids. 


\section{CHAPTER I \\ INTRODUCTION}

\section{Background}

An estimated 625 species of neotropical orchids are pollinated exclusively by male euglossine bees (Apidae:

Euglossini) (Dressler 1982). The tribe Euglossini is composed of five genera of long-tongued, neotropical bees: Euglossa; Eulaema; Eufriesea (incl. Euplusia); Exaerete; and Aglae. Euglossa, Eulaema, and Eufriesea are important pollinators of orchids, and together they comprise about 180 species. The importance of male euglossine bees as pollinators of orchids is now well-documented (Dodson, 1962, 1970; Dodson et al., 1969; Dressler, 1967, 1968a,b; 1982; Hills et al. 1972). Flowers that are pollinated by male euglossine bees are highly fragrant, lack nectar, and attract no other visitors. The above workers have shown that the strong floral fragrance of the orchids is the primary attractant of male euglossine bees. The bees collect the fragrance chemicals from the flower with their modified front legs ("brushing" behavior), hover, and transfer the compounds to their inflated hind tibia, where the fragrance is stored. Female bees lack the inflated hind tibia and are not attracted to the floral fragrances. The purpose of fragrance collection is still unknown, but the compounds might serve as 
pheromone precursors or territorial markers. Most of the identified floral fragrance compounds are commonly occurring plant products, either monoterpenoids or aromatic compounds (Williams and Whitten, 1983).

Pollination by fragrance-collecting male euglossines is not restricted to orchids. Brushing behavior and pollination have been observed in flowers of certain Araceae, Gesneriaceae, and Euphorbiaceae (Williams and Dressler, 1976; Wiehler, 1976; Armbruster and Webster, 1979; Croat, 1980). Both male and female euglossines visit a variety of plants to obtain nectar (Dressler, 1982), and female bees collect resin (for nest construction) from a number of plants such as Dalechampia and Clusia (Armbruster 1984).

The attraction of male euglossine bees to orchid flowers is highly species-specific; a given orchid species may attract only one or a few species of visitors, even though many bee species occur in the area. This specificity is based upon species-specific differences in floral fragrance composition. The fragrances of about 150 species of orchids have been analyzed by gas chromatography (Hills et al. 1972; Hills et al. 1968; Williams and Whitten 1983; Williams and Whitten, unpub.). A total of about 70 major compounds have been identified using gas chromatography/mass spectrometry (GC/MS). Some of the identified compounds are general attractants (e.g. cineole) and attract many species of euglossines, whereas others do not attract any bees and may act as repellents. Mixtures of compounds reduce the number 
of bee species attracted, and appropriate blends may attract only one or a few bee species (Williams and Dodson 1972). Such species-specific floral fragrances may serve as isolating mechanisms between closely-related species by selectively attracting one or a few species of bee as pollinators (Hills et al. 1972; Williams and Dodson 1972; Williams and Dressler 1976). Floral fragrances may be the primary isolating mechanism between closely-related taxa, or may act together with mechanical (e.g. size and placement of pollinaria on the bee), geographical, and temporal isolating mechanisms.

\section{Description of problem}

The genus Gongora (Gongoreae: Orchidaceae) is one of the most taxonomically difficult genera of male euglossinepollinated orchids. About 25 species are currently recognized in the genus, ranging from central Mexico to northern Brazil. The variability of some species (especially in flower shape, color and odor) and their wide geographic range has resulted in considerable taxonomic confusion. The Gongora quinquenervis Ruiz \& Pavon complex contains at least 25 described species. Some current workers have lumped the entire complex into one species (Dunsterville and Garay 1959), while Dressler (1966) suggested that perhaps twelve valid species exist within the complex, based upon floral and vegetative morphology, pollinators, and fragrance composition. Within Panama and Costa Rica, Dressler 
$(1968 a, b)$ recognized six species and two tentative species within the Gongora quinquenervis complex. These morphologically distinguishable species produce different fragrances and are usually pollinated by different euglossine species. Those which share a common pollinator are allopatric. Three species occur in central Panama; these are Gongora quinquenervis, $\underline{G}$. tricolor (Lindley) Rchb.f., and $\underline{G}$. gibba Dressler.

Considerable variation remains within Dressler's Gongora quinquenervis (sensu stricto). He reported (Dressler $1966 ; 1968 a, b)$ that some Panamanian $\underline{G}$. quinquenervis attract only Euglossa variabilis or E. tridentata, whereas other plants attract both bees plus several other species of Euglossa. At least 27 species of male euglossines have been recorded as visitors to $\underline{G}$. quinquinervis throughout its range (Table 1). The number of euglossine species that may carry Gongora pollinaria is amazingly large. This large number probably results from the wide range of $\underline{G}$. quinquenervis s.1., from geographic variation in bee faunas, and from variation in Gongora floral fragrances. Dressler (1968b, 1981) suggests that sympatric speciation might be occurring, based upon the attraction of different pollinators to different fragrance forms. If simple mutations or hybridization produced a plant with a qualitatively different fragrance, it might attract different bee species and therefore be reproductively isolated. Selfing and inbreeding could stabilize the new chemotype and result in a sibling 
Table 1. Euglossine bees known to visit or pollinate Gongora quinquenervis

\begin{tabular}{|c|c|c|c|}
\hline Bee Species & Locality & $\begin{array}{l}\text { Number of Bees } \\
\text { Carrying Pollinaria }\end{array}$ & Reference \\
\hline \multicolumn{4}{|l|}{$\begin{array}{l}\text { EUGLOSSA } \\
\text { allosticta }\end{array}$} \\
\hline augaspis & Peru & 2 & $5, C$ \\
\hline \multirow[t]{2}{*}{ azureoviridis } & Panama & 2 & I, D \\
\hline & Costa Rica & 1 & $\mathrm{D}$ \\
\hline \multirow{2}{*}{ bursigera } & Panama & 7 & $1, D$ \\
\hline & Costa Rica & 3 & $\mathrm{D}$ \\
\hline cordata & $\begin{array}{l}\text { Trinidad } \\
\text { Guyana } \\
\text { Brazil }\end{array}$ & $\begin{array}{l}2 \\
1 \\
10\end{array}$ & $\begin{array}{l}C, D \\
D \\
D\end{array}$ \\
\hline \multirow{2}{*}{$\frac{\text { cyanaspis }}{\text { cybelia }}$} & Panama & 1 & 1,8 \\
\hline & Costa Rica & & 8 \\
\hline$\frac{\text { deceptrix }}{\text { decorata }}$ & Panama & 207 & $D, W$ \\
\hline$\frac{\text { decorata }}{\text { despecta }}$ & Peru & 1 & $5, \mathrm{C}$ \\
\hline \multirow{2}{*}{$\frac{\text { despecta }}{\text { dodsoni }}$} & Panama & 85 & $1, D, C$ \\
\hline & Panama & 1 & $\mathrm{~W}$ \\
\hline \multirow[t]{2}{*}{ dressleri } & Panama & 1 & 1 \\
\hline & Costa Rica & 1 & C \\
\hline gorgonensis & Costa Rica & & 8 \\
\hline hansoni & $\begin{array}{l}\text { Costa Rica } \\
\text { Panama }\end{array}$ & $\begin{array}{l}5 \\
2\end{array}$ & $\begin{array}{l}8, C, D \\
D\end{array}$ \\
\hline \multirow[t]{2}{*}{ hemichlora } & Panama & 6 & $8, D$ \\
\hline & Costa Rica & 1 & $\mathrm{D}$ \\
\hline \multirow{6}{*}{$\begin{array}{l}\text { heterosticta } \\
\text { ignita }\end{array}$} & $\begin{array}{l}\text { Panama } \\
\text { Peru }\end{array}$ & 15 & $\begin{array}{l}D \\
5\end{array}$ \\
\hline & Ecuador & 1 & $\mathrm{c}$ \\
\hline & Colombia & 3 & $\mathrm{D}$ \\
\hline & Brazil & 2 & $D$ \\
\hline & Guyana & 3 & C \\
\hline & Trinidad & 4 & $C, D$ \\
\hline \multirow[t]{2}{*}{ imperialis } & Panama & 6 & 1 \\
\hline & Costa Rica & 9 & $C, D$ \\
\hline ioprosopa & Ecuador & & D \\
\hline \multirow{2}{*}{ mixta } & Panama & 6 & $1, D$ \\
\hline & Peru & 1 & $5, C$ \\
\hline \multirow{2}{*}{$\frac{\text { townsendi }}{\text { tridentata }}$} & Panama & 1 & $8, C$ \\
\hline & Panama & 244 & $2,8, D, C$ \\
\hline \multirow{2}{*}{ tridentata } & Costa Rica & 5 & $C, D$ \\
\hline & Ecuador & 7 & $6, C, D$ \\
\hline \multirow[t]{3}{*}{ variabilis } & Panama & 10 & $1,7,8$ \\
\hline & Costa Rica & 1 & $3,4,8$ \\
\hline & Ecuador & 1 & $w, 5$ \\
\hline
\end{tabular}

References: $\quad D=$ R.L. Dressler bee collection; $C=C . H$. Dodson bee collection; $W=$ Whitten bee collection; $1=$ Ackerman, 1983a; $2=$ Ackerman, 1983b; $3=$ Allen, 1950; $4=$ Allen, 1954; $5=$ Dodson, 1962; $6=$ Dodson \& Gentry, 1978; 7 = Dressler, 1966; 8 = Dressler 1968a 
species differing only in fragrance and pollinators. Gregg (1983) suggests that speciation may be occurring in cycnoches densiflorum via the selection pressure of bees on preferred fragrance forms.

Dodson et al. (1969) described a similar situation at Guapiles, costa Rica. The large population of Gongora at Guapiles contains taxa in which the flowers are morphologically similar but which differ in color, fragrance, and pollinators. One taxon, Gongora unicolor schlechter, has flesh-pink flowers and a sweet fragrance. It is pollinated by Euglossa purpurea Friese. The remaining plants produce flowers which are morphologically indistinguishable, but which vary widely in color. Two fragrance taxa associated with different pollinators were distinguished; one taxon attracted Euglossa gorgonensis Cheeseman, and the other attracted Euglossa bursigera Moure. Dodson suggested that adaptive radiation to different pollinators was taking place, possibly resulting in sympatric speciation. Such a model for reproductive isolation would be applicable to many orchid genera pollinated by male euglossines. Preliminary gas chromatographic analyses of Gongora fragrances (Dodson and Hills, 1966; Hills et al., 1968; Dodson and Williams, unpub.) indicated that great variation in fragrances exists within the $\mathrm{G}$. quinquenervis complex.

Intraspecific variation in fragrance composition has been reported for several other androeuglossophilous orchid species. Dodson et al. (1969) reported two different 
fragrance taxa of Stanhopea tricornis, and Hills et al. (1972) showed that the fragrance of catasetum barbatum from Brazil is dominated by cineole, whereas $c$. barbatum from Ecuador produces ocimene. Dodson (1978) later described the Ecuadorian taxon as Catasetum thompsonii. Gregg (1983) documented fragrance variation in the cycnoches egertonianum Bateman complex and found that previously synonomized species could be distinguished on the basis of floral fragrances and subtle morphological characters of the male flowers.

There are several weaknesses in the existing data on orchid fragrances and male euglossine pollinators. The amount of intraspecific variation in fragrances and pollinator sets is poorly known; literature reports are often based on analyses or observations of one or a few plants per species. Gregg's (1983) study of cycnoches was the first to examine fragrance variation within natural populations, but pollination studies were not included. There are very few instances in which both pollination data and fragrance data are available for an individual plant. The paucity of replicate fragrance data is due primarily to sampling difficulties including the short flowering periods of many orchids and the scarcity of many species in the wild and in cultivation. Technical obstacles to trapping and analysis of fragrances have been greatly reduced in the past decade by the availability of inexpensive GC/MS systems and porous polymer adsorbents. 
I examined geographic variation in floral fragrance composition and pollinators of Gongora quinquenervis (sensu lato) in central Panama. Gongora was chosen because it is relatively common in central panama and because it is easily flowered in cultivation. Although $\mathrm{G}$. quingenervis ranges from Mexico to Brazil, this study was limited to central Panama for practical reasons. Panama has numerous accessible forested habitats, and its euglossine fauna is well-studied. The hypotheses I wished to test may be stated as follows. Do sibling species exist within the Gongora quinquenervis complex-- taxa which are morphologically similar but ethologically isolated by different fragrances and pollinators? Specific questions are: How much variation in fragrances (qualitative and quantitative) occurs in the complex in central Panama? 2. How much variation exists among the visitor and pollinator sets in the complex? 3 . How does fragrance composition correlate with data on pollinators? (Can discrete fragrance/pollinator types be distinguished?). 4. Do different fragrance/pollinator types have consistent morphological differences? 5. Can floral fragrance composition be used to predict pollinators?

Three species of the $\mathrm{G}$. quinquenervis complex are currently recognized from central Panama (Dressler, 1968b): Gongora quinquenervis Ruiz \& Pavon (sensu stricto); Gongora tricolor (Lindl.) Rchb.f; and Gongora gibba Dressler. Gongora quinquenervis is a wide-ranging morphospecies. The synonym $\mathrm{G}$. maculata Lindl. is used commonly in the literature 
(Allen, 1949). The morphology of the labellum of a generalized Gongora flower is illustrated in Figure 1. Plants with essentially identical labellum shapes range from Brazil up to Nicaragua. This species is characterized by abaxially-curved horns on the hypochile of the lip which are thin and elliptical in cross-section and by a concave base of the hypochile (Fig. 2). Two subtly-different groups occur in central Panama. Group "A" is most common; the hypochilar gap is narrow and parallel, and the base of the hypochile is deeply concave. Flower color is cream with confluent spots of yellow to brown, and the flowers produce a sweet, honeylike odor. Group "B" is rare; the hypochilar gap narrows distally, and the base of the hypochile is slightly concave or flat. Flower color is white with linear-confluent spotting of reddish-brown, and the flowers smell like pine resin. Gongora tricolor is restricted to the Atlantic coast of Panama and adjacent costa Rica, and probably occurs in Colombia (Dressler, pers. comm.). It is distinguished by its thick and massive hypochile with the horns reduced to rounded knobs (Fig. 3). The knobs are always round in cross-section, in contrast to the flattened horns of $\underline{G}$. quinquenervis. The flowers are usually brightly mottled in red, yellow, white and brown, although some forms may be nearly pure yellow or red. This species is listed under Gongora maculata Lindl. var. tricolor Lindl. in the Flora of Panama (Allen, 1949), along with Gongora maculata Iindl. var. latibasis 
Figure 1. Lateral and adaxial views of a generalized Gongora labellum, with terminology for labellum structures (redrawn from Dressler, 1972). a. claw; b. hypochilar cavity; c. hypochilar angle; d. horn; e. seta; f. callus; g. mesochilar angle; h. mesochile; i. umbo; j. epichilar cavity. All parts proximal to "h" are the hypochile, and all parts distal to "h" are the epichile. Double-headed arrows indicate the proximal and distal widths of the hypochilar gap. 

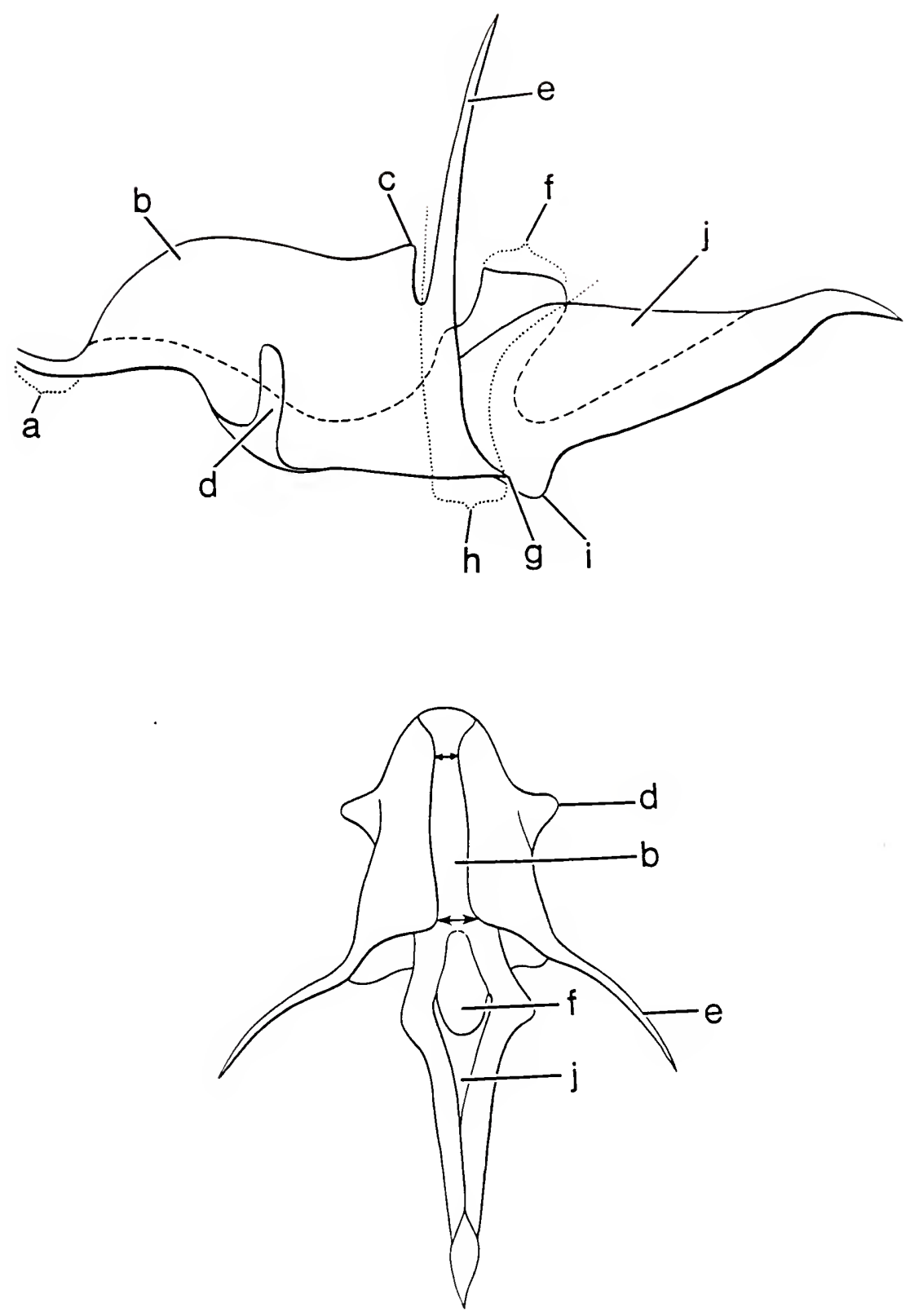


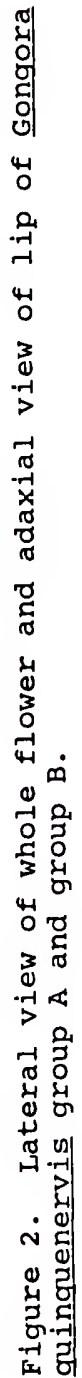



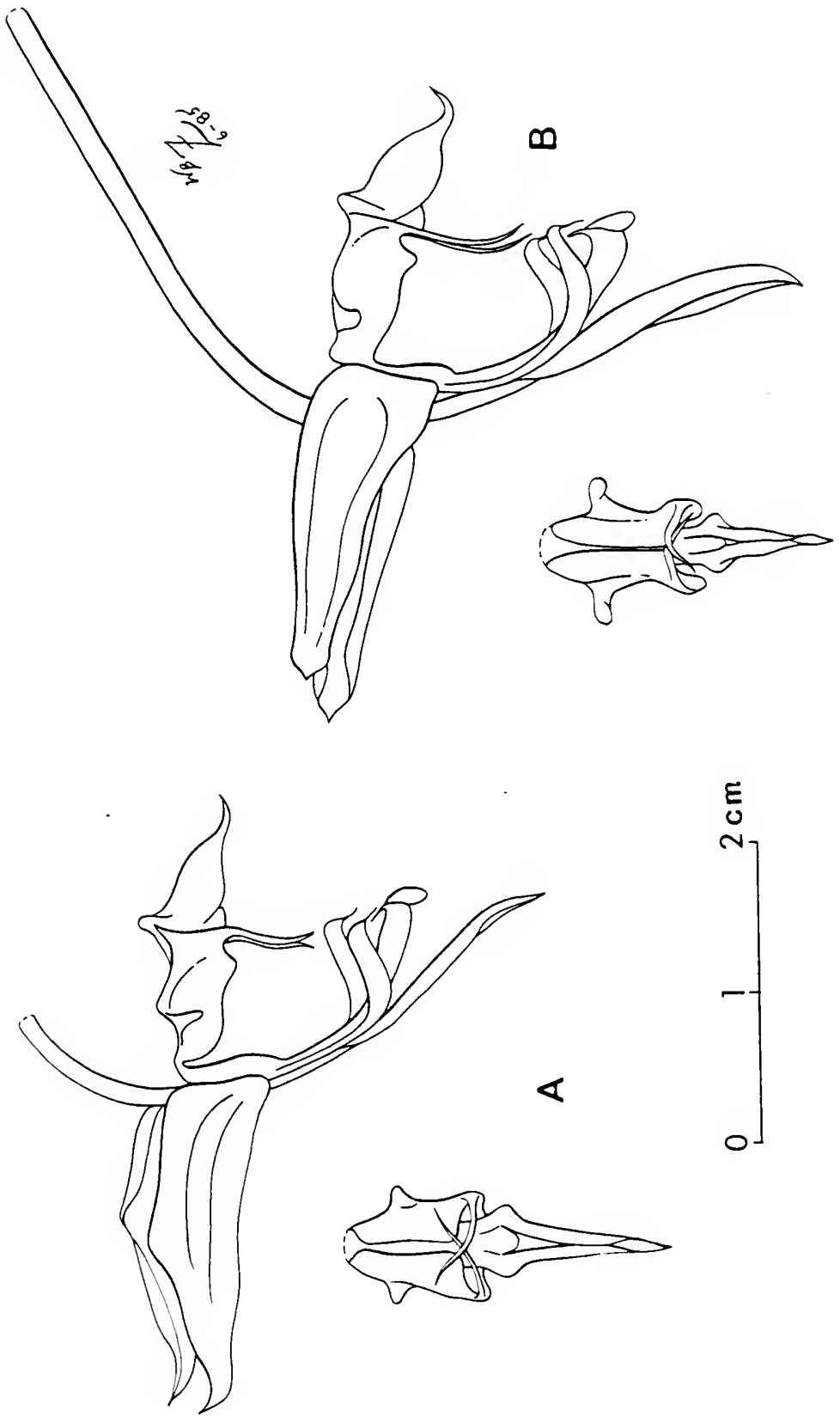


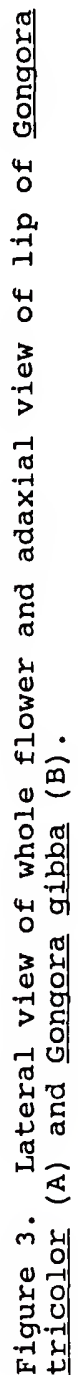




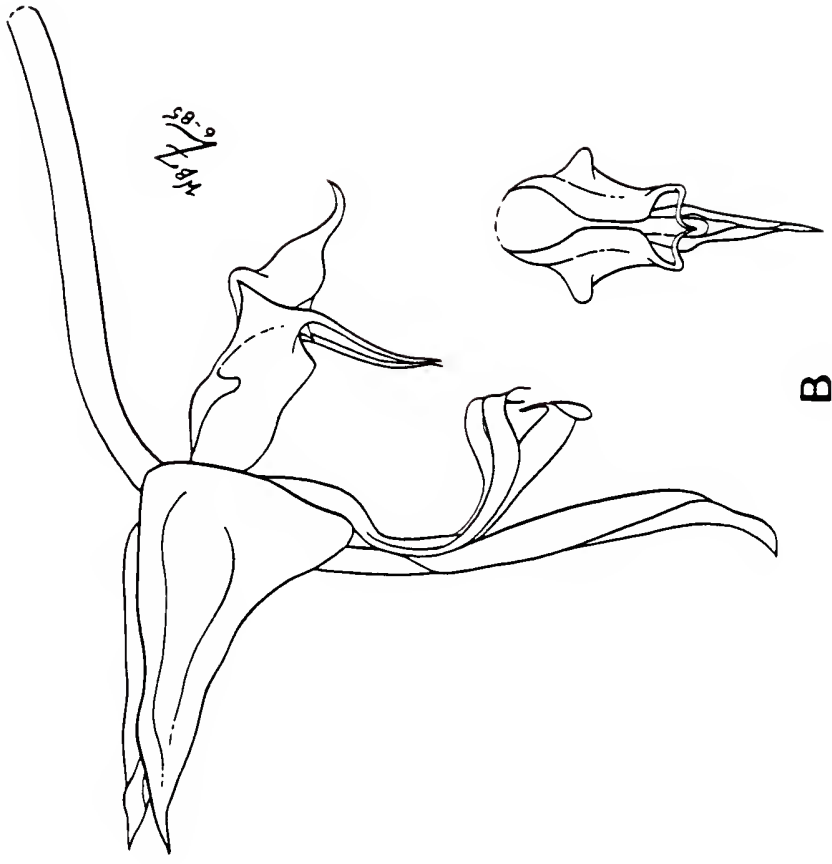

$\infty$

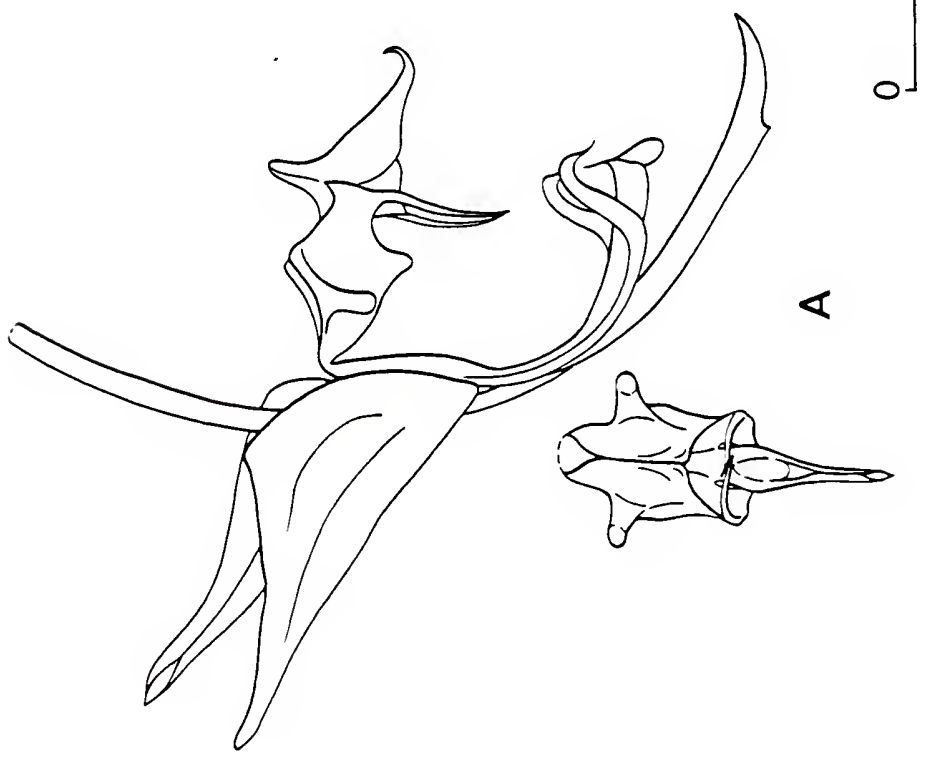


c. Schweinf. \& Allen. The description of the latter variety agrees with forms of $\underline{G}$. tricolor possessing a wider hypochile with broadly auriculate horns. Jenny (1983) reviewed the nomenclatural history of $\underline{G}$. tricolor and concluded that the name $G$. fulva Lindley has priority over tricolor. Since the original description of fulva states that the flowers are smaller than those of $\underline{G}$. quinquenervis (the reverse of the situation in Panama), the name $G$. tricolor will be used in the present work. Gongora gibba was recently described by Dressler (1972) and is an apparently rare species known from central Panama. Dressler (1972) states that it might also occur in Colombia and Peru. It is closely related to $\underline{G}$. quinquenervis but is distinguished by the convex base of the hypochile and by the greater width of the hypochilar gap at the base of the lip (Fig. 3).

The known pollinators to $\underline{G}$. quinquenervis are listed in Table 1. Gongora tricolor is pollinated only by Euglossa cyanura, and occasionally attracts Exaerete smaragdina (Dressler, 1968b; Ackerman, 1983b). Gongora gibba attracts Euglossa asarophora, E. villosa, $\underline{E}$. gorgonensis, and $\underline{E}$. nigrosignata (Dressler, 1968b, 1972), but Dressler states that probably only the latter two species are valid pollinators.

\section{Phenetic Studies Utilizing Essential oils}

Previous phenetic studies based on quantitative analysis of plant volatiles are few (Baum et al., 1984). Virtually 
all of the studies deal with variation in leaf or stem essential oils or waxes. Adams and coworkers have studied interspecific and geographical variation in Juniperus leaf oils using principal coordinates analysis (Adams and Hogge, 1983; Adams et al. 1983; Adams et al., 1984). Whiffin (1977a,b; 1981) studied variation in leaf oils of various Rutaceae using principal coordinates analysis and singlelinkage clustering. Pollack and Dancik (1985) used principal components analysis, cluster analysis, and stepwise discriminant analysis to examine introgression of two Canadian species of pinus. Cuticular waxes of sedum were examined by Bowman (1983) using principal components analysis, factor analysis, and cluster analysis. Bowman (1980) used discriminant function analysis to compare leaf waxes among species of zauschneria (Onagraceae). Tulloch et al. (1980) and Baum et al. (1980) used principal coordinates analysis to compare cuticular waxes of grasses. Stone et al. (1969) used cluster analysis to compare Carya nut oil composition. Smith et al. (1985) used linear discriminant analysis and other multivariate techniques to demonstrate that GC analyses of marking pheromones could be used to distinguish subspecies and gender of the tamarin monkey.

There are even fewer phenetic studies using floral fragrances as taxonomic characters. Williams (1983) reviewed the literature on floral fragrances and pollinators (excluding perfume industry literature). Thien et al. (1975) were the first to use GC/MS to analyze floral fragrances of 
eight species of Magnolia and one Liriodendron, but data analysis was restricted to calculation of similarity coefficients. Gregg (1983) studied variation in cycnoches fragrances using principal components analysis, but her data lacked mass spectral identifications of fragrance components. The present study differs from those above by combining a phenetic analysis of floral fragrance characters with information on the pollinators attracted to the fragrances. Hopefully, the addition of pollination data will clarify the biological significance of variation in fragrances. 


\section{CHAPTER II \\ MATERIALS AND METHODS \\ Study sites}

Gongora plants and bees were sampled at six sites in central Panama (Fig. 4). The sites are

1. Forested slopes $0.5 \mathrm{~km}$ west of Cerro Gaital, along road to La Mesa, above El Valle de Antón, Coclé Prov. Elev. $950 \mathrm{~m}$.

2. Forested slopes above Rio Iguanita, ca. $3 \mathrm{~km}$ upstream from bridge on the road to Portobelo; Colon Prov. Elev. $50 \mathrm{~m}$.

3. Forested slopes one $\mathrm{km}$ north of dirt road along Santa Rita Ridge, ca. $15 \mathrm{~km}$ east of Transisthmian Highway; Colón Prov. Elev. ca. $300 \mathrm{~m}$.

4. Forests along El Llano-Carti road, $18 \mathrm{~km}$ north of Panamerican Highway; Panama Prov. Elev $200 \mathrm{~m}$.

5. Slopes along continental divide near old logging camp near El Copé; Coclé Prov. Elev. $1200 \mathrm{~m}$.

6. Forested slopes on Finca El Indio, Cerro Azul, Panama Prov. Elev. ca. $700 \mathrm{~m}$.

\section{collection of Plants}

Gongora plants were located by searching in trees along streams and rivers where they often occur on branches hanging 


$$
\begin{aligned}
& \underset{\substack{0 \\
0}}{0} \\
& \text { 突 } \\
& \text { 齐 } \\
& \text { 站 } \\
& \text { 章 }
\end{aligned}
$$

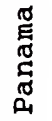

$$
\begin{aligned}
& \text { 章 } \\
& \text { 岁 } \\
& \text { 일 } \\
& \div \\
& \text { 峁 }
\end{aligned}
$$




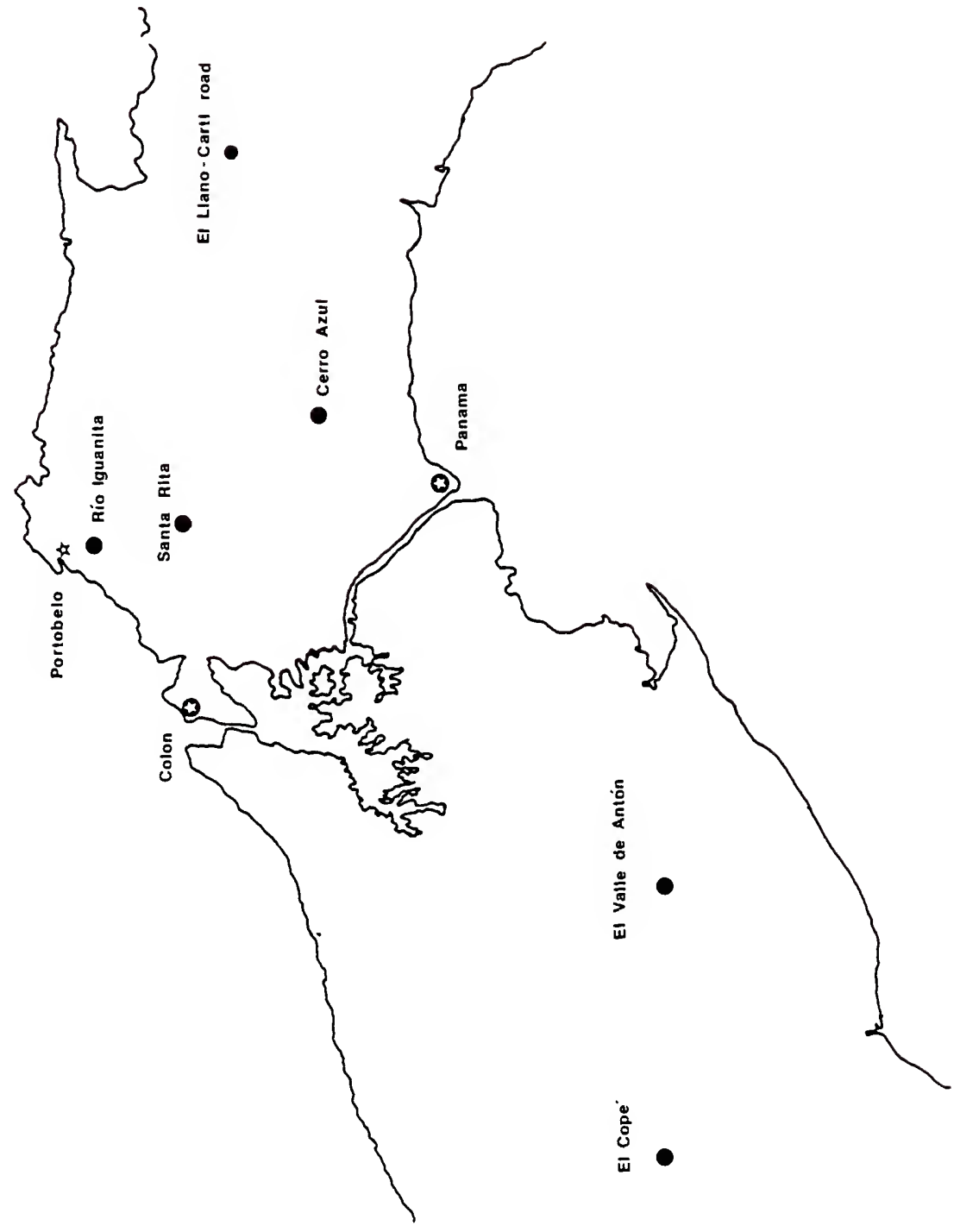


over the water. orange groves also proved to be good collecting areas. Plants were collected using long poles or a high-limb chainsaw. The plants were labelled and returned to my house in El Valle, where they were cultivated. Plants which subsequently produced inflorescences could be taken to the field for pollination studies. At the end of the field season, plants were exported to the University of Florida and cultivated in the greenhouse for fragrance analysis.

Interspecific and intervarietal crosses were made between representative plants of each species to examine crossing relationships.

\section{Collection of Bees}

Visitors to Gongora flowers were observed and collected whenever flowering plants were available. Bees were allowed to land upon the flowers and exhibit typical fragrancecollecting behavior before they were netted and pinned.

The euglossine fauna of each site was sampled in order to estimate what species were present in addition to those caught at Gongora flowers, and also to determine which euglossine bees were carrying Gongora pollinaria. I censused bees attracted to sixteen fragrance chemicals used by Ackerman (1983a), plus several chemicals present in Gongora fragrances. The compounds are 1,8-cineole, benzyl acetate, eugenol, vanillin, methyl benzoate, methyl salicylate, methyl cinnamate, 1inalool, geraniol, skatole, beta-ionone, phenyl 
ethyl alcohol, phenyl ethyl acetate, myrcene, d-carvone, benzyl benzoate, beta-ocimene, p-cresol, p-cresyl acetate, pdimethoxybenzene, racemic ipsdienol, trans-carvone oxide, cis- and trans-methyl-p-methoxycinnamate, and trans-elemicin. Ipsdienol, carvone oxide, and elemicin were available only in 1984 and in limited quantities (< 2 grams), and less than 0.1 gram was used per day. Most chemicals were purchased from chemical supply houses at $95 \%$ or better purity and were not refined further. Some chemicals were synthesized and purified in our lab. Blotter pads were saturated with the chemical and tacked at breast height to trees at least $2 \mathrm{~m}$ apart in a suitable forested habitat. Bees attracted to the pad were netted and killed in separate vials. About 5-10\% of the bees escaped capture. Censuses were conducted from 08001300 hours for three successive mornings at each site.

Field work was conducted during January-March, 1982 and March of 1983 and 1984. Observation of pollinators was abandoned in 1983; a severe dry season caused by the El Niño phenomenon caused severe reductions in flowering and bee populations.

\section{Collection and Analysis of Floral Fragrances}

Gongora plants were cultivated in greenhouses at the University of Florida. Most plants survived importation and establishment, and they began to flower the following winter. Fragrances were trapped in glass cartridges $(9 \mathrm{~mm} 0 . \mathrm{D} . \mathrm{X} 75$ $\mathrm{mm}$ ) filled with Tenax GC and activated charcoal. The two 
adsorbents were separated by a plug of glass wool; the charcoal serves to retain the more volatile components which are poorly retained by Tenax. An inflorescence was enclosed in a glass or plexiglass chamber, and fragrance-laden air was pulled from the chamber and through the cartridge (flow rate $=0.5 \mathrm{l} / \mathrm{min}$.$) . The cartridge was oriented so that the air$ passed through the Tenax first. Plants were sampled for 3-5 hours between 0800-1400 hrs, depending upon the weather. After sampling, the cartridge was tightly wrapped in aluminum foil until desorbed (within one week). All plants were sampled on the first or second day of anthesis. Only one fragrance sample was taken of most plants due to the analysis time per sample. One plant of each taxon was sampled repeatedly to examine variation among samples, among days, and among inflorescences. Two successive inflorescences on the same plant were sampled on the first, second, and third day of anthesis, using three cartridges in parallel (a total of 18 samples per plant). Plants often produced several inflorescences in succession, and an attempt was made to sample successive inflorescences of aberrant samples. Voucher specimens of representative taxa are deposited at FLAS, and liquid-preserved specimens are deposited in the collection of N.H. Williams.

Cartridges were thermally desorbed under a slow stream of nitrogen gas (ca. $2 \mathrm{ml} / \mathrm{min}$ ) at $250 \mathrm{C}$ for ten minutes. The desorbed compounds were condensed by passing the nitrogen stream through a $100 \mathrm{~cm}$ capillary tube chilled with liquid 
nitrogen. The condensed fragrance was then dissoved in $1 \mathrm{ml}$ of hexane, sealed in autosampler vials, and stored in a freezer until analyzed. Details of the trapping and desorption devices are diagrammed in Williams (1983).

Fragrance samples were analyzed by capillary GC/MS using a Hewlett-Packard 5995 GC/MS system equipped with a $30 \mathrm{~m} \mathrm{DB}-5$ column. Percent composition of samples was determined from peak integration of flame ionization detector runs. Peaks were identified by comparing electron impact mass spectra (EM voltage $=70$ ) with spectra of authentic standards and by comparison of retention times. Some compounds were tentatively identified by comparison of mass spectra with published spectra.

The percent composition data of all individuals were used to construct a matrix of individuals (termed operational taxonomic units, or oTUs) by compounds. Compounds that did not exceed $5 \%$ in any of the samples were deleted, giving a total of 52 compounds. The matrix and selected subsets of it were analyzed using principal components analysis (PCA) and cluster analysis, using the CLUSTAN package (Wishart, 1978). Raw data were standardized using the "z-score" of Sneath and Sokal (1973) and were unweighted. The correlation matrix from the PCA was used to calculate a squared Euclidean distance matrix, and hierarchical cluster analysis was performed using Ward's method (error sum of squares method) (Wishart, 1978). The entire matrix was subdivided for analysis in two ways, either by taxa or by locality. Taxa 
subsets consisted of 1) Gongora tricolor; 2) Gongora quinquenervis and G. gibba; and 3 ) one variety of $G$. quinquenervis and G. gibba. Locality subsets consisted of 1) all oTUs from Rio Iguanita and Santa Rita; and 2) all OTUs from sites west of the Canal Zone (El Valle and El Copé). The two techniques (PCA and cluster analysis) were used as primarily descriptive techniques since the qualitative distinctions among the taxa were clear-cut. The techniques were selected because they are commonly used in plant taxonomy and in essential oil studies. Ordination limits the graphical representation of variation to two or three axes, but it can increase the information content of those axes. ordination techniques are particularly useful in the study of hybridization; hybrids usually lie midway in multidimensional space between parental taxa (Whiffin, 1977a; Schilling and Heiser, 1976). Classification techniques such as clustering impose a series of hierarchichal, non-overlapping clusters on the oTUs. The two techniques are often complementary, confirming phenetic relationships by two different techniques (Crisci et al., 1979).

\section{syntheses of selected compounds}

Two compounds were not commercially available and had to be synthesized. Trans-methyl-p-methoxycinnamate was synthesized using the procedure of Mohacsi (1982). Ten grams of p-methoxycinnamic acid (Aldrich) was mixed with an equimolar amount of o-methylcaprolactim. The mixture was incubated at $80-85 \mathrm{C}$ for 24 hours. The product was 
recrystallized from ethanol, yielding white plates (m.p. $=90$ C). Purity was $99.9 \%$ trans by GC/MS analysis. Cis-methylmethoxycinnamate was prepared by isomerization of the trans isomer under ultraviolet light. Five grams of pure trans isomer was dissolved in ethanol and irradiated with a shortwave UV lamp for 24 hours, yielding a mixture of $45 \%$ cis and 55\% trans isomers. The trans isomer is less soluble in ethanol than the cis, and repeated recrystallizations gave a product consisting of $93 \%$ cis-methyl-p-methoxycinnamate. Rao and Filler (1976) report a method for trans to cis conversion of cinnamic acid using polyphosphoric acid. This procedure was tried without success.

Trans-elemicin $(3,4,5$-trimethoxyphenylprop-l-ene) was synthesized by Terry Davis of the Insects Affecting Man and Animals Lab at Gainesville. 2,6-dimethoxyphenol was converted quantitatively to the corresponding allyl ether using allyl bromide and anhydrous potassium carbonate in refluxing acetone. Upon heating to $200 \mathrm{C}$ under argon, the ether underwent para-Claisen rearrangement to 4-allyl-2,6dimethoxyphenol, which was subsequently methylated with dimethyl sulfate/potassium carbonate in acetone (room temperature, overnight) to afford elemicin. overall yield from the starting material was $90 \%$. 
CHAPTER III

RESULTS AND DISCUSSION

\section{Floral Biology of Gongora}

All species of the Gongora quinquenervis complex flower most heavily during the dry season in Panama (DecemberApril), but occasional inflorescences may be produced at any time of year (Ackerman 1983b; Dressler, pers. comm.; pers. obs.). The inflorescences are produced from the base of the pseudobulb and are strongly pendent. The number of flowers depends upon the health of the plant and also upon the taxon; Gongora tricolor typically produces long racemes over a meter in length, whereas those of Gongora gibba are usually 30-50 $\mathrm{cm}$ in length, with only 8-12 flowers. Some geographic races of $\mathrm{G}$. quinquenervis also produce short inflorescences. The pedicels and ovaries are curved downward so that the lip is uppermost. All flowers on an inflorescence open synchronously in the early morning and immediately begin secreting fragrance. Visitation by male bees may begin within minutes of anthesis.

The stigma consists of a transverse slit near the apex of the column. Gongora flowers appear to be protandrous; for the first day or two after opening, the stigmatic slit is too narrow to accept a pollinium. After that time, the slit gradually widens enough for pollination to occur. It is not 
clear whether removal of the pollinarium speeds this process. outcrossing is also favored by the thickness of a freshlyremoved pollinium; after several minutes of drying, the pollinia are noticably thinner and are more easily inserted into the stigma.

Fragrance compounds are secreted by the hypochile of the lip and to a lesser extent by the base of the lateral sepals. The epidermal and subepidermal tissues in these areas are rich in starch, which presumably serves as a substrate for fragrance secretion. Fragrance is secreted most strongly from dawn to about 1300 hrs, corresponding to the period of greatest fragrance-collecting activity of male bees. Fragrance production ceases at night. Flowers last from three to six days before senescing, depending upon temperature, humidity and health of the plant. Pollination results in the swelling and closure of the stigma, wilting of the perianth, cessation of odor production, and straightening of the ovary (all within 24 hours). Under greenhouse conditions, the capsules mature and dehisce about 80 days after pollination.

Some anecdotal observations in the field and greenhouse suggest that Gongora might produce functionally dioecious flowers. No obvious sexual dimorphism exists (like that of Catasetum and Cycnoches), but all flowers of some plants never open the stigmatic slit. This was noticed in attempts to hand-pollinate plants, and closed slits seemed most common on small plants in mediocre health. The stigmatic slits of 
large, robust plants were much easier to pollinate. This suggests that plants in poor health are functionally male, while only robust plants may be pollinated and set fruits. Much of the general morphology and presentation of Gongora flowers is explained by the unusual pollination mechanism. Pollination of Gongora was first described by Allen (1954) and later by Dodson and Frymire (1961) and Dressler $(1966,1968 \mathrm{~b})$. Male bees are attracted to the flowers by the odor and approach the flower from downwind. Most bees alight on the lateral sepals and begin brushing behavior there, concentrating upon the base of the sepals. Several cycles of brushing and transfer behavior occur before the bee begins brushing on the lip. Since the secretory tissues are located on the abaxial (bottom) side of the lip, the bee must hang upside down from the lip while brushing occurs. When the bee releases from the lip to hover and transfer fragrances, or if the bee slips and falls from the lip, it immediately contacts the curved column. The bee slides down the column, presumably guided by the adnate petals, and the bee's scutellum hooks under the viscidium and removes the pollinarium. Since the stigmatic slit is positioned next to the viscidium, the mechanism for insertion of pollinia into the stigma is identical. Although each pollinarium contains two pollinia, probably only one is inserted into the stigma during a pollination event. Many bees carry pollinaria with only one pollinium present, and one pollinium is adequate for full seed set. 
Fruit set was rare in all the observed populations; only five plants bearing fruits were observed. The number of capsules ranged from three to five. All fruiting plants were relatively large and healthy, and three were in partial shade at the edge of a pasture. Since my observations are biased towards plants near the ground, fruit set might be greater in plants higher in the canopy.

\section{Gongora Species Present at Each site}

Most Gongora plants encountered in the field were not in flower and could not be identified to species. Table 2 lists the numbers of each species at each site that were collected and flowered in cultivation. The sampling of each site was very uneven; most plants were collected at El Valle or at Rio Iguanita. This uneven sampling reflects the abundance of Gongora at each site, since at least one week of collecting was performed at each site. Gongora guinquenervis var. A was relatively common at El Valle, and many more plants were seen but not collected. Gongora tricolor was most abundant at Rio Iguanita and Cerro Azul, on the Caribbean slope east of the Canal zone. Gongora gibba was collected at four sites, but is rare and was never found in bud or flower. Gongora quinquenvervis var. B occurs at at least three study sites, and is also represented by a series of plants from western Panama and Costa Rica obtained from $R$. Dressler and the Marie Selby Botanical Gardens. Dressler (1968b) collected 
Table 2. Numbers of Gongora species sampled at each site.

$$
\text { Species }
$$

site

\begin{tabular}{llll}
\hline quinque- & quinque- & tricolor & gibba \\
nervis A & nervis $B$ & &
\end{tabular}

\section{El Copé}

El Valle

Rio Iguanita

Santa Rita

El Lano-Carti

Cerro Azul

other

Total

66

2

66

4

0

0

5

77
1

2

5

0

0

0

9

17

$\begin{array}{rl}0 & \\ 2 & 1 \\ 30 & 3 \\ 6 & 3 \\ 0 & 0 \\ 6 & 1 \\ 0 & 0\end{array}$

44

8 
plants which appear to be this same variety in costa Rica and recognized its distinctiveness, calling it Gongora "Golfito".

\section{Compounds Present in Floral Fragrances}

The 52 fragrance compounds are listed in Table 3 . Fifteen minor compounds remain unidentified; most of these are monoor sesquiterpenes or sesquiterpene alcohols. Most of the 37 identifications are based on comparisons of retention times, mass spectra, GC/FTIR spectra and some NMR spectra with authentic samples. Compounds tentatively identified by mass spectra only include aminitol, 1,4-cineole, methylphenyl acetate, sabinene, terpinyl-4-acetate, and thujyl alcohol; all of these compounds are minor fragrance constituents. Two of the major compounds, ipsdienol and terpinen-4-ol, are chiral, but their enantiomeric composition was not determined.

Most of the fragrance compounds are common natural products that are known from many essential oils and fragrances. There is at least one major compound produced by each species that is either a novel natural product or is rarely reported as a natural product. These compounds are 1. Ipsdienol (2-methyl-6-methylene-2,7-octadien-4-ol). This compound from $G$. tricolor has not been reported as a plant product but occurs as a pheromone/allomone in various species of Ips bark beetles. It is present in the fragrances of several other euglossine-pollinated orchid species (Huntleya burtii, Stanhopea anfracta, Notylia latilabia) and 
Table 3. Major compounds identified in the floral fragrances of Gongora quinquenervis, $\mathrm{G}$. tricolor, and $\mathrm{G}$. gibba.

\section{Terpenoids}

aminitol

camphene

carveol

1,8-cineole

1,4 -cineole

ipsaienol

limonene

linalool

8-carboxylinalool, methyl ester

myrcene

beta-ocimene

sabinene

terpinen-4-ol

alpha-terpinene

alpha-terpineol

terpinyl-4-acetate

thujyl alcohol

unid. monoterpene la

unid. monoterpene $1 \mathrm{~b}$

unid. monoterpene 2

unid. monoterpene 3

unid. monoterpene 4

unid. monoterpene 5

unid. monoterpene 6

unid. monoterpene 7

unid. monoterpene 8

unid. monoterpene 9

unid. sesquiterpene 1

unid. sesquiterpene 2
Aromatics

\section{anisaldehyde}

anisyl acetate

$\mathrm{p}$-cresol

p-cymene

p-dimethoxybenzene

trans-elemicin

eugenol

isoelemicin

isoeugenol

trans-methyl cinnamate methyl isoeugenol

cis-methyl-pmethoxycinnamate

trans-methyl-pmethoxycinnamate methyl phenyl acetate phenyethyl alcohol phenylethyl acetate vanillin

\section{others}

indole 
one aroid (Anthurium ochranthum) (Whitten, unpub.) In Ips beetles, enantiomeric composition is critical, since the (t) isomer may serve as the pheromone of one species and the (-) isomer act as pheromone for another sympatric species (Light and Birch, 1982). At least some euglossine bees can distinguish enantiomers of some compounds. Eulaema nigrita is attracted to $(-)$ alpha-pinene ( $n=17$, ten mornings), but not to (t) alpha-pinene (no bees, ten mornings) (Whitten, unpub.). The pure enantiomers of ipsdienol were not available for bioassay, and the enantiomeric composition of the orchid-produced compound is unknown.

2. Trans-elemicin (3,4,5-trimethoxyphenylprop-l-ene). This compound is the major component of the fragrance of Gongora gibba. It is chemically related to eugenol, and occurs as a minor constituent in nutmeg and mace and many other plants, and as a major constituent of Asian Heterotropa spp. (Aristolochiaceae) (Hayashi et al. 1983).

3. Methyl-p-methoxycinnamate (hereafter abbreviated as MMC). This compound, found in Gongora quinquenervis, occurs in cis and trans isomers which are readily interconverted under UV light; hence, both isomers probably are produced from flowers in sunlight. It is closely related to the common methyl cinnamate but rarely has been reported as a natural product. It has been reported in large amounts only from the Australian Eriostemon obovalis (Rutaceae) (Lassak and Southwell, 1974). It also occurs as a major component of Catasetum fimbriatum fragrance (Whitten, unpub.). It is the 
least volatile orchid fragrance compound known (mp=90 c), and crystalline deposits may accumulate on the lip and sepals during the morning (Williams, Whitten, and Pedrosa, 1985). 4. 8-carboxylinalool methyl ester (2-trans-2,6-dimethyl-6hydroxy-2,7-octadienoic acid, methyl ester). This compound (hereafter abbreviated as CLME) is produced by some clones of Gongora quinquenervis, but has not been reported previously as a natural product. It has been reported as a glycoside from the fruits of an Asian Gymnocladus (Konoshima and Sawada, 1984) and as an unesterified acid glycoside from the fruits of Gleditsia (okada et al., 1980). It has not been synthesized, and bioassays using it were not performed. Identification of this compound is based upon agreement of mass spectral, proton NMR, and GC/FTIR data with data published in the above references.

\section{Reproducibility of Fragrance Samples}

Adams (1972) studied the effects of common chemosystematic errors on phenetic analyses (single-linkage cluster analysis based on a weighted matching coefficient). He found that the most serious source of error is error in the quantification of a series of analyses, such as seasonal variation in essential oil composition. Using data from Juniperus oils, he demonstrated that the season of sample collection (winter vs. summer) was critical, and samples of different seasons could not be combined in the same analysis of clinal variation. Other sources of error, such as 
misidentification of compounds and incomplete resolution of GC peaks, had minor effects on the phenograms. The most serious source of error in the present study is probably within-plant variation due to health of the plant and environmental conditions at time of sampling, and to variation between the first and second day of anthesis. other potential errors are probably minor. Misidentification of compounds was minimized by use of mass spectra and relative retention times for routine compound identification. The use of capillary GC columns maximized peak resolution and minimized non-random error due to column bleeding.

The variation among replicate samples for single individuals of gongora tricolor and of $\mathrm{G}$. quinquenervis is shown in Figs. 5 and 6 . The variation between inflorescences for both samples was small, and data for both inflorescences were pooled. Variation among days greatly exceeded variation among replicate samples for all plants examined. Since the variation between inflorescences is small, samples taken on the first day of anthesis for any inflorescence of one clone should give reproducible, consistent results. If the differences in fragrance composition reflect genetic variation and not sampling error, then replicate samples of different inflorescences of the same plant should cluster together in the cluster analyses. In order to test the clustering of replicates, the mean values for days 1,2 , and 3 of $\mathrm{G}$. tricolor (OTU \#12) were included in a cluster analysis with all tricolor samples. 
Figure 5. Variation in floral fragrance composition over the first three days of anthesis of one plant of Gongora quinquenervis group B. Each bar represents the mean percent composition of $\mathrm{six}$ samples (three replicates $\mathrm{X}$ two inflorescences). Vertical lines indicate the standard deviation. Compounds are: A. unidentified monoterpene; $B$. myrcene; $C$. p-cymene; D. unidentified monoterpene; $E$. terpinen-4-ol; F. indole; G. eugenol; $H$. 8carboxylinalool methyl ester; $I$. unidentified sesquiterpene. 


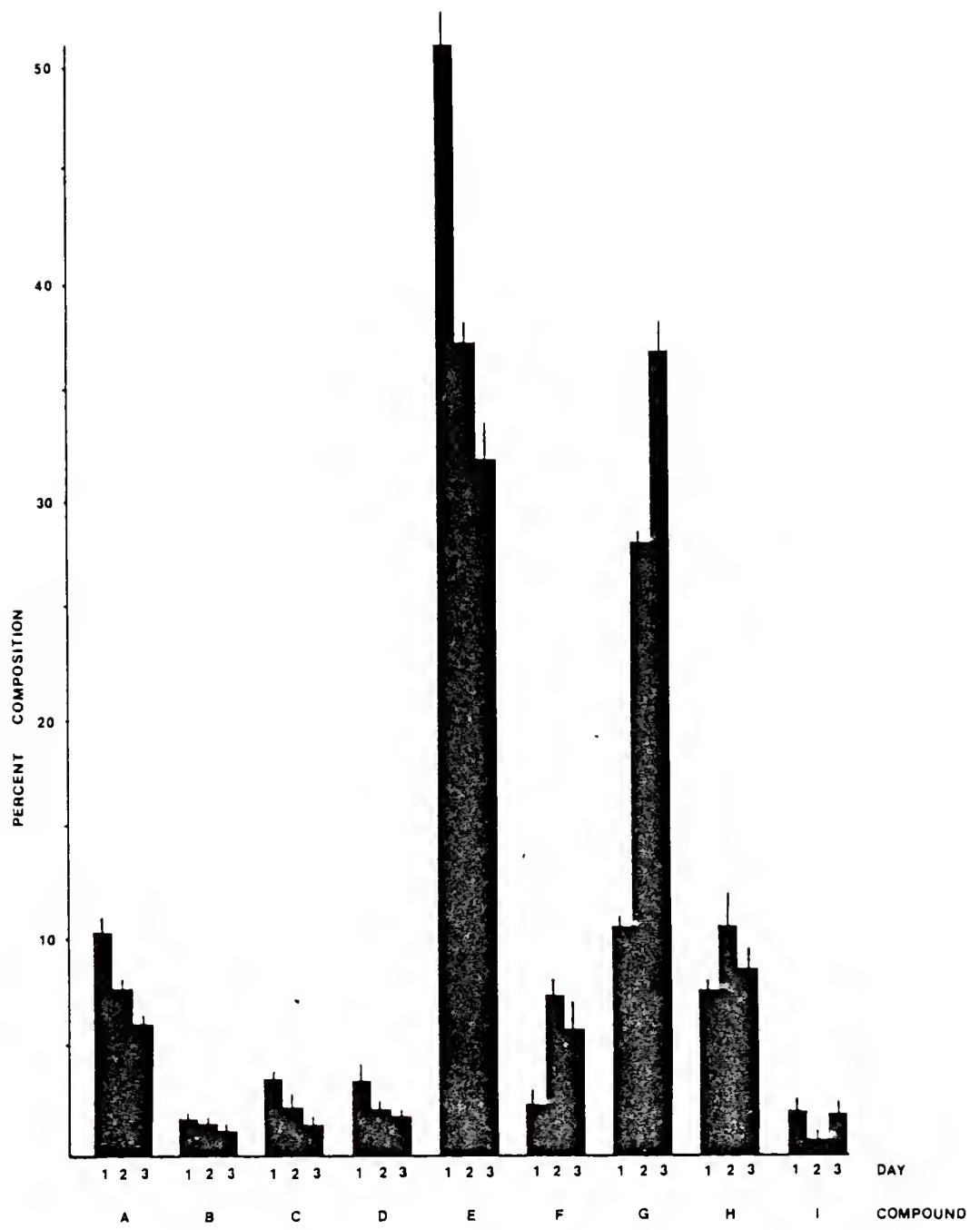


Figure 6. Variation in floral fragrance composition over the first three days of anthesis of one plant of Gongora

tricolor. Each bar represents the mean percent composition of six samples (three replicates $X$ two inflorescences).

Vertical lines indicate the standard deviation. Compounds are: A. p-methyl anisole; B. p-cresol; C. phenylethyl alcohol; D. phenylethyl acetate; E. indole; $F$. anisyl acetate; G. unidentified sesquiterpene; H. unidentified sesquiterpene. 


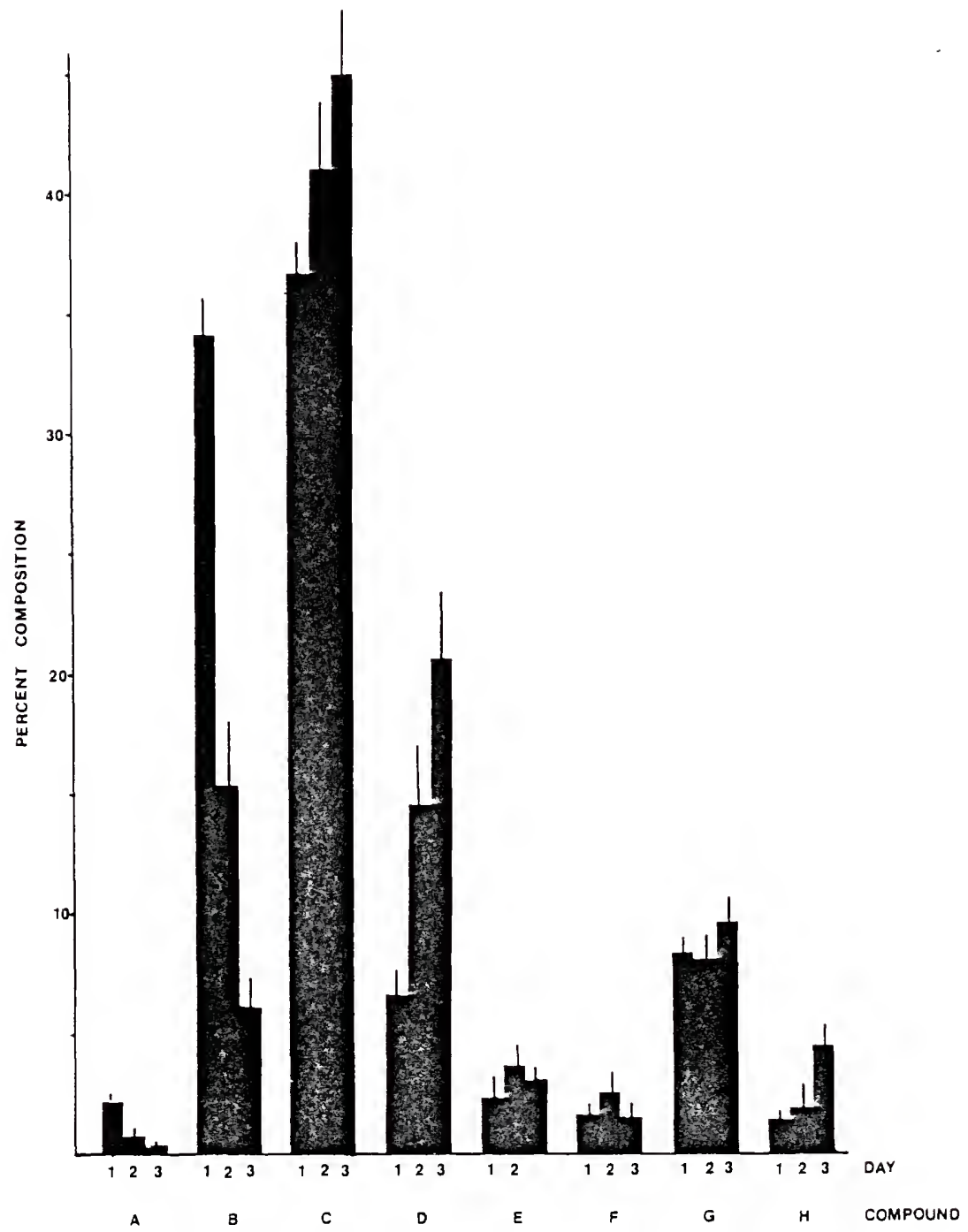


Figure 7. Phenogram of fragrance composition of 44 plants of Gongora tricolor plus replicate samples of one plant, showing variation in fragrances among days. The closed circle represents the original unicate sample of one individual. The open circles represent the mean of three replicates; two inflorescences were sampled on days $1-3$. 


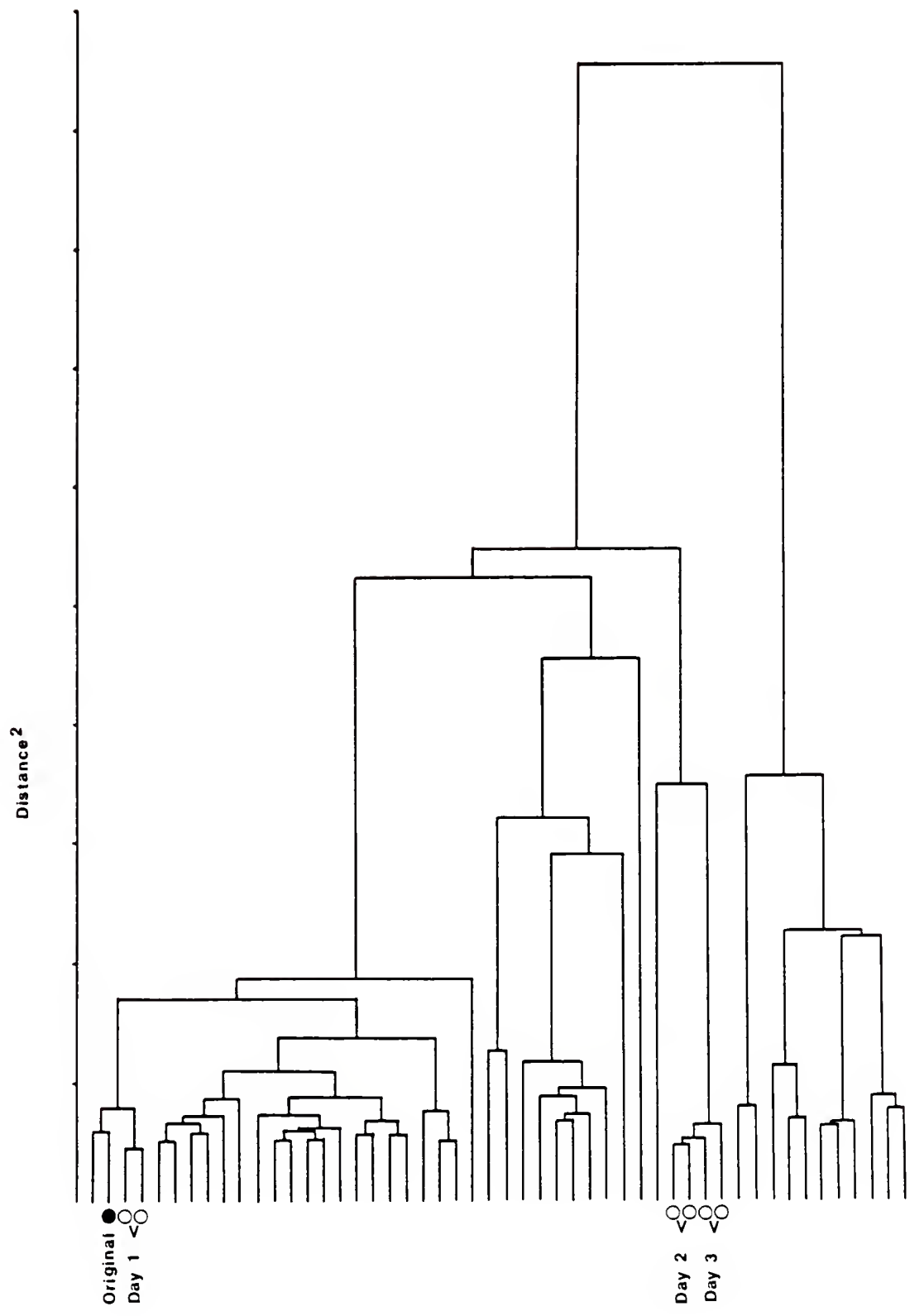


The resulting phenogram (Fig. 7) shows that both day-1 samples of the replicate inflorescences cluster together with the original unicate sample collected two years earlier, indicating good reproducibility. The replicates for day 2 and day 3 cluster with other OTUs in the dendrogram, showing the importance of variation among days.

A distinction should be made between statistical significance and biological significance. Although variation among days and among conspecifics may be statistically significant, the pollinators may tolerate considerable quantitative variation; such variation may be biologically insignificant if it does not alter the attraction of bees. plants that attract different pollinator sets usually differ qualitatively in fragrance composition. Due to small and uneven sample sizes, the present study does not address the question of minor quantitative variation among sites.

\section{Variation in Floral Fragrance Composition}

Floral fragrance compositions for each species are given in Tables 4-8. The three morphological species differ. qualitatively in fragrance composition. Gongora tricolor is characterized by large amounts of phenylethyl acetate, phenylethyl alcohol, indole, anisyl acetate, p-cresol, myrcene and ipsdienol. Samples of $\underline{G}$. tricolor are divided $\underline{a}$ posteriori into two groups (Tables 4 and 5 ); one group contains large amounts of p-cresol and lacks ipsdienol, and the other group is low in p-cresol and contains large amounts 
Table 4. Fragrance composition of 34 plants of Gongora tricolor var. A. Values are percentages of total fragrance.

\begin{tabular}{|c|c|c|c|}
\hline Compound & Mean & Range & $\begin{array}{l}\text { Standard } \\
\text { Deviation }\end{array}$ \\
\hline aminitol & $\overline{0}$ & 0 & $\overline{0}$ \\
\hline anisaldehyde & 0 & 0 & 0 \\
\hline anisyl acetate & 4.8 & $0-16.0$ & 4.2 \\
\hline camphene & 0 & 0 & 0 \\
\hline carveol & 0 & 0 & 0 \\
\hline cineole, $1,4-$ & 0 & 0 & 0 \\
\hline cineole, 1,8- & 0 & $0-1 \cdot 1$ & 0.2 \\
\hline p-cresol & $28 \cdot 1$ & $2 \cdot 6-58 \cdot 3$ & 16.2 \\
\hline p-cymene & 1.7 & $0-15.6$ & 3.2 \\
\hline p-dimethoxybenzene & 0.1 & $0-1 \cdot 8$ & 0.4 \\
\hline $\begin{array}{l}\text { trans-elemicin } \\
\text { eugenol }\end{array}$ & 0.8 & $0-8 \cdot 1$ & 1.5 \\
\hline eugenol & 0.2 & $0-6.9$ & 1.2 \\
\hline indole & 6.3 & $0-21.2$ & 3.7 \\
\hline ipsdienol & 0 & $0-1 \cdot 3$ & 0.2 \\
\hline isoelemicin & 0.4 & $0-11.0$ & 1.9 \\
\hline isoeugenol & 0 & 0 & 0 \\
\hline Iimonene & 0.2 & $0-4.7$ & 0.8 \\
\hline linalool & 0 & 0 & 0 \\
\hline p-methyl anisole & 5.5 & $0-20.1$ & 4.3 \\
\hline trans-methyl cinnamate & 0 & 0 & 0 \\
\hline methyl isoeugenol & 0.2 & $0-1.9$ & 0.5 \\
\hline methyl Iinaloolate & 0.1 & $0-3.4$ & 0.6 \\
\hline cis-methyl-p-methoxycinnamate & 0.1 & $0-2.2$ & 0.4 \\
\hline trans-methyl-p-methoxycinnamate & 0.1 & $0-2.7$ & 0.5 \\
\hline methyl phenylacetate & 0 & 0 & 0 \\
\hline methyl propenylbenzene & 0 & 0 & 0 \\
\hline myrcene & 0 & $0-1.6$ & 0.3 \\
\hline beta-ocimene & 0 & 0 & 0 \\
\hline phenylethyl acetate & 12.9 & $0-40.1$ & 10.2 \\
\hline phenylethyl alcohol & 24.9 & $0-49.7$ & 9.1 \\
\hline sabinene & 0 & 0 & 0 \\
\hline terpinen-4-ol & 0 & 0 & 0 \\
\hline alpha-terpinene & 0 & 0 & 0 \\
\hline alpha-terpineol & 0 & 0 & 0 \\
\hline terpinyl-4-acetate & 0 & 0 & 0 \\
\hline thujyl alcohol & 0 & 0 & 0 \\
\hline vanilitin & 0 & 0 & 0 \\
\hline unid. monoterpene la & 0 & 0 & 0 \\
\hline unid. monoterpene $1 \mathrm{~b}$ & 0 & 0 & 0 \\
\hline unid. monoterpene 2 & 0 & 0 & 0 \\
\hline unid. monoterpene 3 & 0 & 0 & 0 \\
\hline unid. monoterpene 4 & 0.2 & $0-1.6$ & 0.5 \\
\hline unid. monoterpene 5 & 0.4 & $0-5.6$ & 1.2 \\
\hline unid. monoterpene 6 & 0 & 0 & 0 \\
\hline unid. monoterpene 7 & 0 & 0 & 0 \\
\hline unid. monoterpene 8 & 0 & 0 & 0 \\
\hline unid. monoterpene 9 & 0 & 0 & 0 \\
\hline unid. sesquiterpene I & 0.6 & $0-5.9$ & 1.3 \\
\hline unid. sesquiterpene 2 & 2.5 & $0-15.4$ & 3.4 \\
\hline
\end{tabular}


Table 5. Fragrance composition of 10 plants of Gongora tricolor var. B. Values are percent of total fragrance.

\begin{tabular}{|c|c|c|c|}
\hline Compound & Mean & Range & $\begin{array}{l}\text { Standard } \\
\text { Deviation }\end{array}$ \\
\hline aminitol & $\overline{4.0}$ & $0-12 \cdot 3$ & 4.2 \\
\hline \multirow{2}{*}{$\begin{array}{l}\text { anisaldehyde } \\
\text { anisyl acetate }\end{array}$} & 0 & 0 & 0 \\
\hline & 0.6 & $0-3.5$ & 1.1 \\
\hline camphene & 0 & 0 & 0 \\
\hline \multirow{2}{*}{$\begin{array}{l}\text { carveol } \\
\text { cineole, 1,4- }\end{array}$} & 4.2 & $0-20.1$ & 7.4 \\
\hline & 0 & 0 & 0 \\
\hline cineole, $1,8-$ & 2.7 & $0-7 \cdot 5$ & 2.3 \\
\hline p-cresol & 10.9 & $0-37 \cdot 0$ & 10.8 \\
\hline p-cymene & 2.4 & $0-10.2$ & 3.5 \\
\hline p-dimethoxybenzene & 0 & 0 & 0 \\
\hline \multirow{2}{*}{$\begin{array}{l}\text { trans-elemicin } \\
\text { eugenol }\end{array}$} & 0.4 & $0-3 \cdot 3$ & 1 \\
\hline & 0 & 0 & 0 \\
\hline indole & 3.2 & $0-12 \cdot 6$ & 3.5 \\
\hline $\begin{array}{l}\text { ipsdienol } \\
\text { isoelemicin }\end{array}$ & 19.4 & $0-53 \cdot 4$ & 17.6 \\
\hline $\begin{array}{l}\text { isoelemicin } \\
\text { isoeugenol }\end{array}$ & 0 & 0 & 0 \\
\hline isoeugenol & 0 & 0 & 0 \\
\hline Iimonene & 0.1 & $0-1.0$ & 0.3 \\
\hline linalool & 0 & 0 & 0 \\
\hline p-methyl anisole & 3.2 & $0-11 \cdot 3$ & 3.1 \\
\hline \multirow{2}{*}{ trans-methyl cinnamate } & 0 & 0 & 0 \\
\hline & 0.2 & $0-2 \cdot 7$ & 0.8 \\
\hline methyl linaloolate & 0 & 0 & 0 \\
\hline cis-methyl-p-methoxycinnamate & 0 & 0 & 0 \\
\hline \multirow{2}{*}{$\begin{array}{l}\text { trans-methyl-p-methoxycinnamate } \\
\text { methyl phenylacetate }\end{array}$} & 0 & 0 & 0 \\
\hline & 0 & 0 & 0 \\
\hline methyl propenylbenzene & 0 & 0 & 0 \\
\hline \multirow{2}{*}{$\begin{array}{l}\text { myrcene } \\
\text { beta-ocimene }\end{array}$} & 23.3 & $8 \cdot 6-41 \cdot 4$ & 10.4 \\
\hline & 0 & 0 & 0 \\
\hline phenylethyl acetate & 5.2 & $0-21.1$ & 5.6 \\
\hline phenylethyl alcohol & 10.7 & $5 \cdot 2-18 \cdot 5$ & 4.2 \\
\hline sabinene & 0 & 0 & 0 \\
\hline terpinen-4-ol & 0 & 0 & 0 \\
\hline alpha-terpinene & 0 & 0 & 0 \\
\hline alpha-terpineol & 0 & 0 & 0 \\
\hline terpiny $1-4$-acetate & 0 & 0 & 0 \\
\hline thujyl alcohol & 0 & 0 & 0 \\
\hline vanilitin & 0 & 0 & 0 \\
\hline unid. monoterpene la & 0 & 0 & 0 \\
\hline unid. monoterpene $1 \mathrm{~b}$ & 0 & 0 & 0 \\
\hline unid. monoterpene 2 & 0 & 0 & 0 \\
\hline unid. monoterpene 3 & 0 & 0 & 0 \\
\hline unid. monoterpene 4 & 0.5 & $0-2.6$ & 0.9 \\
\hline unid. monoterpene 5 & 0 & 0 & 0 \\
\hline unid. monoterpene 6 & 0 & 0 & 0 \\
\hline unid. monoterpene 7 & 0 & 0 & 0 \\
\hline unid. monoterpene 8 & 0 & 0 & 0 \\
\hline unid. monoterpene 9 & 0 & 0 & 0 \\
\hline unid. sesquiterpene 1 & 0.1 & $0-1.1$ & 0.3 \\
\hline unid. sesquiterpene 2 & 0 & 0 & 0 \\
\hline
\end{tabular}


Table 6. Fragrance composition of 77 plants of Gongora quinquenervis var. A. Values are percent of total fragrance.

\begin{tabular}{|c|c|c|c|}
\hline Compound & Mean & Range & $\begin{array}{l}\text { Standard } \\
\text { Deviation }\end{array}$ \\
\hline aminitol & $\overline{0.1}$ & $\overline{0-5.4}$ & 0.7 \\
\hline anisaldehyde & 1.6 & $0-26.3$ & 3.7 \\
\hline anisyl acetate & 0 & 0 & 0 \\
\hline camphene & 0 & $0-3.6$ & 0.4 \\
\hline carveol & 0 & 0 & 0 \\
\hline cineole, 1,4- & 0.1 & $0-6.8$ & 0.8 \\
\hline cineole, $1,8-$ & 0.1 & $0-3.6$ & 0.4 \\
\hline p-cresol & $0 . \overline{3}$ & $0-8.0$ & 1.4 \\
\hline p-cymene & 3.2 & $0-36.3$ & 7.6 \\
\hline p-dimethoxybenzene & 0.3 & $0-21.5$ & 2.4 \\
\hline trans-elemicin & 0.1 & $0-2 \cdot 3$ & 0.3 \\
\hline eugenol & 6.9 & $0-56.2$ & 10.5 \\
\hline indole & 0 & 0 & 0 \\
\hline ipsdienol & 0 & 0 & 0 \\
\hline isoelemicin & 0 & 0 & 0 \\
\hline isoeugenol & 0 & 0 & 0 \\
\hline Iimonene & 0.1 & $0-2 \cdot 4$ & 0.4 \\
\hline linalool & 7 & $0-37.6$ & 9.5 \\
\hline p-methyl anisole & 0.5 & $0-23.6$ & 2.7 \\
\hline trans-methyl cinnamate & 5.2 & $0-59.2$ & 9.4 \\
\hline methyl isoeugenol & 1.3 & $0-13.0$ & 2.7 \\
\hline methyl linaloolate & 0 & 0 & 0 \\
\hline cis-methyl-p-methoxycinnamate & 14.4 & $0-47.0$ & 10.7 \\
\hline trans-methyl-p-methoxycinnamate & 24.7 & $0-66.3$ & 14.6 \\
\hline methyl phenylacetate & 1.0 & $0-11.7$ & 2.2 \\
\hline methyl propenylbenzene & 1.8 & $0-21 \cdot 4$ & 4.0 \\
\hline myrcene & 0.2 & $0-6.9$ & 1.0 \\
\hline beta-ocimene & 20.5 & $0-80.7$ & 20.7 \\
\hline phenylethyl acetate & 0 & $0-3.6$ & 0.4 \\
\hline phenylethyl alcohol & 0.2 & $0-3.1$ & 0.7 \\
\hline sabinene & 0 & 0 & 0 \\
\hline terpinen-4-ol & 0.1 & $0-4.5$ & 0.7 \\
\hline alpha-terpinene & 0 & 0 & 0 \\
\hline alpha-terpineol & 0.2 & $0-12 \cdot 3$ & 1.4 \\
\hline terpiny $1-4$-acetate & 0 & 0 & 0 \\
\hline thujyl alcohol & 0 & 0 & 0 \\
\hline vanillin & 0 & 0 & 0 \\
\hline unid. monoterpene la & 0.4 & $0-14.5$ & 2.2 \\
\hline unid. monoterpene Ib & 1 & $0-35.1$ & 5.3 \\
\hline unid. monoterpene 2 & 0 & 0 & 0 \\
\hline unid. monoterpene 3 & 0 & $0-2 . I$ & 0.2 \\
\hline unid. monoterpene 4 & 0.1 & $0-3 \cdot 3$ & 0.5 \\
\hline unid. monoterpene 5 & 0 & 0 & 0 \\
\hline unid. monoterpene 6 & 0 & 0 & 0 \\
\hline unid. monoterpene 7 & 0.1 & $0-4.7$ & 0.6 \\
\hline unid. monoterpene 8 & 0.2 & $0-17.9$ & 2.0 \\
\hline unid. monoterpene 9 & 0 & 0 & 0 \\
\hline unid. sesquiterpene 1 & 0 & $0-3.8$ & 0.4 \\
\hline unid. sesquiterpene 2 & 0 & 0 & 0 \\
\hline
\end{tabular}


Table 7. Fragrance composition of 17 plants of Gongora quinquenervis var. B. Values are percent of total fragrance.

\begin{tabular}{|c|c|c|c|}
\hline Compound & Mean & Range & $\begin{array}{l}\text { Standard } \\
\text { Deviation }\end{array}$ \\
\hline aminitol & $\overline{0}$ & $\overline{0}$ & $\overline{0}$ \\
\hline anisaldehyde & 0 & 0 & 0 \\
\hline anisyl acetate & 0 & 0 & 0 \\
\hline camphene & 0 & 0 & 0 \\
\hline carveol & 0 & 0 & 0 \\
\hline \multirow{2}{*}{$\begin{array}{l}\text { Cineole, 1,4- } \\
\text { cineole, 1,8- }\end{array}$} & 1.0 & $0-5.5$ & 1.9 \\
\hline & 2.7 & $0-17 \cdot 2$ & 4.8 \\
\hline p-cresol & 0 & 0 & 0 \\
\hline p-cymene & 5.2 & $0-26.5$ & 8.6 \\
\hline p-dimethoxybenzene & 0 & 0 & 0 \\
\hline trans-elemicin & 0 & 0 & 0 \\
\hline eugenol & 3.2 & $0-22.5$ & 6 \\
\hline indole & 2.6 & $0-9.0$ & 2.9 \\
\hline ipsdienol & 0 & 0 & 0 \\
\hline isoelemicin & 0 & 0 & 0 \\
\hline isoeugenol & 0.3 & $0-4.7$ & 1.1 \\
\hline limonene & 1.9 & $0-11.3$ & 3.5 \\
\hline linalool & 4.8 & $0-24.9$ & 6.7 \\
\hline p-methyl anisole & 0 & 0 & 0 \\
\hline & 0 & 0 & 0 \\
\hline $\begin{array}{l}\text { trans-methyl cinnamate } \\
\text { methyl isoeugenol }\end{array}$ & 0 & 0 & 0 \\
\hline methyl linaloolate & 28.4 & $0-83.3$ & 28.9 \\
\hline cis-methyl-p-methoxycinnamate & 0 & 0 & 0 \\
\hline trans-methyl-p-methoxycinnamate & 2.5 & $0-42 \cdot 3$ & 10.0 \\
\hline methyl phenylacetate & 0 & 0 & 0 \\
\hline methyl propenylbenzene & 0 & 0 & 0 \\
\hline myrcene & 3.9 & $0-7.6$ & 2.4 \\
\hline beta-ocimene & 3.7 & $0-45.0$ & 10.5 \\
\hline phenylethyl acetate & 0 & 0 & 0 \\
\hline phenylethyl alcohol & 0.3 & $0-4.7$ & 1.1 \\
\hline sabinene & 0.9 & $0-15.5$ & 3.6 \\
\hline terpinen-4-ol & 23.0 & $0-52.0$ & 19.0 \\
\hline alpha-terpinene & 2.9 & $0-16.3$ & 4.7 \\
\hline alpha-terpineol & 0 & 0 & 0 \\
\hline terpinyl-4-acetate & 0 & 0 & 0 \\
\hline thujyl alcohol & 0.5 & $0-8.8$ & 2.1 \\
\hline vanillin & 0 & 0 & 0 \\
\hline unid. monoterpene la & 0 & 0 & 0 \\
\hline unid. monoterpene $1 b$ & 0 & 0 & 0 \\
\hline unid. monoterpene 2 & 2.3 & $0-12.7$ & 4.1 \\
\hline unid. monoterpene 3 & 0.8 & $0-5.8$ & 1.7 \\
\hline unid. monoterpene 4 & 0.3 & $0-3 \cdot 2$ & 0.9 \\
\hline unid. monoterpene 5 & 0 & 0 & 0 \\
\hline unid. monoterpene 6 & 1.2 & $0-7.8$ & 2.3 \\
\hline unid. monoterpene 7 & 0 & 0 & 0 \\
\hline unid. monoterpene 8 & 0 & 0 & 0 \\
\hline unid. monoterpene 9 & 0.3 & $0-5.0$ & 1.2 \\
\hline unid. sesquiterpene 1 & 0 & 0 & 0 \\
\hline unid. sesquiterpene 2 & 0 & 0 & 0 \\
\hline
\end{tabular}


Table 8. Fragrance composition of 8 plants of Gongora gibba. Values are percent of total fragrance.

\begin{tabular}{|c|c|c|c|}
\hline Compound & Mean & Range & $\begin{array}{l}\text { Standard } \\
\text { Deviation }\end{array}$ \\
\hline aminitol & $\overline{0}$ & $\overline{0}$ & $\overline{0}$ \\
\hline anisaldehyde & 0 & 0 & 0 \\
\hline anisyl acetate & 0 & 0 & 0 \\
\hline camphene & 0.2 & $0-1 \cdot 2$ & 0.4 \\
\hline carveol & 0 & 0 & 0 \\
\hline cineole, $1,4-$ & 0 & 0 & 0 \\
\hline \multirow{2}{*}{ cineole, $1,8-$} & 0.3 & $0-2.7$ & 0.9 \\
\hline & 0.2 & $0-1.6$ & 0.5 \\
\hline p-cymene & 2.2 & $0-8.0$ & 2.8 \\
\hline p-dimethoxybenzene & 0 & 0 & 0 \\
\hline trans-elemicin & 54.9 & $37.5-78.1$ & 15.2 \\
\hline eugenol & 0 & 0 & 0 \\
\hline indole & 0 & 0 & 0 \\
\hline ipsdienol & 0 & 0 & 0 \\
\hline isoelemicin & 0 & 0 & 0 \\
\hline isoeugenol & 0 & 0 & 0 \\
\hline limonene & 0 & 0 & 0 \\
\hline linalool & 0.9 & $0-7.2$ & 2.4 \\
\hline p-methyl anisole & 0 & $\begin{array}{r}1 \\
0\end{array}$ & 0 \\
\hline trans-methyl cinnamate & 28.9 & $4.0-53.6$ & 16.8 \\
\hline methyl isoeugenol & 0 & 0 & 0 \\
\hline methyl linaloolate & 2.9 & $0-11.4$ & 4.1 \\
\hline cis-methyl-p-methoxycinnamate & 0 & 0 & 0 \\
\hline trans-methyl-p-methoxycinnamate & 0.8 & $0-3 \cdot 3$ & 1.1 \\
\hline methyl phenylacetate & 0 & 0 & 0 \\
\hline methyl propenylbenzene & 0.1 & $0-1.1$ & 0.4 \\
\hline myrcene & 0.1 & $0-1 \cdot 1$ & 0.4 \\
\hline beta-ocimene & $\overline{0}$ & 0 & 0 \\
\hline phenylethyl acetate & 0 & 0 & 0 \\
\hline phenylethyl alcohol & 0 & 0 & 0 \\
\hline sabinene & 0 & 0 & 0 \\
\hline terpinen-4-ol & 0 & 0 & 0 \\
\hline alpha-terpinene & 0 & 0 & 0 \\
\hline alpha-terpineol & 0 & 0 & 0 \\
\hline terpinyl-4-acetate & 0 & 0 & 0 \\
\hline thujyl alcohol & 0 & 0 & 0 \\
\hline vaniliin & 0 & 0 & 0 \\
\hline unid. monoterpene la & 0 & 0 & 0 \\
\hline unid. monoterpene ib & 0 & 0 & 0 \\
\hline unid. monoterpene 2 & 0 & 0 & 0 \\
\hline unid. monoterpene 3 & 0 & 0 & 0 \\
\hline unid. monoterpene 4 & 0.2 & $0-1.8$ & 0.6 \\
\hline unid. monoterpene 5 & 0 & 0 & 0 \\
\hline unid. monoterpene 6 & 0 & 0 & 0 \\
\hline unid. monoterpene 7 & 0 & 0 & 0 \\
\hline unid. monoterpene 8 & 0 & 0 & 0 \\
\hline unid. monoterpene 9 & 0 & 0 & 0 \\
\hline unid. sesquiterpene 1 & 2.3 & $0-8.8$ & 3.3 \\
\hline unid. sesquiterpene 2 & 0 & 0 & 0 \\
\hline
\end{tabular}


of ipsdienol and myrcene. Gongora gibba produces a simple fragrance dominated by elemicin and a smaller amount of methyl cinnamate. Gongora guinquenervis group A usually contains MMC, beta-ocimene, linalool, methyl cinnamate and eugenol, but there is considerable variation in fragrances. Seven OTUS (\#S 84, 108, 112, 119, 147, 148, 151) lack MMC and contain large amounts of beta-ocimene, linalool, and eugenol. Gongora guinquenervis group $B$ is also variable, but is dominated by terpinen-4-OI and/or CLME and lacks MMC.

In each PCA analysis, the percent variance explained by each principal component is low, with usually about 10\% explained by the first principal component and less for the subsequent components. These low values are probably due to the great qualitative differences among the fragrance taxa, plus the high qualitative and qualitative variation among the minor compounds present in each data set. Such extensive variation prevents the summarizing of variation into just a few principal components. In all the data sets analyzed, the plots of the first and second principal components provided the best separation of taxa. Plots of lower order are not presented.

The plot of the first two principal components of all samples (Fig. 8) shows good separation of tricolor and quinquenervis/gibba. G. quinquenervis group A forms a tight cluster in the lower left quadrant, but $\underline{G}$. gibba is poorly separated from it. $\underline{G}$. quinguenervis group B forms an elongate cluster in the upper half of the diagram. Gongora 







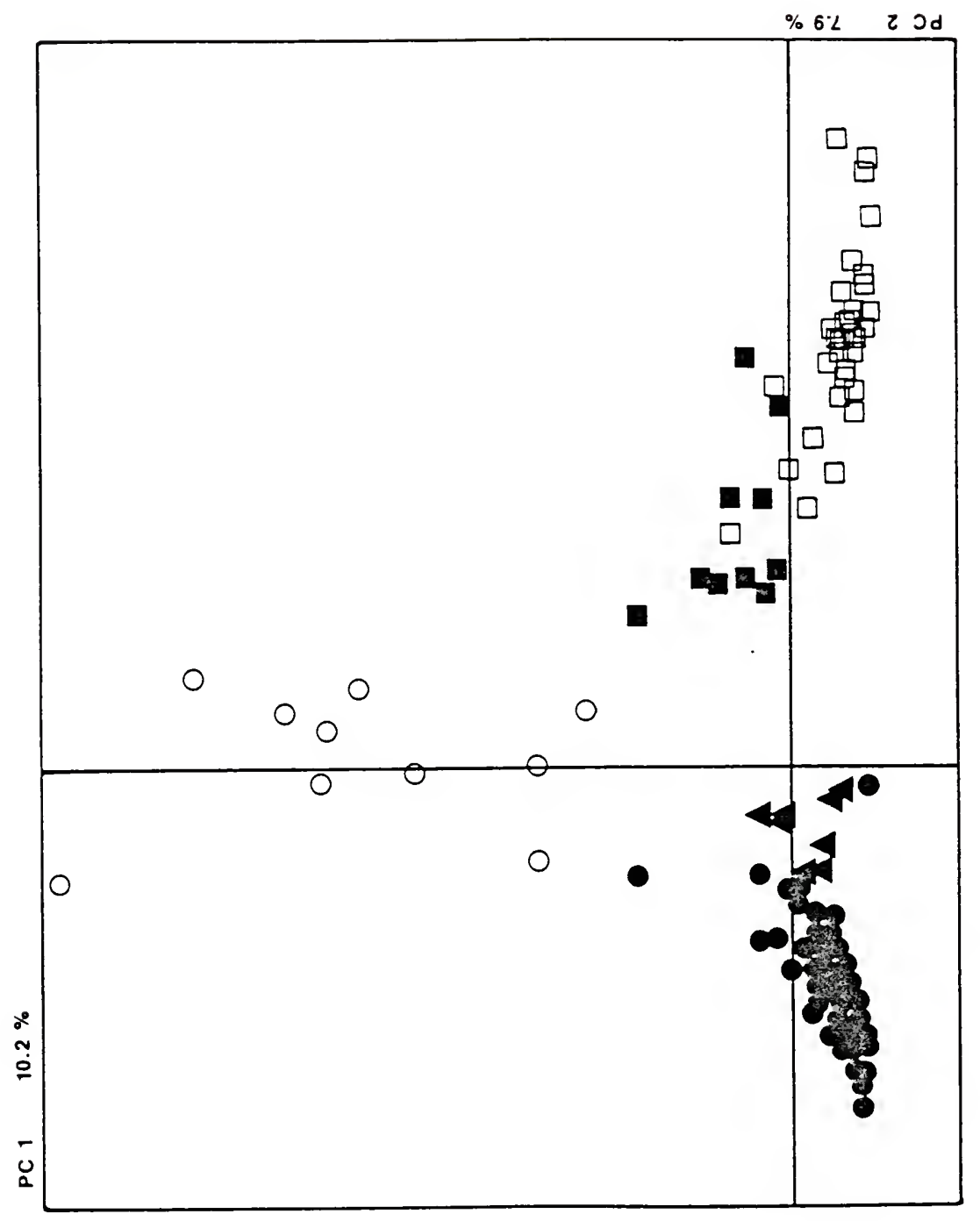


tricolor is restricted to the right half of the plot, and the two varieties are partially separated into the upper and lower right quadrants. The corresponding phenogram for all samples is divided into two figures (Figs 9 and 10). The initial dichotomy of the phenogram separates the samples into G. tricolor (Fig. 9) and G. quinquenervis/gibba (Fig. 10). Gongora tricolor (Fig. 9) is divided into two clusters at a distance value of 13; the larger cluster consists of forms with large amounts of p-cresol and little ipsdienol (group A; Table 4); the smaller cluster consists of individuals with large amounts of ipsdienol and/or myrcene (group B; Table 5). The remaining samples (Fig. 10) are divided at a distance value of 20 into two groups consisting of: 1 . G. quinquenervis group $B$; and 2 . G. quinquenervis group A plus G. gibba. One aberrant OTU (\#151) of group A which lacks MMC is clustered with group B. $\underline{G}$. gibba is separated from $\underline{G}$. quinquenervis group $A$ at a distance value of 10 , but two OTUs of group A (\#S 63 and 81) are clustered with G. gibba; these two OTUs possess abnormally large amounts of methyl cinnamate which probably results in their inclusion with $\underline{G}$. gibba. With three minor exceptions, the phenogram correctly clusters the morphological species together.

In order to resolve taxa in the numerical analyses more completely, the data were divided into subsets for PCA and cluster analysis. The PCA for G. tricolor only (Fig. 11) shows the two groups separated into the left and right halves of the plot. The corresponding cluster analysis (Fig. 12) 
Figure 9. Portion of phenogram of analysis of full fragrance data set; Gongora tricolor only. Symbols: open square $=\underline{G}$. tricolor group $A ;$ solid square $=G$. tricolor group $B$. 


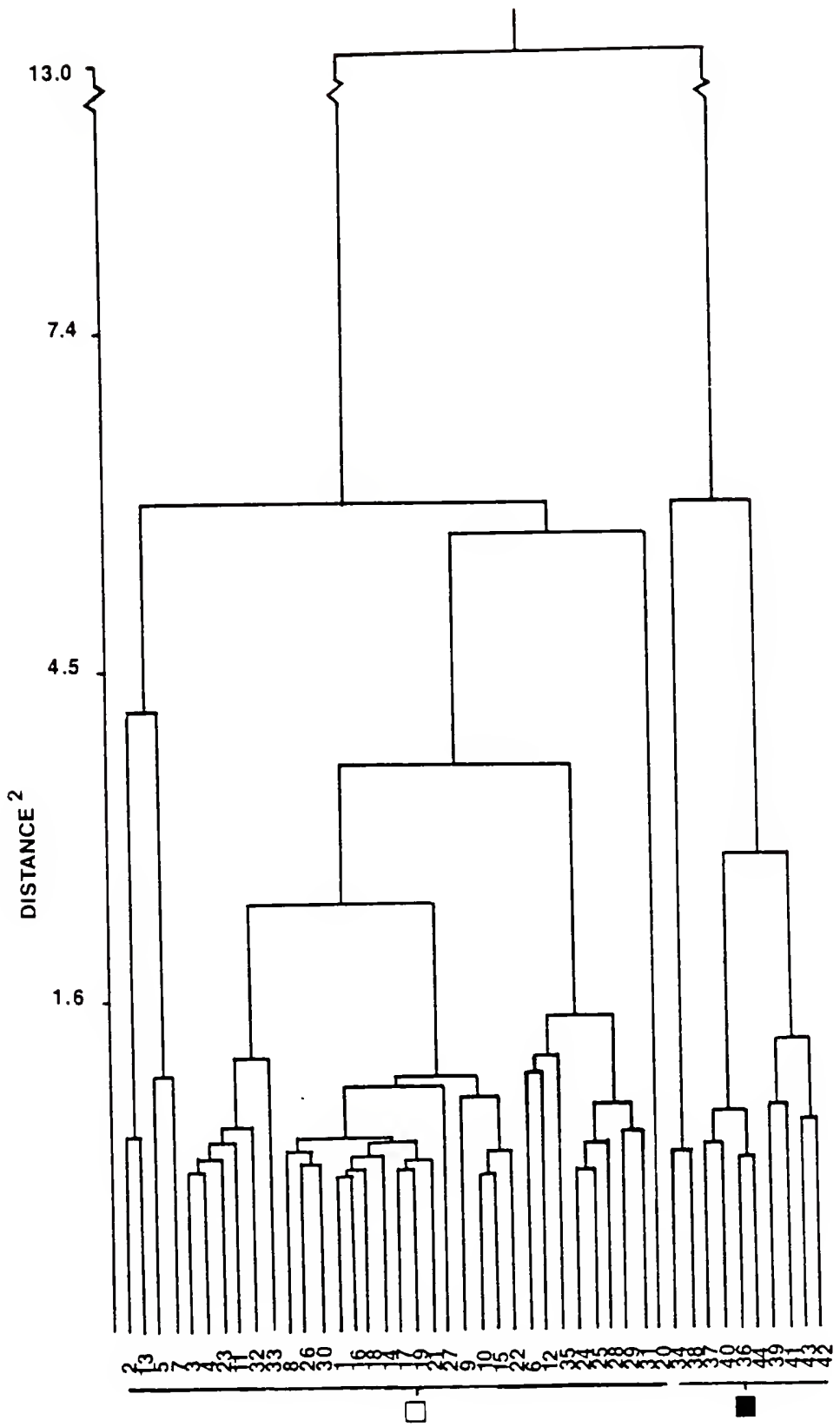




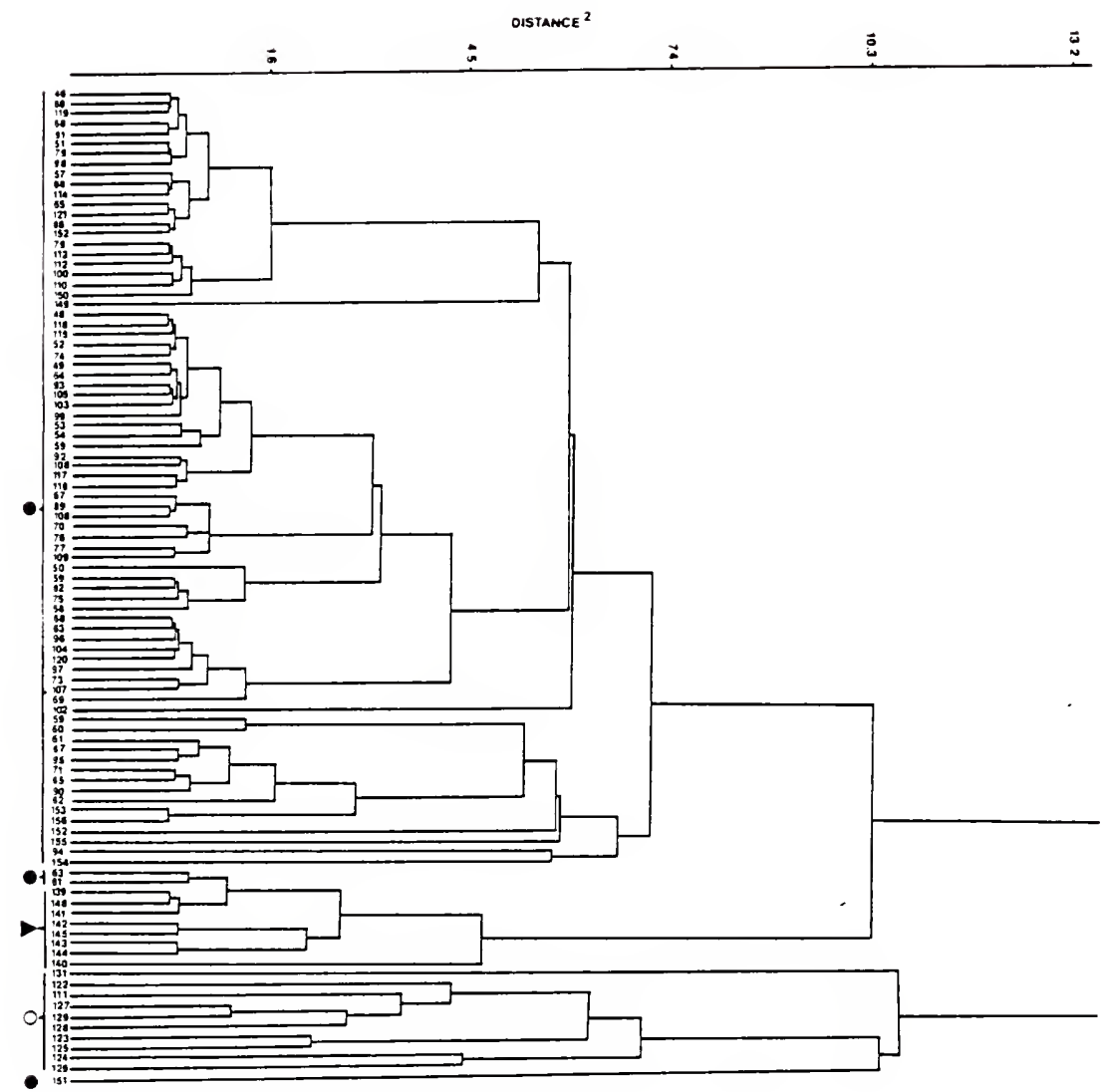

Figure 10. Portion of phenogram of analysis of full data set; Gongora quinquenervis and $\mathrm{G}$. gibba only. Symbols: solid circle $=\mathrm{G}$. quinquenervis group $\mathrm{A}$; open circle $=\mathrm{G}$. quinquenervis group $\mathrm{B}$; triangle $=\mathrm{G}$. gibba. 


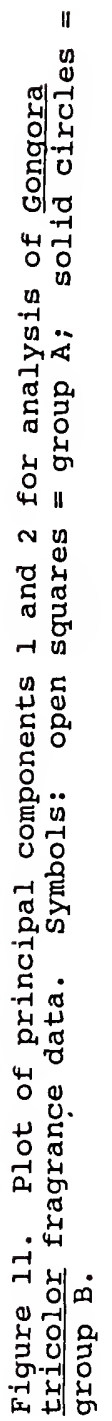




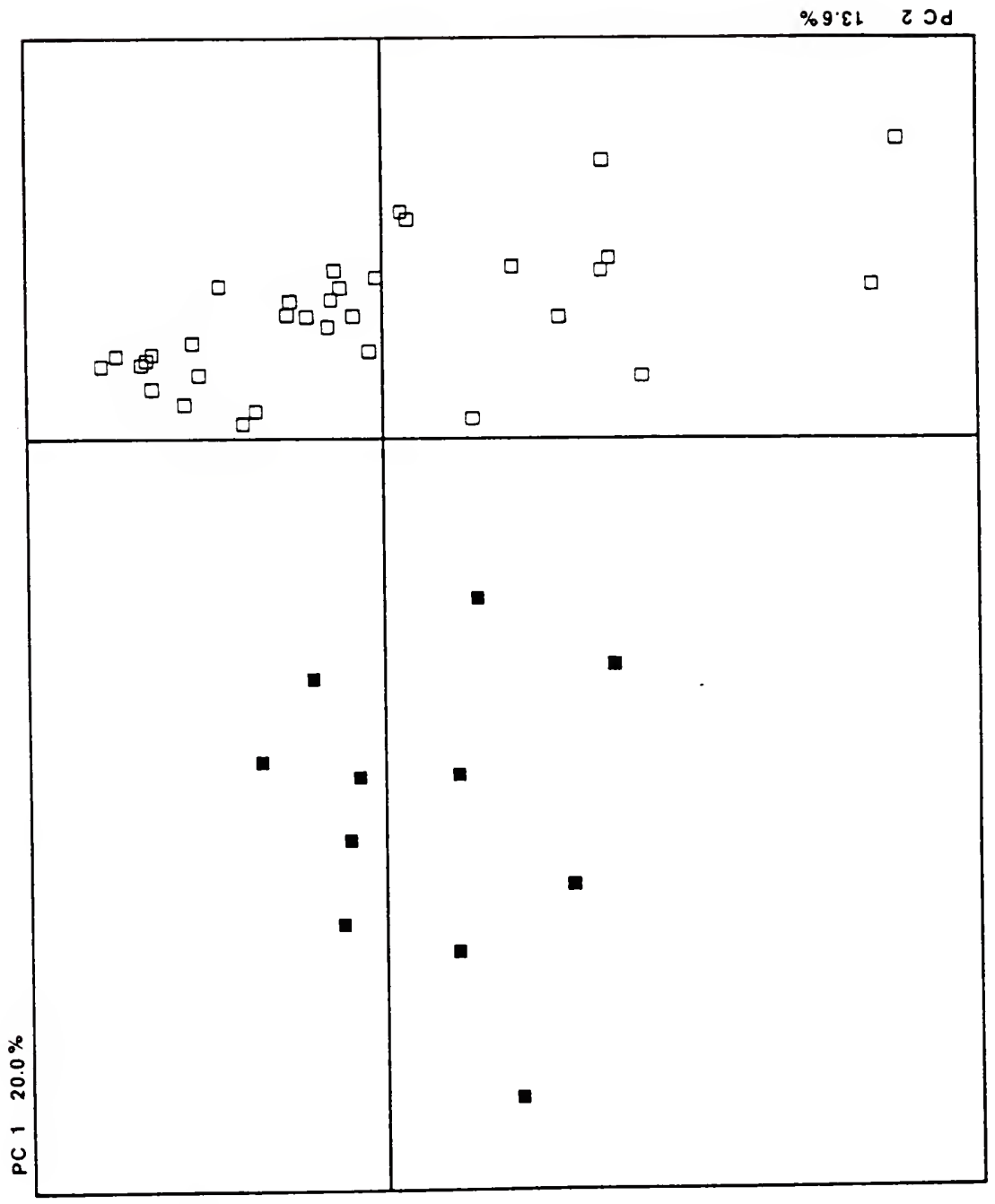


Figure 12. Phenogram of Gongora tricolor fragrance data.

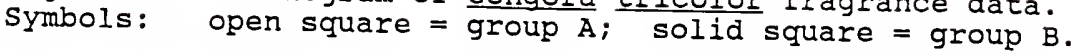




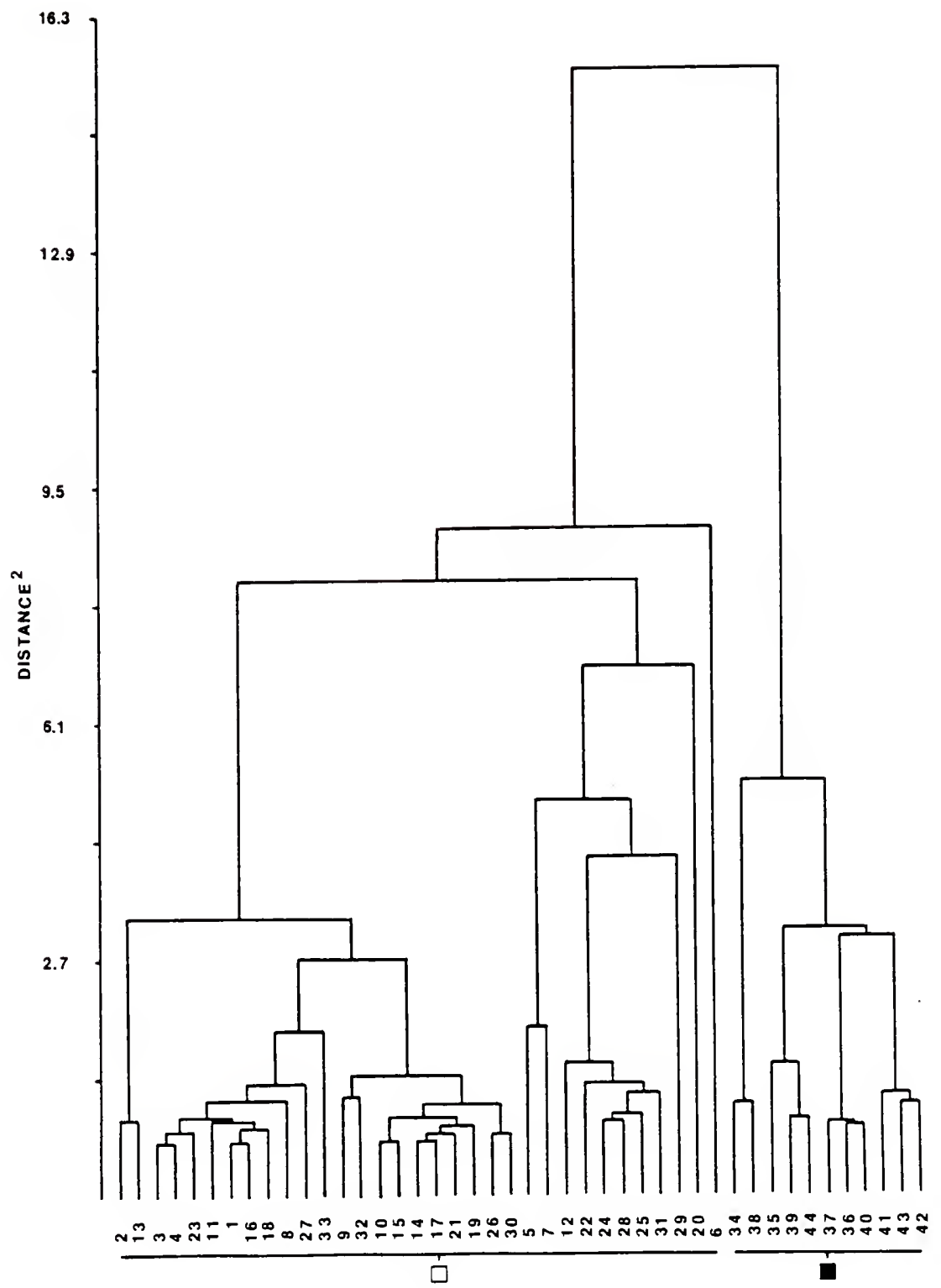


shows the same dichotomy into two groups as the phenogram for the full data set (Fig. 9), but the lower level clusters differ between the two phenograms. The lower level clusters are sensitive to sample size and the inclusion of other oTUS and are not easily interpretable in terms of fragrance composition. The PCA of the subset containing $\underline{G}$. quinquenervis groups $A$ and $B$ and $G$. gibba (Fig. 13) shows group $B$ forming a diffuse cluster on the right half of the plot. Individuals of $\underline{G}$. gibba are tightly clustered, but are poorly separated from $G$. quinquenervis group $A$. The corresponding phenogram (Fig. 14) shows $\underline{G}$. quinquenervis group $B$ and $G$. gibba forming monophentic groups, but group A is split into one large group and one small $(n=4)$ cluster. The members of the small cluster are chemically aberrant; they contain little or no MMC and large amounts of other compounds such as eugenol or linalool.

If $G$. quinquenervis group $B$ is excluded, leaving only group $A$ and $G$. gibba, the PCA plot (Fig. 15) still shows poor separation of the two species (although G. gibba is restricted to the upper left quadrant). The corresponding phenogram (Fig. 16) shows the two species forming separate clusters except for three aberrant individuals of $\underline{G}$. quinquenervis that cluster with $\underline{G}$. gibba; OTU \#61 lacks MMC, and oTUs \#63 and \#81 contain large amounts of methyl cinnamate.

Geographic subsets of the data were also analyzed in order to test the performance of phenetic analysis with 


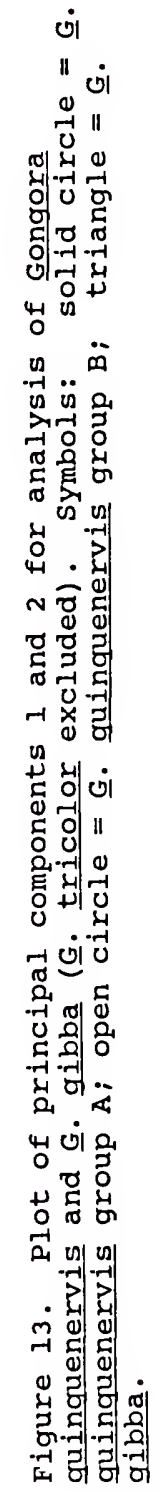




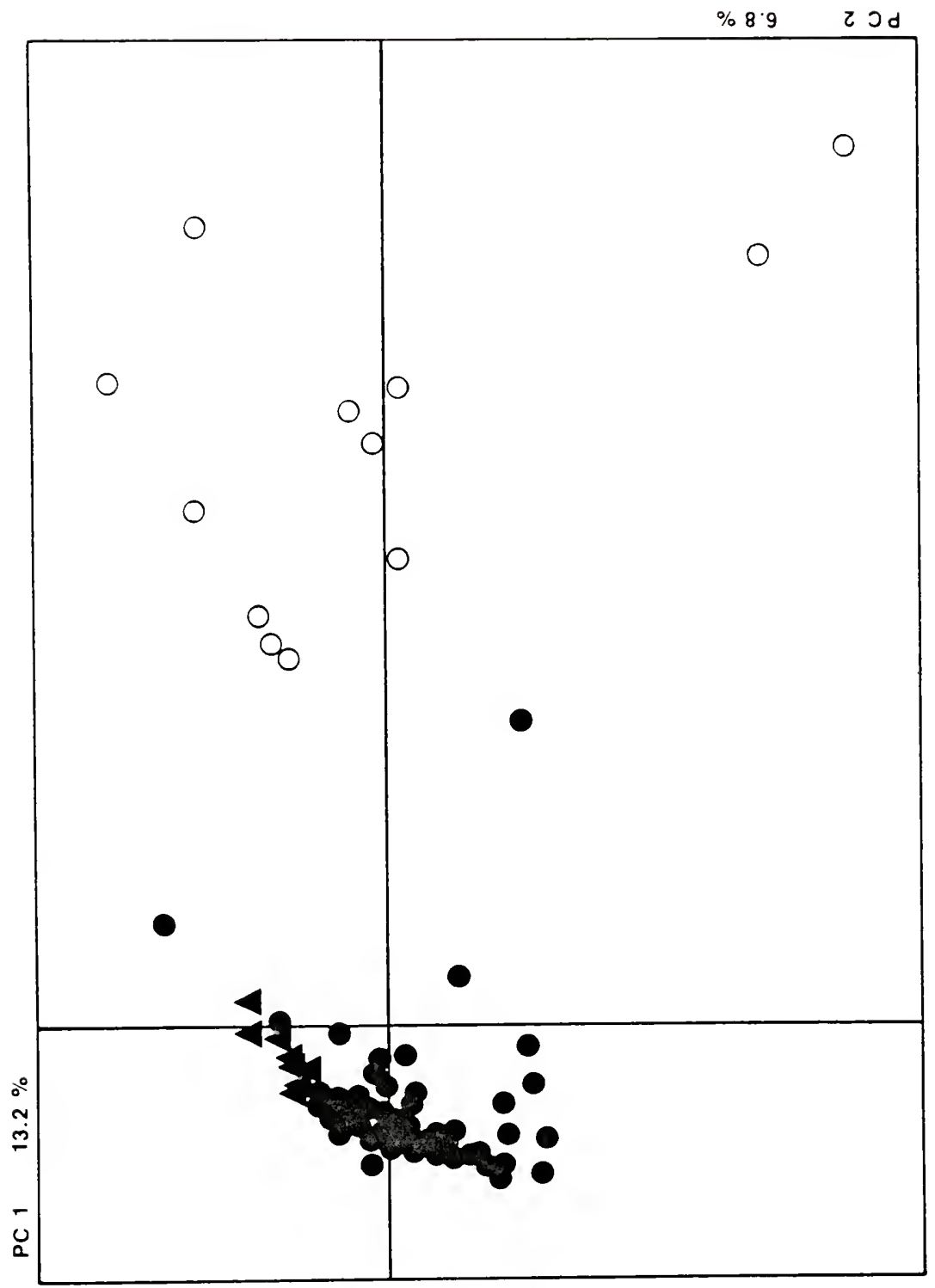


\ْ

ठิ ن

เ

냉

कू

ક્ષ

4.

잉

命

б) مू

نi

ס

ชิ

이 으

-1)

त्र

의 용

(4) 3

다 0

던

하 희 II

빅금

의

ㄱ.

위 نं. म्न

41

00

获

है

내요

O

둥

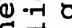

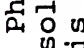

-

$+0$

in 0

$0-1$

닝을

官

$\rightarrow{ }_{1}$

है क ह 


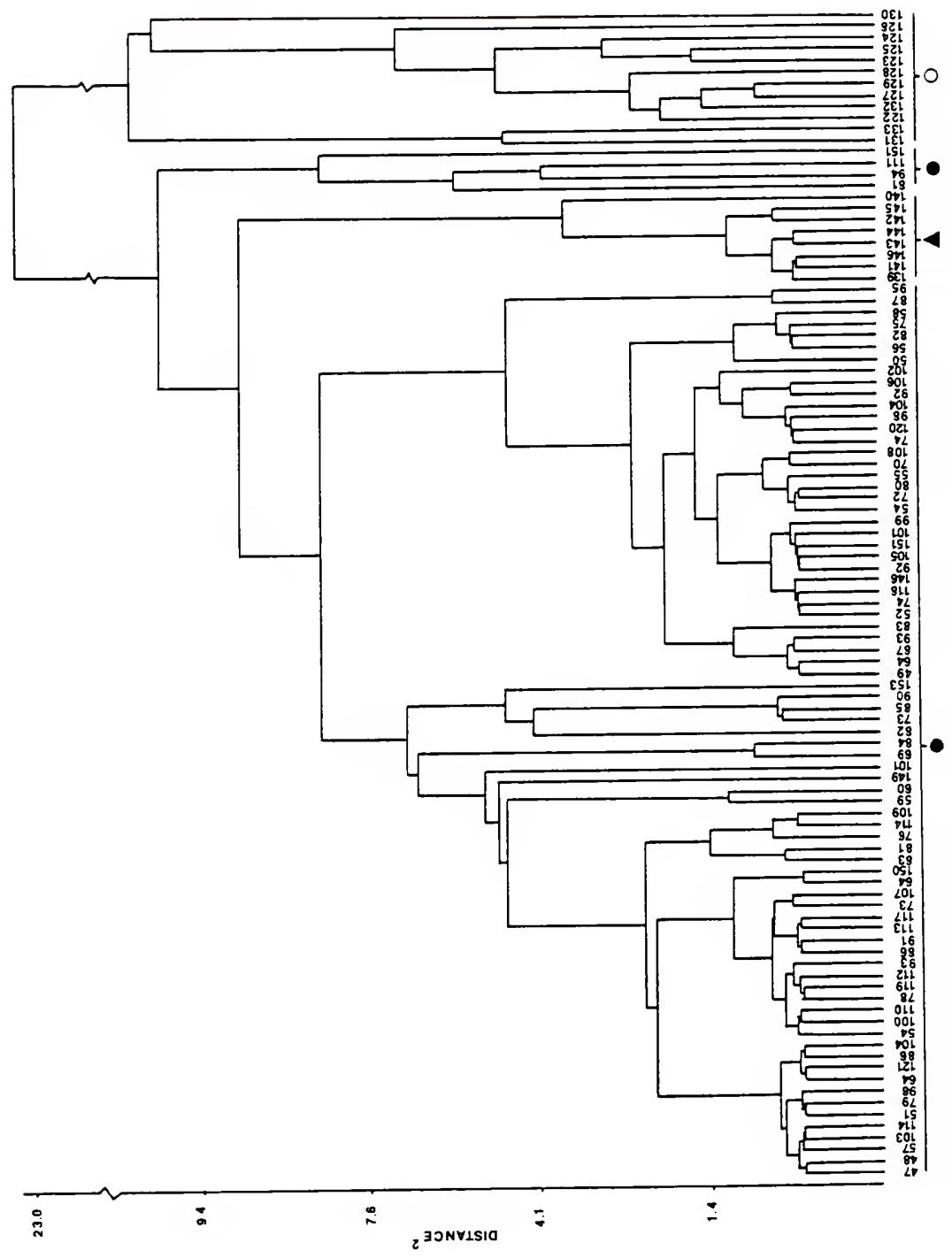




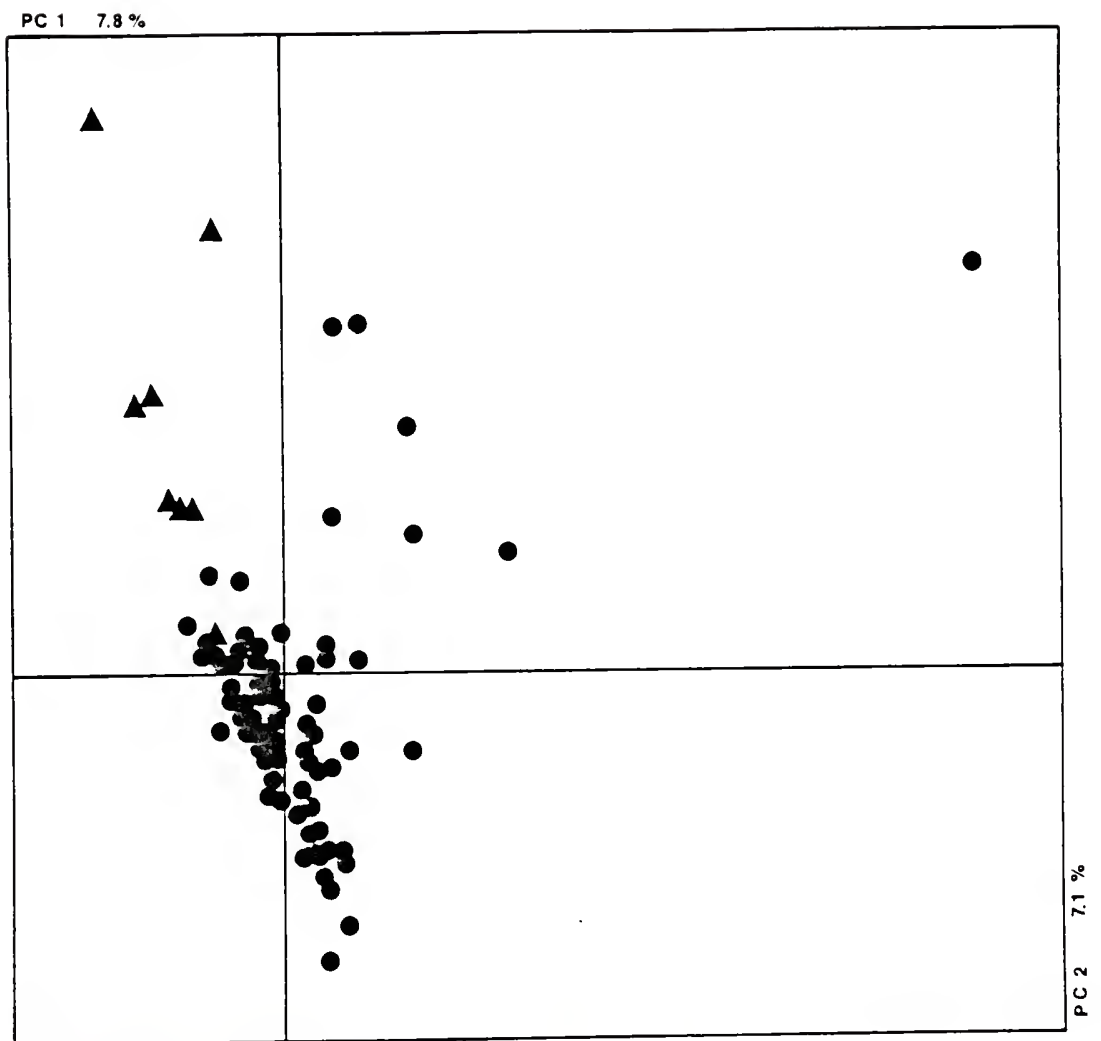

Figure 15. Plot of principal components 1 and 2 of analysis of Gongora quinquenervis group $A$ and $G$. gibba fragrance data. Symbols: solid circle $=\underline{G}$. quinquenervis group $A$; triangle $=$ G. gibba. 
Figure 16. Phenogram of Gongora quinquenervis group $A$ and $G$. gibba fragrance data. Symbols: solid circle $=\underline{G}$.

quinquenervis group $A$; triangle $=G$. gibba. 


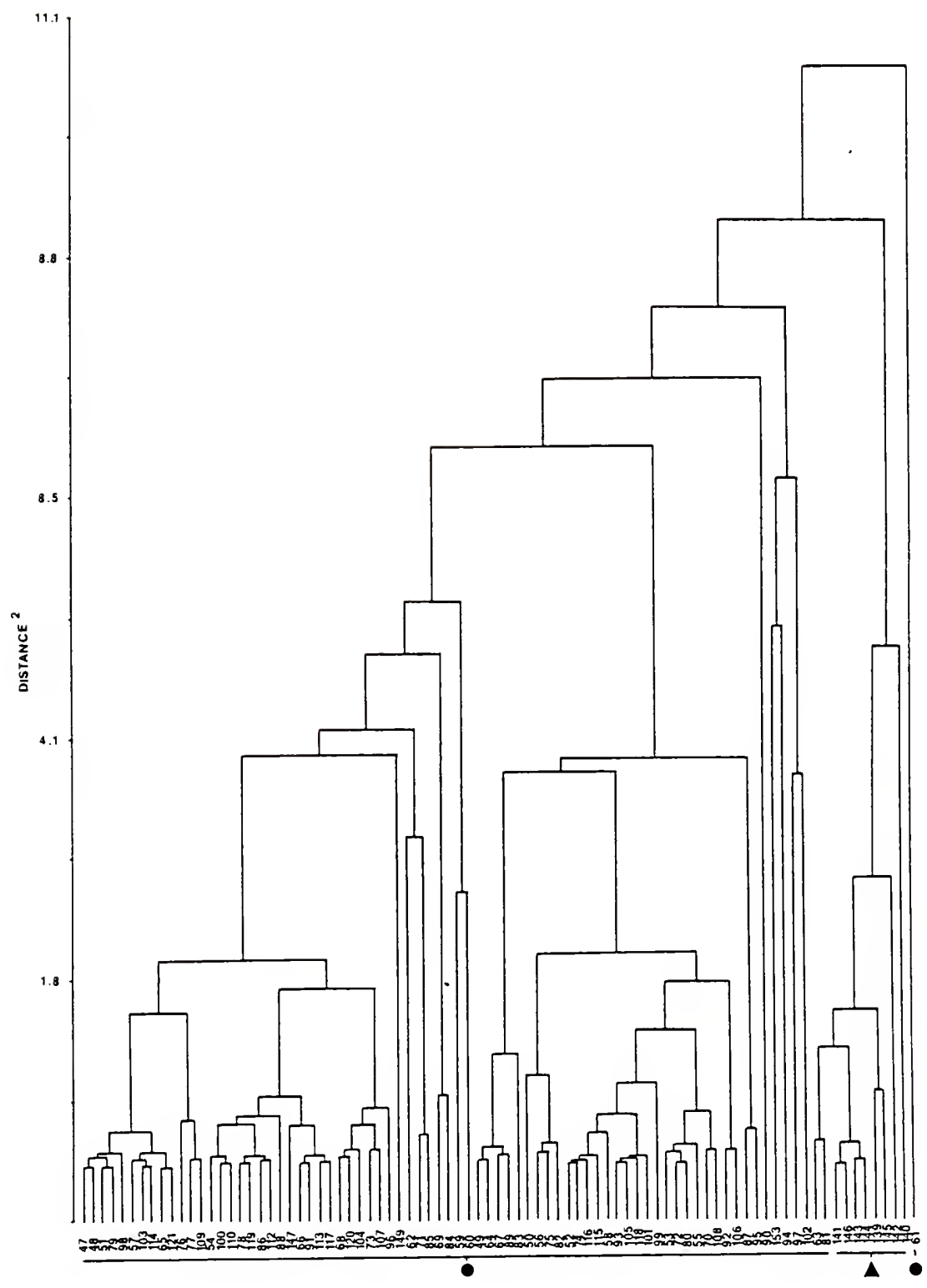


uneven and low sample sizes. A data set consisting of all OTUs from Rio Iguanita and nearby Santa Rita was analyzed; the PCA plot (Fig. 17) shows tight, well-resolved clusters of $\mathrm{G}$. tricolor and $\mathrm{G}$. quinguenervis group $A$ (with the exception of one aberrant OTU \#15I of the latter taxon). $G$. gibba is not resolved, and $\underline{G}$. quinquenervis group B forms a diffuse cluster in the upper left quadrant, reflecting the heterogeneity of this variety. The phenogram (Fig. 18) shows groupings similar to earlier phenograms, except for the inclusion of OTU \#20 into G. tricolor group B. OTU \#15I clusters with quinquenervis group $B$, as it did in the phenogram of the full data set.

A second subset, consisting of all OTUs from the two highland, western sites (El Valle and El Copé) was analyzed. In the PCA plot (Fig. 19), G. quinquenervis group A forms a very tight cluster with the four OTUs of $G$. gibba lost within it. The other two taxa are well-separated from the main cluster of quinquenervis group A. The corresponding phenogram (Fig. 20) shows G. tricolor and $\underline{G}$. quinquenervis group B split off at high distance values, but $G$. gibba forms a cluster submerged within $\underline{G}$. quinquenervis group $A$. If the two samples of $\underline{G}$. tricolor are removed and the analyses rerun (Fig. 21), G. gibba is still not resolved in the PCA analysis. The corresponding phenogram (Fig. 22) shows $\underline{G}$. gibba submerged even deeper within $\mathrm{G}$. quinquenervis group $A$. The difficulty in resolving $\mathrm{G}$. gibba is probably due to the simplicity of its fragrance (only two major compounds) 


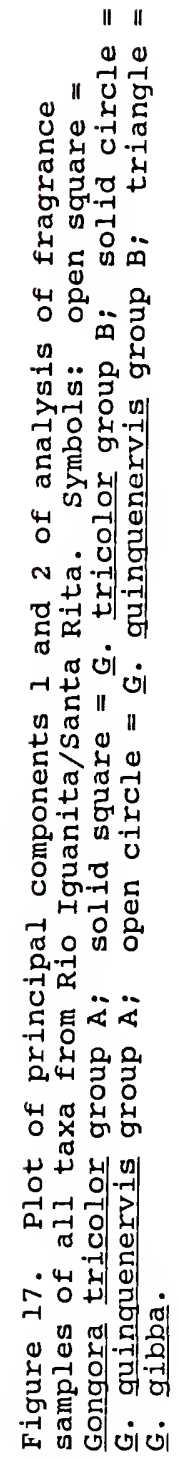


$\% 6 L 20 d$

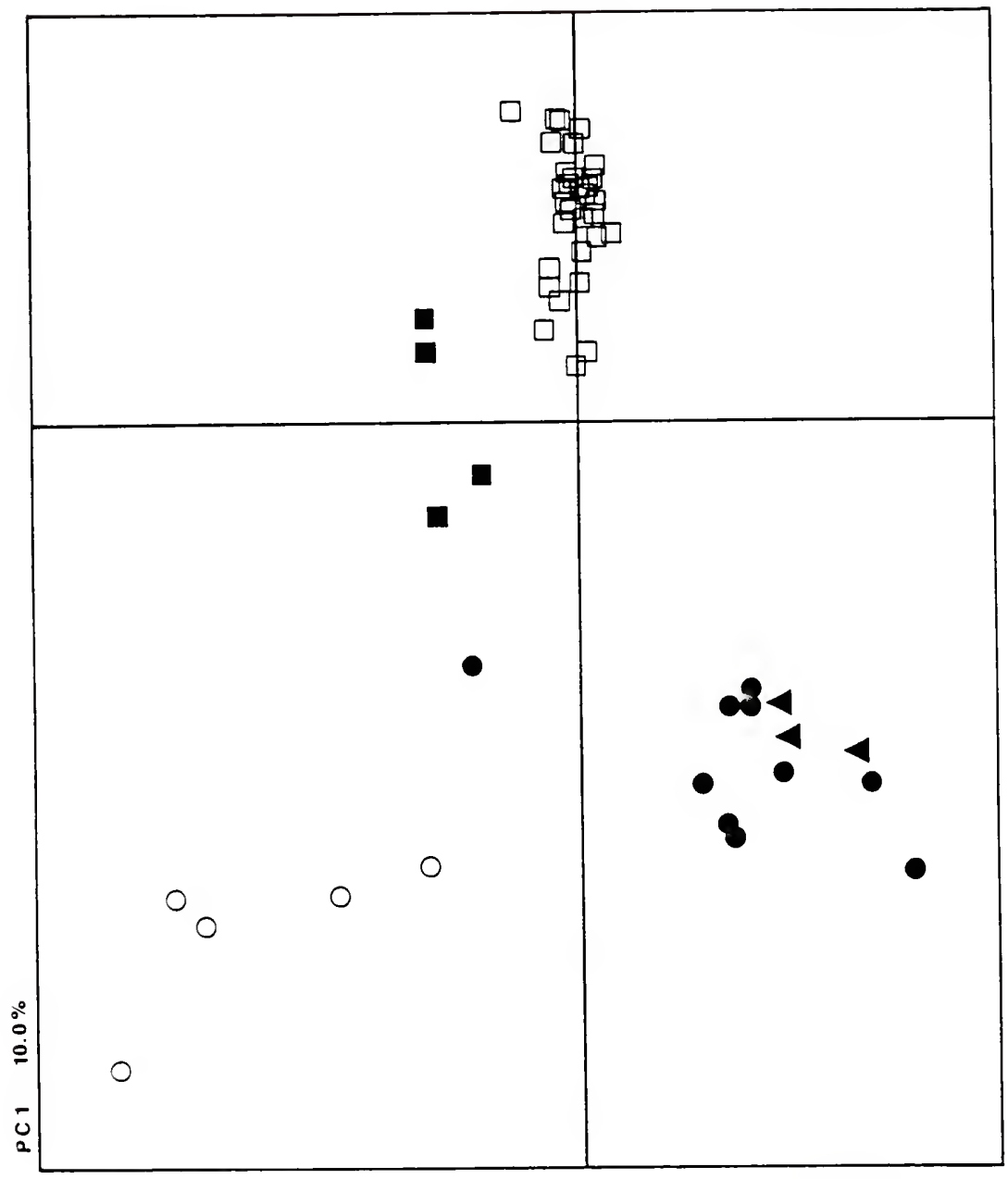


Figure 18. Phenogram of fragrance samples of all taxa from Rio Iguanita/Santa Rita. Symbols: open square = Gongora tricolor group $A$; solid square $=G$. tricolor group $B$; solid circle $=\mathrm{G}$. quinquenervis group $\mathrm{A} ;$ open circle $=\underline{\mathrm{G}}$. quinquenervis group $B ;$ triangle $=\mathrm{G}$. qibba. 


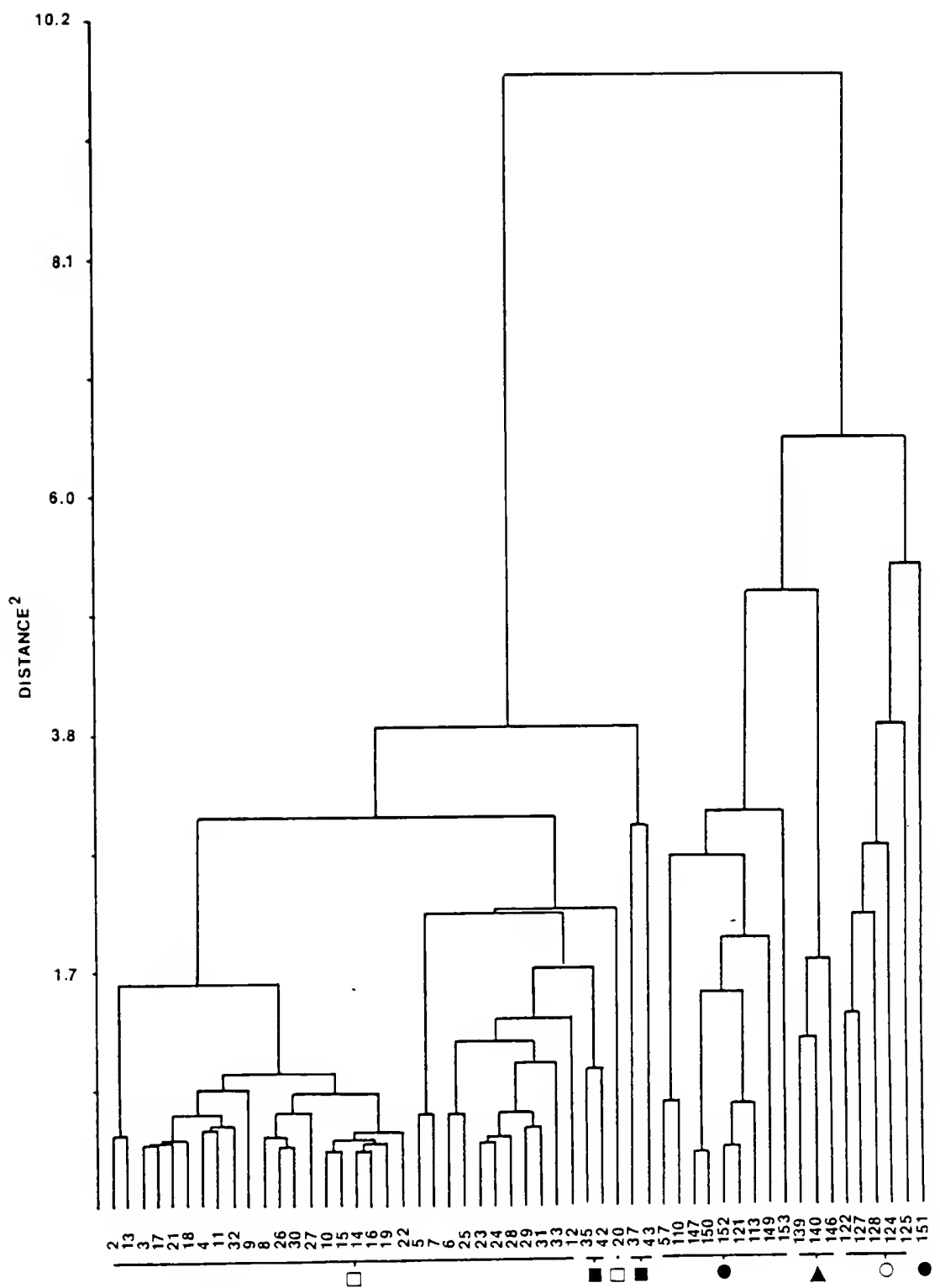




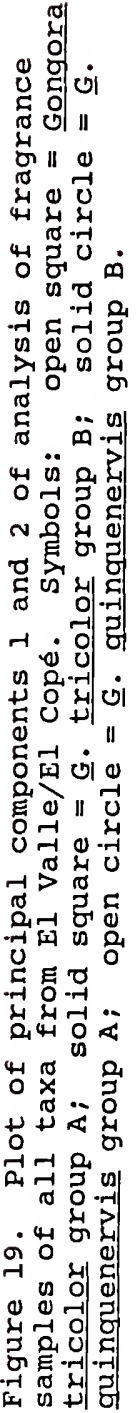


$\% 2 \cdot 8$

$20 d$

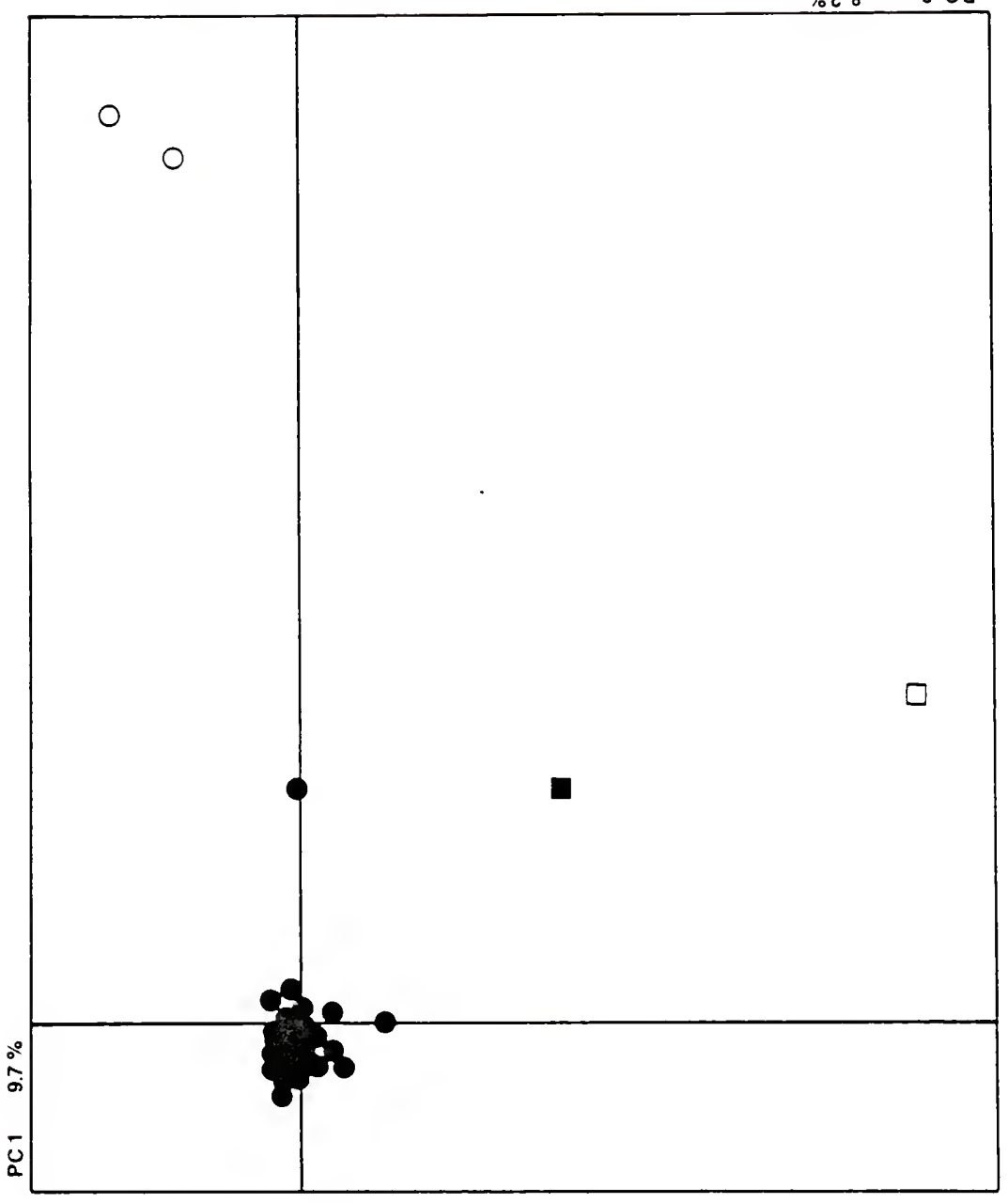


Figure 20. Phenogram of fragrance samples of all taxa from El Valle/El Copé. Symbols: open square = Gongora tricolor group $A ;$ solid square $=\underline{G}$. tricolor group $B ;$ solid circle $=$ G. quinquenervis group $A ;$ open circle $=\underline{G}$. quinquenervis group $B ;$ triangle = G. gibba. 


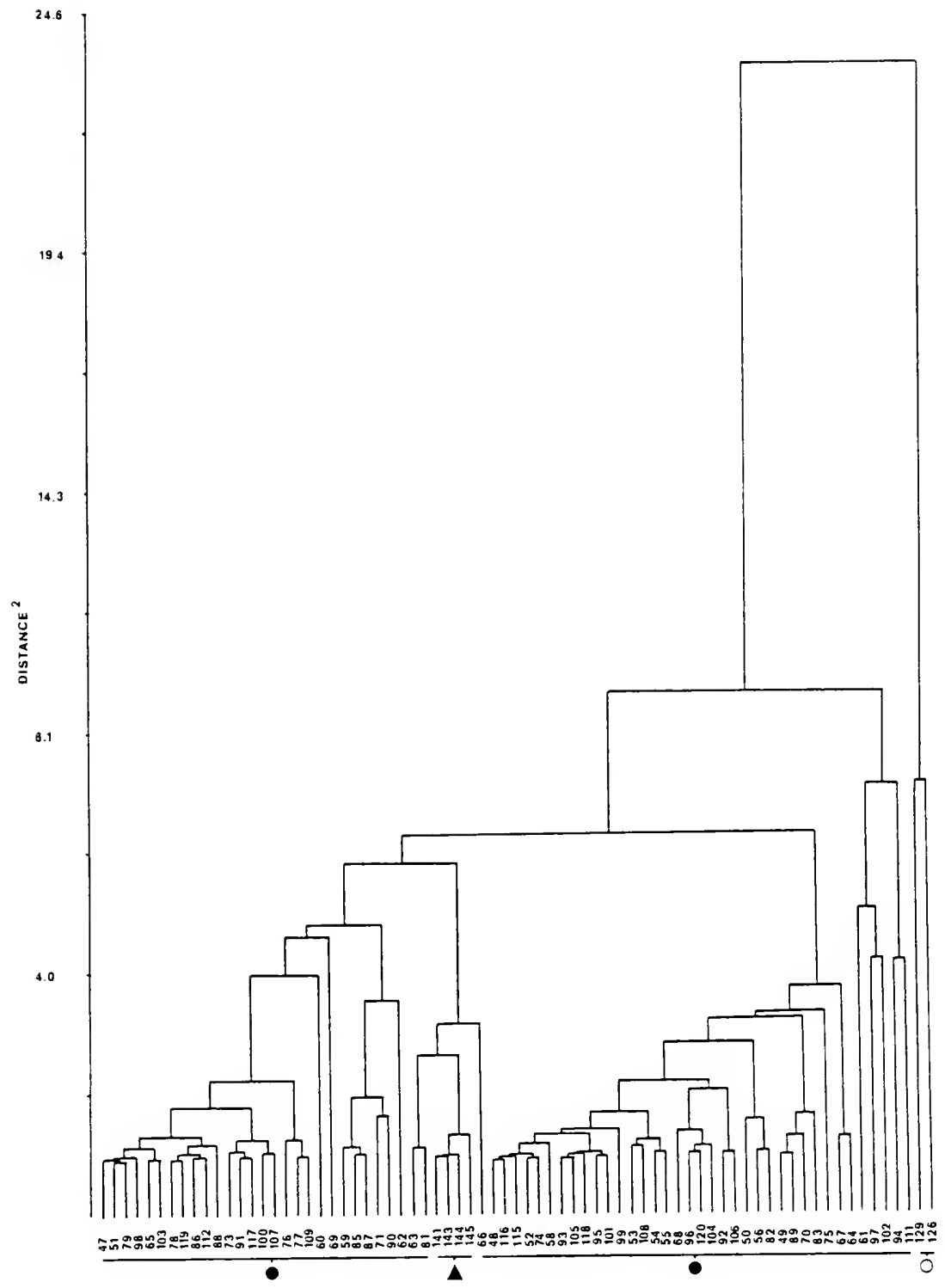




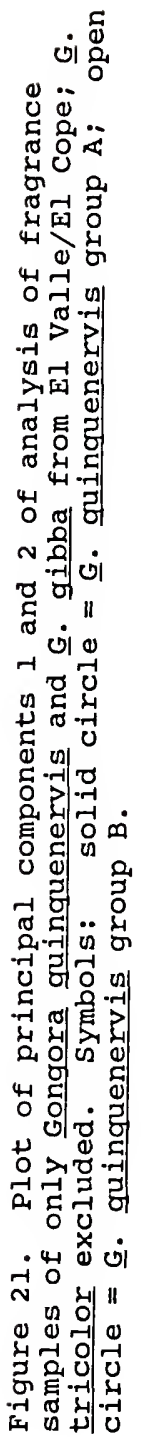




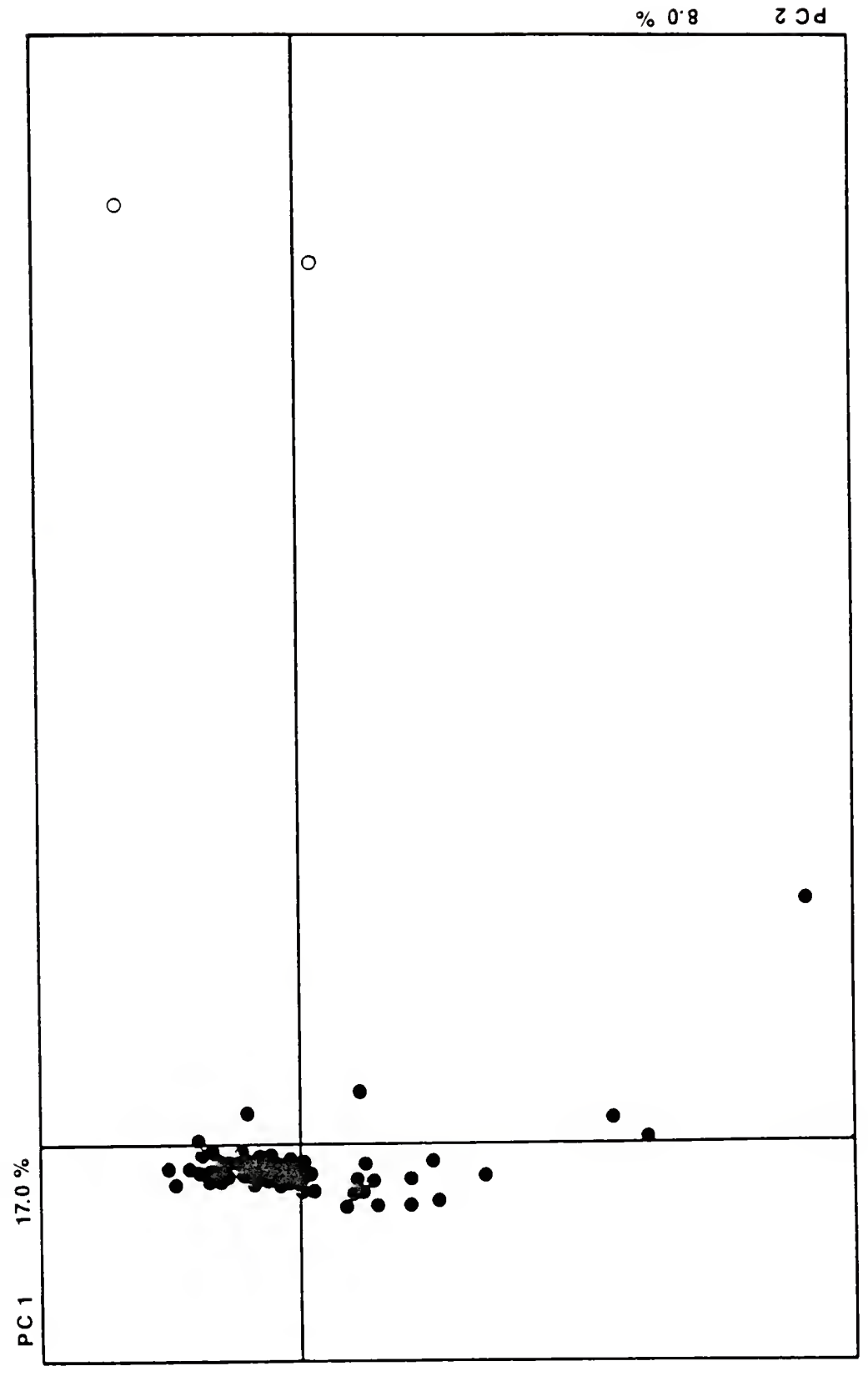


Figure 22. Phenogram of fragrance samples of only Gongora quinquenervis and $G$. gibba from El Valle/El Copé; G. tricolor excluded. Symbols: solid circle $=\underline{G}$. quinquenervis group $\mathrm{A}$; open circle $=\mathrm{G}$. quinquenervis group $\mathrm{B} ;$ triangle $=\underline{G}$. gibba. 


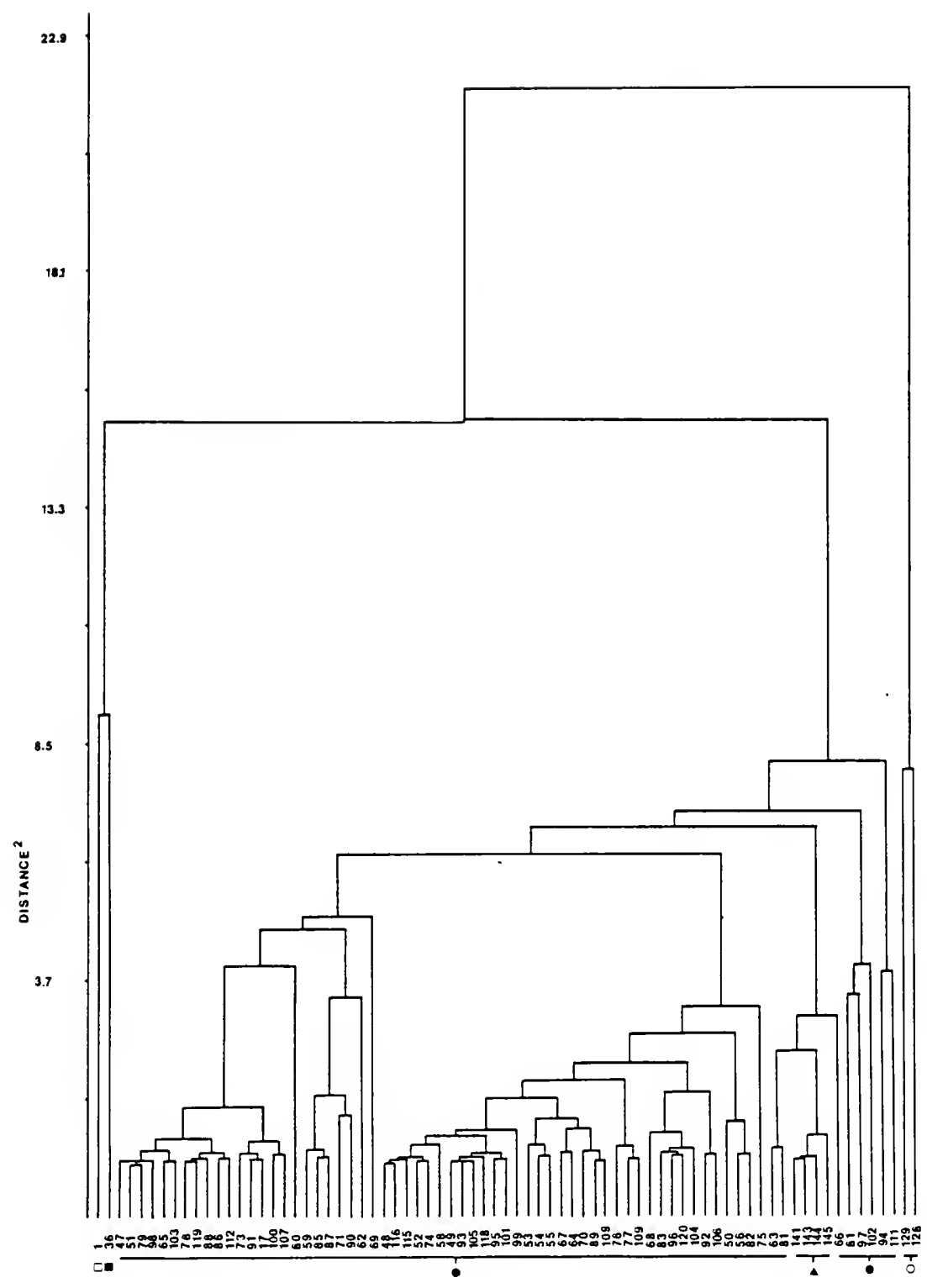


and the fact that one of its compounds (methyl cinnamate) is also present in $\underline{G}$. quinquenervis in moderate amounts. An additional reason for the poor resolution of $\mathrm{G}$. gibba may lie in the choice of clustering technique. The error sum of squares method used here is sensitive to numbers of OTUs within clusters, compared to the weighted and unweighted pair group methods (Sneath, 1976). The addition of more individuals of $G$. gibba results in its separation at higher distance values. The weighted and unweighted pair group methods were also used to analyze the data sets, but they produced uninterpretable results; the resulting phenograms displayed extensive chaining of OTUs and failed to cluster conspecifics together. The error sum of squares method is known to produce relatively tight clusters with minimal chaining, and is suited for the sparse data sets generated in this study. Wishart (1978) considers the error sum of squares method as perhaps the best clustering algorithm.

\section{Bee Species Present at Each Site}

Bee censuses were performed at El Valle and Rio Iguanita in 1982, 1983 and 1984, and at Cerro Azul and El Copé in 1982 and 1984, respectively (Table 9). Nearly 2,700 bees comprising 41 species were collected. Sorensen's coefficient of similarity (Southwood, 1978) was calculated to compare similarities in species composition between pairs of pooled season censuses. The similarity values range from 69-78\%, slightly lower than the values reported for seasonal 
Table 9. Numbers of euglossine bees collected at fragrance baits.

\begin{tabular}{|c|c|c|c|c|c|c|c|}
\hline \multirow[t]{2}{*}{ Bee species } & \multicolumn{7}{|c|}{ Site $^{a}$ and Year } \\
\hline & $\overline{\text { EV82 }}$ & EV83 & EV84 & RI83 & RI84 & CA82 & EC84 \\
\hline \multicolumn{8}{|l|}{ Euglossa } \\
\hline allosticta & 31 & 15 & 10 & 2 & 6 & 6 & 8 \\
\hline asarophora & 5 & 0 & 0 & 1 & 0 & 13 & 1 \\
\hline azureoviridis & 0 & 0 & 0 & 1 & 0 & 1 & 0 \\
\hline bursigera & 0 & 0 & 0 & 0 & 9 & 1 & 5 \\
\hline championi & 12 & 6 & 8 & 0 & 1 & 1 & 41 \\
\hline crassipunctata & 5 & 1 & 0 & 1 & 1 & 2 & 12 \\
\hline cyanaspis & 10 & 0 & 1 & 24 & 36 & 3 & 0 \\
\hline cyanura & 20 & 1 & 9 & 7 & 4 & 0 & 0 \\
\hline cybelia & 24 & 2 & 5 & 0 & 0 & 3 & 7 \\
\hline deceptrix & 316 & 199 & 231 & 1 & 6 & 2 & 72 \\
\hline despecta & 3 & 0 & 2 & 17 & 14 & 1 & 3 \\
\hline dissimula & 28 & 4 & 6 & 7 & 21 & 8 & 0 \\
\hline dodsoni & 86 & 18 & 32 & 62 & 190 & 22 & 115 \\
\hline dressleri & 5 & 1 & 0 & 0 & 2 & 3 & 3 \\
\hline flammea & 3 & 0 & 0 & 8 & 38 & 0 & 3 \\
\hline gorgonensis & 3 & 0 & 0 & 10 & 39 & 1 & 26 \\
\hline hansoni & 48 & 0 & 3 & 28 & 34 & 4 & 2 \\
\hline hemichlora & 0 & 0 & 0 & 0 & 0 & 0 & 0 \\
\hline heterosticta & 2 & 0 & 0 & 2 & 0 & 0 & 0 \\
\hline imperialis & 39 & 1 & 8 & 3 & 1 & 8 & 34 \\
\hline maculilabris & 8 & 4 & 1 & 0 & 0 & 0 & 1 \\
\hline mixta & 19 & 5 & 3 & 5 & 6 & 9 & 14 \\
\hline purpurea & 1 & 1 & 1 & 0 & 0 & 0 & 0 \\
\hline sapphirina & 2 & 0 & 0 & 6 & 7 & 0 & 0 \\
\hline townsendi & 8 & 0 & 8 & 0 & 0 & 0 & 0 \\
\hline tridentata & 16 & 2 & 2 & 12 & 68 & 0 & 7 \\
\hline turbinifex & 4 & 0 & 0 & 0 & 0 & 1 & 7 \\
\hline variabilis & 28 & 4 & 2 & 8 & 12 & 2 & 2 \\
\hline villosiventris & 1 & 0 & 0 & 0 & 0 & 0 & 0 \\
\hline \multicolumn{8}{|l|}{ Eulaema } \\
\hline bombiformis & 2 & 1 & 0 & 6 & 2 & 0 & 1 \\
\hline cingulata & 42 & 20 & 15 & 12 & 10 & 9 & 29 \\
\hline meriana & 21 & 2 & 5 & 3 & 11 & 3 & 7 \\
\hline nigrita & 92 & 12 & 38 & 10 & 15 & 9 & 40 \\
\hline polychroma & 20 & 10 & 10 & 0 & 1 & 0 & 7 \\
\hline speciosa & 5 & 0 & 0 & 0 & 1 & 0 & 0 \\
\hline \multicolumn{8}{|l|}{ Eufriesea } \\
\hline anisochlora & 2 & 0 & 0 & 0 & 0 & 0 & 0 \\
\hline chrysopyga & 6 & 0 & 0 & 0 & 0 & 0 & 8 \\
\hline Iucifera & 2 & 0 & 0 & 4 & 0 & 0 & 7 \\
\hline ornata & 1 & 0 & 0 & 1 & 0 & 0 & 0 \\
\hline schmidtiana & 1 & 0 & 0 & 2 & 0 & 0 & 0 \\
\hline \multicolumn{8}{|l|}{ Exaerete } \\
\hline frontalis & 6 & 1 & 0 & 8 & 2 & 1 & 0 \\
\hline Total & 927 & 310 & 400 & 251 & 537 & 113 & 462 \\
\hline
\end{tabular}


variations in the euglossine fauna of Barro Colorado Island (Ackerman, 1981). Sample sizes for most taxa are too small for valid comparison, but the data show a striking difference in the abundance of Euglossa deceptrix between the western and eastern sites. Euglossa deceptrix is the most common species sampled at El Valle, but is uncommon at the lowland eastern sites.

\section{Pollinarium Loads}

Bees collected at fragrance baits were examined for Gongora pollinaria. Since the pollination mechanism that results in removal of a pollinarium is the same as that for insertion of a pollinium into the stigma, any bee carrying pollinaria on the scutellum can be regarded as a pollinator. Pollinaria could not be identified to species due to the morphological similarity among the three Gongora species. The totals for data pooled by years is presented in Table 10. Seven bee species carried pollinaria and hence are probably legitimate pollinators of at least one species of Gongora. Sample sizes of six species are low, but 394 (49.5\%) of Euglossa deceptrix at El Valle and seventeen $\underline{E}$. deceptrix (24\%) at El Copé bore pollinaria. Previous censuses of euglossine bees in Panama (Ackerman, 1983a) and Costa Rica (Janzen et al., 1982) reported low percentages of pollinarium-laden bees (below 5\%). The high percentage at El Valle ( $50 \%$ of E. deceptrix, or $15 \%$ of all bees sampled) is unusual, and is a reflection of the large numbers of Gongora 
Table 10. Numbers of bees captured carrying Gongora pollinaria.

\begin{tabular}{|c|c|c|c|c|c|c|}
\hline \multirow{4}{*}{$\frac{\text { Euglossa }}{\text { Species }}$} & \multicolumn{6}{|c|}{ Site and Year } \\
\hline & \multicolumn{3}{|c|}{ El Valle } & \multicolumn{2}{|c|}{$\begin{array}{l}\text { Rio } \\
\text { Iguanita }\end{array}$} & \multirow{3}{*}{$\begin{array}{c}\begin{array}{c}\text { El } \\
\text { Copé }\end{array} \\
1984\end{array}$} \\
\hline & & & & & & \\
\hline & 1982 & 1983 & 1984 & 1983 & 1984 & \\
\hline asarophora & & & & 1 & & \\
\hline cyanaspis & & & & 1 & 2 & \\
\hline deceptrix & 201 & 84 & 109 & & & 17 \\
\hline despecta & & & & 2 & 2 & \\
\hline gorgonensis & 1 & & & & & \\
\hline tridentata & 1 & & & & 6 & 1 \\
\hline variabilis & 1 & 1 & & & 2 & \\
\hline
\end{tabular}


quinquenervis and its main pollinator ( $\underline{E}$. deceptrix) at El Valle.

Some bees carried pollinaria of other orchid genera in addition to those of Gongora. These genera include Kefersteinia, Mormodes, Peristeria, and Notylia. Pollinaria of other genera seen on other bees include Houlettia, Sievekingia, Catasetum, Coryanthes, and cycnoches (see Dressler, 1982 and Ackerman, 1983b for illustrations of pollinaria and their placement on bees).

\section{Visitors and Pollinators of Gongora}

Plants were rarely encountered in flower, and any found in flower were too high for collection of visitors. Pollination data were obtained on plants collected in spike or bud and cultivated until the flowers opened. All observations of visitors were made using plants transplanted to a branch or trunk about two meters above the ground. A list of the visitors to 29 plants is given in Table 11. No distinction is made between visitors and pollinators because actual pollination is an infrequent event due to the chancy fall-through pollination mechanism. Actual pollination (insertion of a pollinarium as the bee falls through the flower) was observed only twice. Except for the large Eulaema meriana and possibly Euglossa imperialis, all of the visitors are the appropriate size to effect pollination.

Twenty-three plants of $\underline{G}$. quinquenervis were observed at El Valle. Eight plants attracted no visitors; the rest 
Table 11. Numbers of individuals of Euglossa visitors to Gongora inflorescences.

\begin{tabular}{|c|c|c|c|c|c|}
\hline$\frac{\text { Gongora }}{\text { Species }}$ & OTU\# & $\begin{array}{l}\text { Collection } \\
\text { Localitya }\end{array}$ & $\begin{array}{l}\text { Observation } \\
\text { Locality }\end{array}$ & visitor & Number \\
\hline \multicolumn{6}{|l|}{ quinque- } \\
\hline nervis $A$ & 47 & $\mathrm{EV}$ & EV & deceptrix & 6 \\
\hline " & 49 & EV & EV & none & \\
\hline$"$ & 50 & EV & EV & deceptrix & 5 \\
\hline$"$ & 51 & $\mathrm{EV}$ & $\mathrm{EV}$ & none & \\
\hline$"$ & 53 & $\mathrm{EV}$ & EV & deceptrix & 1 \\
\hline$"$ & 56 & $\mathrm{EV}$ & EV & none & \\
\hline$"$ & 59 & EV & EV & none & \\
\hline$"$ & 61 & EV & EV & deceptrix & 1 \\
\hline$"$ & 62 & $\mathrm{EV}$ & EV & none & \\
\hline$"$ & 63 & $\mathrm{EV}$ & EV & none & \\
\hline$"$ & 65 & EV & EV & none & \\
\hline$"$ & 66 & EV & EV & deceptrix & 1 \\
\hline$"$ & 67 & EV & $\mathrm{EV}$ & deceptrix & 2 \\
\hline$"$ & 73 & EV & $E V$ & deceptrix & 1 \\
\hline$"$ & 75 & EV & $E V$ & deceptrix & 6 \\
\hline$" 1$ & 76 & EV & EV & none & \\
\hline$" 1$ & 77 & EV & $\mathrm{EV}$ & $\frac{\text { deceptrix }}{\text { variabilis }}$ & $\begin{array}{l}5 \\
2\end{array}$ \\
\hline$"$ & 78 & $\mathrm{EV}$ & EV & deceptrix & 1 \\
\hline$"$ & 79 & $\mathrm{EV}$ & $\mathrm{EV}$ & deceptrix & 1 \\
\hline$"$ & 81 & EV & EV & deceptrix & 4 \\
\hline$"$ & 82 & $\mathrm{EV}$ & EV & deceptrix & 10 \\
\hline \multirow[t]{2}{*}{$"$} & 83 & $\mathrm{EV}$ & $\mathrm{EV}$ & deceptrix & 14 \\
\hline & & & & $\frac{\overline{\text { despecta }}}{\text { variabilis }}$ & $\begin{array}{l}1 \\
1\end{array}$ \\
\hline$"$ & 84 & EV & EV & deceptrix & 4 \\
\hline \multirow[t]{8}{*}{$"$} & 119 & EV & RI & despecta & 17 \\
\hline & & & & dodsoni & 1 \\
\hline & & & & hemichlora & 5 \\
\hline & & & & imperialis & 2 \\
\hline & & & & townsendi & 1 \\
\hline & & & & tridentata & 1 \\
\hline & & & & variabilis & 23 \\
\hline & & & EV & deceptrix & 2 \\
\hline \multirow[t]{3}{*}{$"$} & 80 & Almirante, & EV & deceptrix & 25 \\
\hline & & Bocas del & oro & gorgonensis & 2 \\
\hline & & Panama & & variabilis & 4 \\
\hline \multicolumn{6}{|l|}{ quinque- } \\
\hline nervis $B$ & 138 & $\begin{array}{l}\text { Golfito, } \\
\text { Costa Rica }\end{array}$ & EV & dodsoni & 8 \\
\hline$"$ & 129 & $\mathrm{EV}$ & $\mathrm{EV}$ & gorgonensis & 4 \\
\hline tricolor & 32 & RI & EV & cyanura & 8 \\
\hline tricolor & 43 & $\mathrm{CA}$ & RI & cyanura & 6 \\
\hline
\end{tabular}


attracted from 1 to 12 Euglossa deceptrix. Two plants also attracted a few Euglossa variabilis and/or Euglossa despecta. In general, visitors to Gongora at $\mathrm{El}$ Valle were rather uncommon, even though flowering Gongoras are common and visitation to baits is high. one plant of $\underline{G}$. quinquenervis group A from El Valle attracted no visitors at El Valle, but the same plant attracted over fifty bees of seven species when transported to Rio Iguanita. Another plant from Rio Iguanita was transplanted to El Valle, where it attracted no bees during two mornings. At Rio Iguanita, heavy bee visitation was observed on two out-of-reach inflorescences of G. quinquenervis. This contrasts with the low visitation rates observed at El Valle.

one plant of $\underline{G}$. quinquenervis group A from Almirante (western Panama) flowered at El Valle alongside two plants from El Valle. The flowers of the Almirante plant are virtually identical in morphology, coloration and scent to the El Valle plants, yet it attracted 31 individuals of 3 species whereas the two El Valle plants beside it attracted only two or three bees each (Table 11). Fragrance analysis revealed that the Almirante plant produces a higher percentage of MMC ( $86 \%$; both isomers) than do the El valle plants $($ mean $=42 \%$ ). This higher percentage might explain the larger number of bees (especially E. deceptrix) attracted by the Almirante plant. Clearly, larger sample sizes are needed for fragrance analysis and reciprocal transplants. 
Visitors were observed at two plants of $\mathrm{G}$. quinquenervis group B (\#129 and \#138). One plant (\#129) was collected at El Valle, and its fragrance is dominated by terpinen-4-ol (41\% terpinen-4-01,18\% CLME, $9 \%$ cineole, $7 \%$ myrcene). This plant attracted four Euglossa gorgonensis. The other plant is from Golfito, Costa Rica, and produces mostly CLME (56\% CLME, $18 \%$ p-cymene); it attracted four E. dodsoni. Dressler (1968a) reported that a plant of this variety attracted $\underline{E}$. flammea and $\underline{E}$. dodsoni at Golfito and $\underline{E}$. dodsoni in central Panama.

Two plants of $G$. tricolor, one of the p-cresol form from Rio Iguanita (\#32) and one of the ipsdienol form from cerro Azul (\#43), were observed at El Valle; both plants attracted only Euglossa cyanura.

\section{Bees Attracted to Synthetic Fragrance compounds}

Most of the major compounds of each fragrance were available in synthetic form for bioassay (Table 12). Of the six compounds tested from G. tricolor, only three compounds (p-cresol, ipsdienol, and phenylethyl alcohol) attracted the pollinator, E. cyanura. The attraction is not speciesspecific; two of the compounds attracted numerous other species in addition to $\underline{E}$. cyanura. The key attractants in the fragrance of each variety are probably p-cresol (group A) and ipsdienol (group B), and the other compounds probably act as modifiers to exclude all other bee species. 
Table 12. Numbers of bees attracted to synthetic Gongora fragrance compounds at four sites.

\begin{tabular}{|c|c|c|c|c|c|}
\hline \multirow[b]{2}{*}{ Compound } & \multirow[b]{2}{*}{ Bee Species ${ }^{a}$} & \multicolumn{4}{|c|}{ Locality $^{b}$} \\
\hline & & EV & $\mathrm{EC}$ & $\overline{R I}$ & $\mathrm{CA}$ \\
\hline anisyl acetate & $\begin{array}{l}\text { El} \cdot \text { bombiformis } \\
\underline{\text { El}} \cdot \text { cingulata }\end{array}$ & $\begin{array}{l}1 \\
1\end{array}$ & & & \\
\hline p-cresol & $\begin{array}{l}\frac{E q}{E g} \cdot \frac{\text { asarophora }}{\text { bursigera }} \\
\frac{E q}{E q} \cdot \frac{\text { crassipunctata }}{\text { Cyanura }} \\
\frac{E q}{\text { dissimula }} \\
\frac{E q}{\text { dodsoni }} \\
\frac{E l}{E l} \cdot \frac{\text { tridentata }}{\text { meriana }} \\
\text { nigrita }\end{array}$ & $\begin{array}{r}1 \\
9 \\
10 \\
2 \\
5\end{array}$ & $\begin{array}{r}60 \\
3 \\
4 \\
11\end{array}$ & $\begin{array}{r}8 \\
1 \\
62 \\
1\end{array}$ & \\
\hline ipsdienol & $\begin{array}{l}\frac{E g}{E g} \cdot \frac{\text { cyanaspis }}{\text { cyanura }} \\
\frac{E q}{E g} \cdot \frac{\text { crassipunctata }}{\text { despecta }} \\
\frac{E q}{E g} \cdot \frac{\text { flammea }}{\text { gorgonensis }} \\
\frac{E q}{E l} \cdot \frac{\text { tridentata }}{\text { meriana }} \\
\underline{E l} \cdot \frac{\text { nigrita }}{}\end{array}$ & 12 & 1 & $\begin{array}{r}2 \\
3 \\
1 \\
1 \\
14 \\
1 \\
2 \\
1\end{array}$ & \\
\hline $\begin{array}{l}\text { p-methyl anisole } \\
\text { phenylethyl } \\
\text { acetate }\end{array}$ & $\begin{array}{l}\text { Eg. deceptrix } \\
\text { none }\end{array}$ & 1 & & & \\
\hline $\begin{array}{l}\text { phenylethyl } \\
\text { alcohol }\end{array}$ & $\frac{E g}{E g} \cdot \frac{\text { cybelia }}{\text { cyanura }}$ & $\begin{array}{l}1 \\
1\end{array}$ & & & \\
\hline eugenol & $\begin{array}{l}\frac{E g}{E g} \cdot \frac{\text { bursigera }}{\text { crassipunctata }} \\
\frac{E g}{\text { deceptrix }} \\
\frac{E g}{E g} \cdot \frac{\text { dodsoni }}{\text { dressleri }} \\
\frac{E g}{E g} \cdot \frac{\text { mixta }}{\text { flammea }} \\
\frac{E g}{E g} \cdot \frac{\text { tridentata }}{\text { imperialis }} \\
\frac{E l}{E f} \cdot \frac{\text { cingulata }}{\text { lucifera }}\end{array}$ & $\begin{array}{r}1 \\
13\end{array}$ & $\begin{array}{r}1 \\
2 \\
16\end{array}$ & $\begin{array}{l}1 \\
4\end{array}$ & 3 \\
\hline
\end{tabular}


Table 12 (Continued).

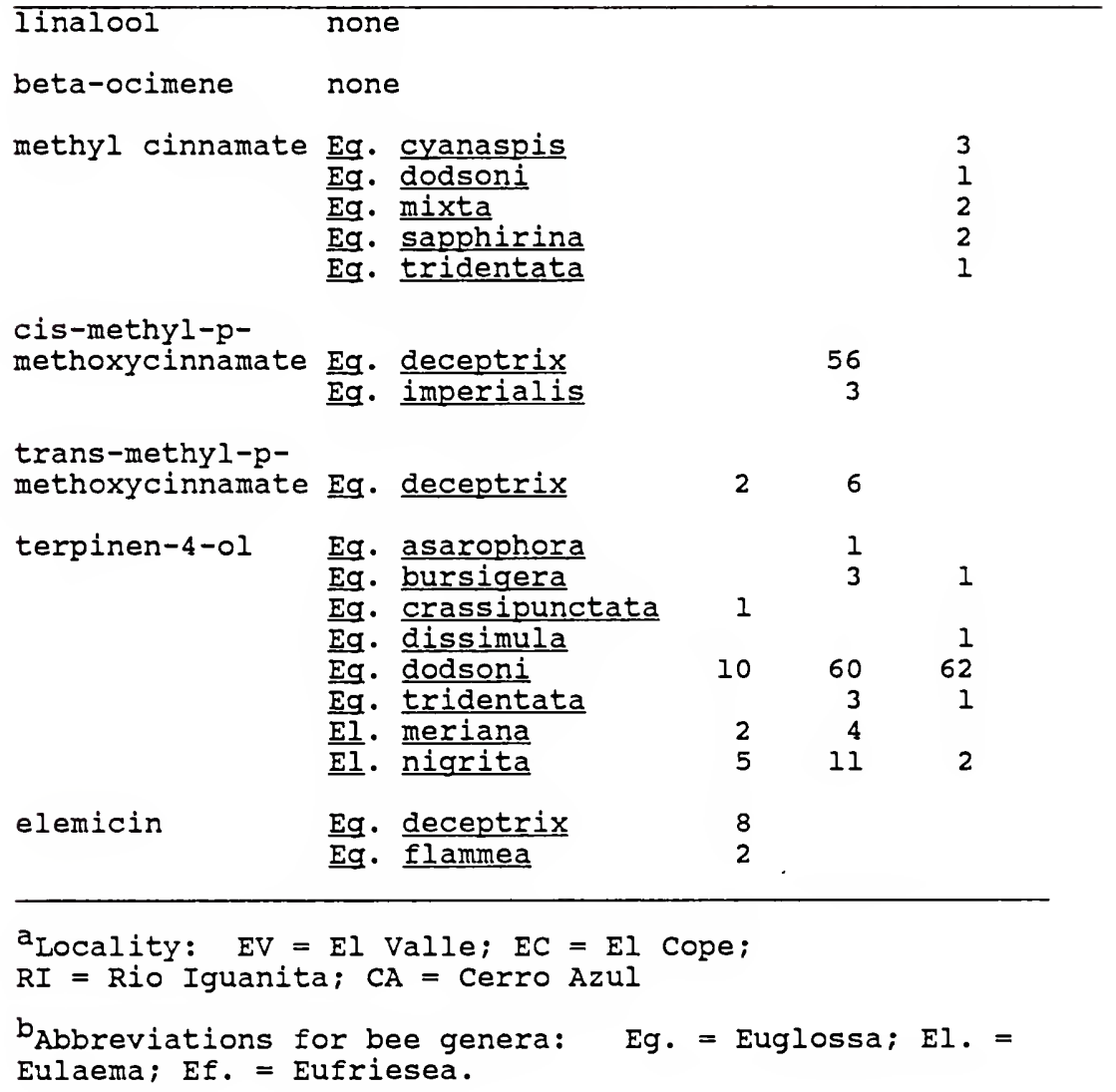


Gongora gibba fragrance contains only MMC and elemicin, but both of these compounds failed to attract the known visitors. Reasons for this failure are unknown.

Gongora quinquenervis group B attracts $\underline{E}$. dodsoni, E. flammea, and/or E. gorgonenesis, depending upon the individual and locality. The only potent attractant tested was terpinen-4-ol; it attracted a variety of bees including $\underline{E}$. dodsoni, but not $\underline{E}$. flammea or $\underline{E}$. gorgonensis. CIME was not tested, but it is probably a key attractant of $\underline{G}$. quinquenervis group $B$. The ratio of this compound to terpinen-4-ol might determine the pollinators attracted.

Iinalool, beta-ocimene, methyl cinnamate, eugenol, and MMC occur in the fragrance of $G$. quinquenervis group $A$. Linalool, beta-ocimene, and methyl cinnamate attracted few or no bees. MMC was a good attractant of $\underline{E}$. deceptrix at El Copé, but it attracted few bees at other sites. Euglossa deceptrix at El Copé were more strongly attracted to the cisisomer than the trans ( 56 bees to cis vs. 6 to trans). Eugenol attracted nine species of Euglossa, seven of which visit Gongora flowers (Table 12). However, it is a poor attractant of $\underline{E}$. tridentata and $\underline{E}$. deceptrix, and failed to attract $\underline{E}$. Variabilis. Since these three bee species are the major pollinators of $\underline{G}$. quinquenervis in central Panama, and since eugenol is present in only about $50 \%$ of the individuals of this variety, it seems improbable that eugenol is the key attractant. MMC is almost always present and is a specific attractant of the pollinator at EI Valle and El copé. 
The between site variation in bees attracted to MMC is perplexing. Virtually all of the Euglossa deceptrix caught at El Valle were collected at cineole, with only two caught at MMC, the major fragrance component of the orchid that it visits. It seems paradoxical that both the pollinator and orchid are very abundant at this site, yet natural and synthetic fragrance compounds attracted so few $\underline{E}$. deceptrix. At EI Cope, where $G$. quinquenervis is uncommon and $\underline{E}$. deceptrix is abundant, the synthetic MMC attracted 72 bees. The most likely hypothesis to explain the differences in fragrance-collecting behavior is that most of the $\underline{E}$. deceptrix at El Valle are satiated with MMC obtained from Gongora (or other sources) and hence are not attracted to the synthetic bait. A GC/MS analysis of the extracts of the hind tibia of $40 \mathrm{E}$. deceptrix collected at cineole at El Valle showed that $93 \%$ of the bee legs contained $>1 \%$ of MMC (mean $=$ $3.4 \%$ of volatile extractables; maximum $=6.8 \%$ ), but that only two bees (5\%) contained greater than $1 \%$ of cineole. The presence of MMC and the absence of cineole in their tibial organs implies (but does not prove) that most of the bees had already encountered and collected a quantity of MMC, but that cineole was a scarce resource which they were avidly seeking. The E. deceptrix at El Copé are not satiated because $\underline{G}$. guinguenervis is rare, and hence they are attracted to the synthetic MMC. Unfortunately, no samples of bee legs were obtained from El Copé. This hypothesis could be strengthened by comparing the amount of MMC in the hind 
legs of bees caught at Gongora flowers with the amounts present in bees caught at cineole. The above hypothesis does not explain the observations at Rio Iguanita. At Rio Iguanita, synthetic MMC attracted few bees, yet many bees were attracted to $\mathrm{G}$. quinquenervis fragrance containing MMC. one possible explanation is that the bees attracted to the flowers were seeking fragrance components other than MMC.

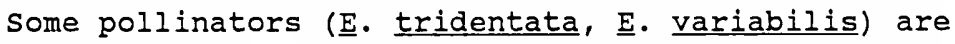
attracted poorly or not at all to the pure compounds. The data suggest that synergisms may occur, i.e., that mixtures of compounds may attract bee species not attracted to any pure compounds. Carefully designed experiments comparing pure compounds vs. mixtures are needed to resolve this question.

The role of individual compounds in the attraction of pollinators is far from clear. Theoretically, it should be possible to analyze completely a fragrance and then duplicate the fragrance with synthetic compounds to attract the same bee species. It should also be possible to vary the ratio of compounds in the mixture to elucidate the role of each compound. Such a study entails considerable difficulty in the synthesis and purification of compounds, in their controlled release, and in the replicates and sample sizes required. Geographic variation in bees' responses also need careful study. The data presented here can only suggest which compounds might be critical to the attraction of 
pollinators and hence might be markers of reproductively isolated forms.

\section{Alternative Fragrance Sources}

Male bee species that visit Gongora flowers were also observed collecting fragrances at other non-orchid sources. Euglossa deceptrix at El Valle collect fragrances from Spathiphyllum quindiuense Engl. ( $n=51$ bees). Williams and Dressler (1976) list E. crassipunctata, E. cyanaspis, and E. tridentata as pollinators of $\underline{S}$. quindiuense. The fragrance is dominated by an unidentified compound, and MMC is absent. Euglossa cyanura at El Valle collects fragrance from Anthurium ochranthum Koch (pers. obs.; Croat, 1980); its fragrance is dominated by ipsdienol (present in some $\underline{G}$. tricolor). At Rio Iguanita, over a hundred Euglossa were observed brushing on a well-rotted, punky log that had been broken open by a treefall on the previous day. A sample of the bees included $18 \mathrm{E}$. variabilis and $3 \mathrm{E}$. despecta. Analysis of a hexane extract of the wood revealed a complex mixture of sesquiterpenes, but no known Gongora fragrance compounds were present. At Rio Iguanita, a single Euqlossa dodsoni was seen brushing on the cut stem of a wilted, unidentified aroid vine.

\section{Floral Morphology of G. quinquenervis and G. gibba}

The two fragrance taxa of $\underline{G}$. quinquenervis and $\underline{G}$. qibba are readily distinguishable on the basis of morphology. of 
the 23 characters measured, two (hypochilar shoulder depth and the ratio of the proximal and distal hypochilar gap widths; see Fig. 1) showed highly significant differences among the three taxa. These two characters are plotted in Fig. 23. Gongora gibba is characterized by a convex base of the hypochile and by a wide hypochilar gap at the base of the lip. Gongora quinquenervis group A possesses a strongly concave hypochilar base and narrow, parallel sides of the hypochilar gap. Gongora quinquenervis group B is clearly intermediate in both characters. Cross-sections of the hypochile of all three forms are illustrated in Figure 24. The intermediacy of $\mathrm{G}$. quinquenervis group $\mathrm{B}$ suggests that it might a series of hybrids or be of hybrid origin. Dressler (1981) collected a plant of this variety near El Valle and regarded it as a natural hybrid between $\mathrm{G}$. quinquenervis and $\mathrm{G}$. gibba. He collected bees at the flowers of this plant and noted that it attracted bee species that do not visit either parent species. Evidence supporting hybridization includes its sympatry with both putative parents (at least in central Panama), the interfertility of all three taxa, and the possibility of overlapping pollinator sets (Euglossa gorgonensis has been recorded as at least a visitor to all three taxa; Table 11). Evidence against hybridization includes its presence in Costa Rica outside the reported range of $\mathrm{G}$. gibba, the largely disjunct pollinator sets of the parents, and a lack of intermediacy in the fragrance profile of the putative hybrid. Direct 


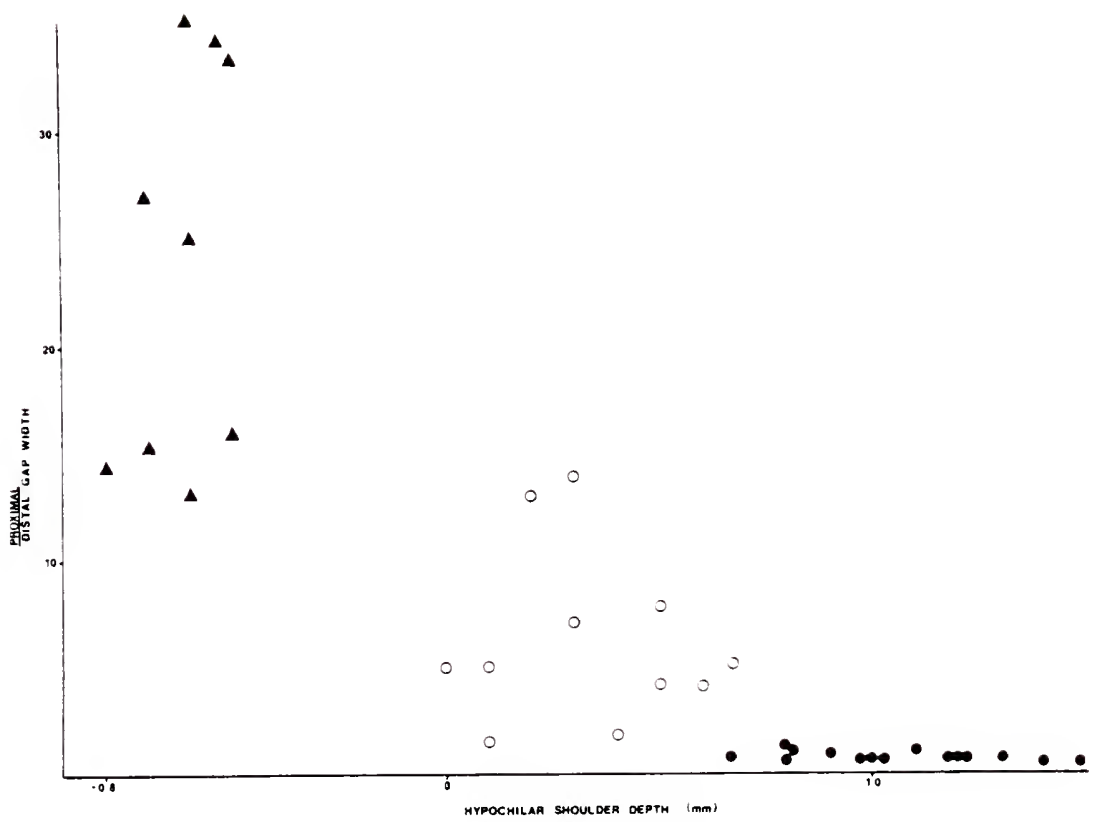

Figure 23. Plot of hypochilar shoulder depth versus the ratio of the proximal and distal widths of the hypochilar gap for Gongora gibba and Gongora quinquenervis group $A$ and group B. Symbols: solid circles $=\underline{G}$. quinquenervis group $A$; open circle $=\mathrm{G}$. quinquenervis group $\mathrm{B} ;$ triangle $=\mathrm{G}$. gibba. 


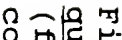

索苗

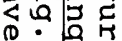

×

ธ

-

'

잉

క. 요

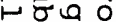

(1)

Do 0 un

$\sigma 1 \mathcal{1}$

ข.

त 20

-

की $\mathrm{th}$ O

叫的

- $r$.

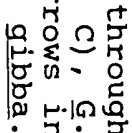

อ

‥

ค

त)

(1)

苗品

(D)

疋占.

on

Q 0

郝品

‥

包帝常

$\infty$

告苛

龺.

음

त

$>>$

م)

ro

(1)

苧

- ia

3.0

نه

(1)

त政

: 

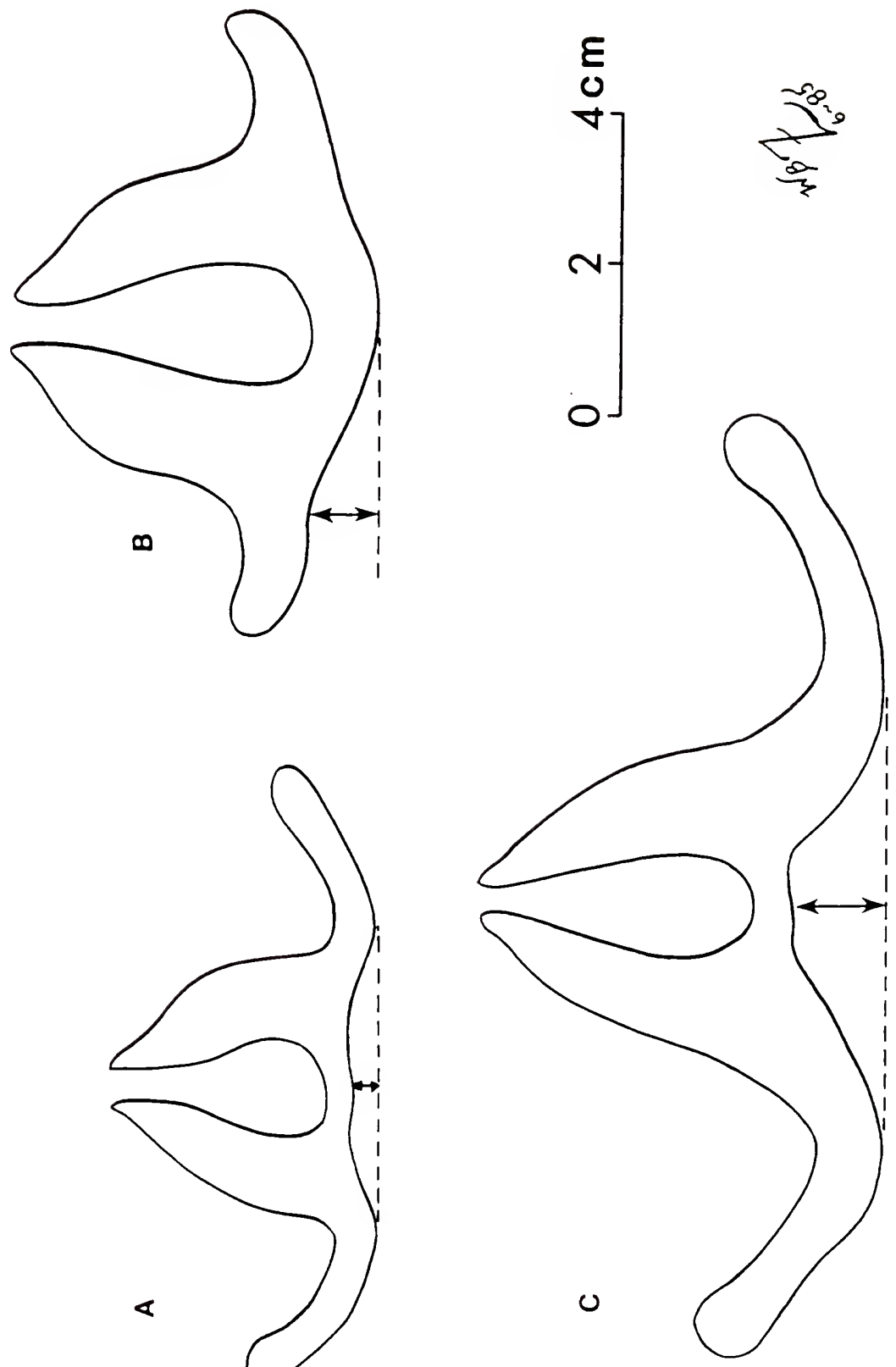
comparison of the morphology and fragrances of the putative hybrids with artificial gibba $\mathrm{x}$ quinquenervis group $\mathrm{A}$ hybrids is not yet possible because the artificial hybrids are still too young to flower.

Artificial hybrids between Gongora tricolor and $\underline{G}$. quinquenervis group A have flowered. Their morphology and fragrances are clearly intermediate between the parents. The hybrid fragrance is dominated by phenylethyl alcohol and phenylethyl acetate (from G. tricolor) and by MMC and eugenol (from $G$. quinquenervis). Compounds absent in the hybrids but present in one of the parents are p-cresol, indole, p-cymene, anisyl acetate, and beta-ocimene. Methyl isoeugenol occurs in the hybrid, but is absent from both parents (and all other Gongora species sampled to date). The inheritance of fragrance compounds appears to follow the patterns common to other secondary plant compounds such as flavonoids.

The fragrance data do not support a hybrid origin of the intermediate plants. Both putative parents are dominated by phenylpropane compounds, whereas the putative hybrids are dominated by terpenoid compounds. The major compounds of both parents are missing or present in small amounts in the putative hybrids. The major compounds of the putative hybrids (terpinene-4-Ol, CLME) are absent from the parents (although some clones of gibba contain small amounts of CLME). This lack of intermediacy is reflected in the PCA plots (Fig. 8); the putative hybrids are not positioned 
between or with the parental taxa, but are well displaced from them. 
CHAPTER IV

CONCLUSIONS

Can discrete fragrance/pollinator types be recognized? Yes, qualitatively different fragrance forms are readily recognizable, but extensive quantitative variation exists within these groups. Gongora tricolor, $\underline{G}$. gibba and $\underline{G}$. quinquenervis are valid biological and taxonomic species that are easily distinguished by floral morphology, fragrances, and pollinators. Data on pollinators are too few to make precise correlations with quantitative variations in compounds. In spite of infraspecific fragrance variation, Gongora tricolor appears to attract only one pollinator. If so, it is solely dependent upon Euglossa cyanura for pollination and cannot exceed the bee's geographic range. Gongora gibba is dominated by a unique compound (elemicin), and if Dressler's observations of visitors are representative, it may utilize any of several bee species as pollinators.

The fragrance of $\underline{G}$. quinquenervis group $A$ is quite variable, but most individuals produce large amounts of MMC. Based upon my observations and those of Dressler (Table 1) and Ackerman (1981), the pollinator fauna varies greatly among sites even in central Panama. The correlation between fragrance composition and pollinators appears to be poor, 
although the pollinator sets do not overlap with other species. The reciprocal transplants between El Valle and Rio Iguanita, as well as the qualitative similarity of fragrances, suggest that this variation in pollinator sets is due mainly to between-site variation in bee faunas, and not to geographic variation in fragrances. It appears that the fragrance of $G$. tricolor is highly specific and attracts only one pollinator species, whereas the fragrance of $\underline{\mathrm{G}}$. quinquenervis group $\mathrm{A}$ is more general and attracts many pollinator species. This generalist strategy could account in part for the wide geographic range of this species. Since bee faunas vary among sites, the corresponding pollinator sets may vary among sites even though fragrance composition is qualitatively identical. Data on pollinators of $\underline{G}$. quinquenervis group $B$ are scanty, but the fact that two clones attracted two different visitor species at the same site implies that the variation in the amounts of terpinen-4ol and CLME might be biologically significant. Gongora quinquenervis group B probably represents a valid, morphologically distinct and reproductively isolated species. More samples of this taxon and more information on its geographic range and variation in its fragrance and pollinators are needed to justify splitting this closelyrelated taxon out of Gongora quinquenervis.

Although floral fragrances can be used to distinguish Gongora taxa, fragrance composition is not uniform within a taxon. Considerable quantitative and qualitative variation 
exists within taxa as evidenced by the wide ranges in percent composition for the compounds in tables 4-8. Some of this variation is due to sampling error and phenotypic variation. However, the replicate sampling (Figs. 5 and 6) suggest that phenotypic variation between inflorescences is low and that most of the variation is genotypic.

This high amount of infraspecific variation suggests two possible explanations. The first is that there is low selective pressure exerted by pollinators on floral fragrance composition, and that minor variation does not affect the attraction of species-specific pollinators. However, observation of several flowering Gongora quinquenervis group A plants separated by less than one meter showed that bees ignored some plants but were attracted to others. Sample sizes of bees are low, but the data do suggest that bees discriminate among individual plants based on fragrance. If reproduction of Gongora is pollinator limited, then the production of a highly attractive fragrance should be under strong selective pressure. Such selective pressure seems highly probable but has not been demonstrated for Gongora. The second explanation of fragrance variation is that such variation is somehow adaptive. If male bees do discriminate among minor fragrance variants, it might be advantageous for an orchid species to vary in fragrance composition. We know that many euglossine species are attracted to several compounds, not just one, and that individual bees vary in their fragrance preferences. The 
basis for these preferences (genetic vs. ecological/metabolic) is unknown, but the preferences are probably affected by the availability of fragrance sources in the habitat. If a bee's fragrance needs vary in time and space, then it may find a particular Gongora fragrance unattractive at times. If the Gongora species offers a broader fragrance "menu", then at least some plants may prove attractive to the fickle bee and receive pollen. Gongora tricolor may serve as a hypothetical example. If the pollinator, Euglossa cyanura, becomes satiated with p-cresol from some other source, it might cease visitation to $\underline{G}$. tricolor group A. However, the bees might still require ipsdienol and hence would preferentially visit $\underline{G}$. tricolor group B. Seasonal and year to year variation in fragrance resources and bees' preferences might select for polymorphism in orchid fragrances, thereby insuring that some individuals of a population are pollinated.

Floral fragrances do have a special importance as taxonomic characters in certain orchids. Unlike most secondary plant chemicals whose biological function is largely unknown, the adaptive value of Gongora fragrance compounds can be demonstrated, at least in theory. This adaptive value is quantifiable in terms of numbers of individuals and species of pollinators (assuming these numbers affect reproductive success and reproductive isolation). Fragrance composition is an expression of a fixed, intrinsic genotype (excluding some phenotypic 
variation) and is a valid set of taxonomic characters. However, the actual pollinator set of a Gongora plant is an extrinsic trait, dependent upon the environment---the local bee fauna, other fragrance sources, habitat, and climate. Janzen (1977) noted the potential effect of habitat on the composition of pollinator sets and bees attracted to baits. The ethological mechanisms that isolate Gongora species are based upon differences in fragrance composition, but a difference in fragrance cannot be used to infer that two plants are ethologically isolated. In short, we cannot predict a priori the bees attracted to a fragrance because we do not understand 1) why bees are attracted to certain compounds; 2) how complex mixtures of compounds affect the attraction potential; and 3) why bee attraction to fragrances varies among individual bees and among sites. Answers to these major questions are necessary before fragrance analysis becomes a predictive tool in orchid pollination biology and taxonomy.

The available data on Gongora and other genera are inadequate to prove sympatric speciation. The sympatry of fragrance-based sibling species is ambiguous evidence for sympatric speciation. An alternative hypothesis to explain sympatric chemotypes is that an orchid species may radiate into different fragrance forms in peripheral or disjunct parts of its range in response to local variation in bee faunas. Once a distinct fragrance form is stabilized, it might expand its range to overlap with other forms, giving 
the appearance of sympatric speciation. Design of appropriate tests of speciation hypotheses appears difficult, especially with the meager data on orchid distributions.

since orchid fragrances are probably controlled by relatively few genes, the production of new fragrance forms might occur easily. If so, fragrance forms could easily be of polyphyletic origin. For example, if a population is limited by pollinator service and if the production of a new compound via a single mutation results in increased fruit set and reproduction, then it is probable that such a change could occur many times to give rise to a second fragrance form. Simple genetic control may also lead to convergence in fragrances between distantly-related species. Gongora claviodora Dressler and $\underline{G}$. atropurpurea Hooker are morphologically very different, yet both their fragrances are nearly pure eugenol. Presumably, they attract similar pollinators, but hybridization is prevented by allopatry. Another example of convergence is carvone oxide, a novel monoterpene produced by several distantly-related orchid genera and one species of Dalechampia (Euphorbiaceae). The likelihood of convergence will probably restrict the taxonomic usefulness of fragrances to specific and subspecific levels.

The present study has not fully unravelled the chemical ecology or the species relationships for the Gongoras of even a small geographic area. As Dressler (1972) stated, Gongoras probably will continue to cause headaches for botanists for 
years to come, and intensive field studies are necessary to resolve the taxonomic and ecological problems in the genus. 


\section{CHAPTER V}

\section{SPECULATION ON THE ORCHID/EUGLOSSINE INTERACTION AND SUGGESTIONS FOR FUTURE STUDIES}

At first glance, the orchid/euglossine interaction seems a spectacular example of coevolution. Several workers have examined the interaction critically and have found no evidence for a tight coevolved relationship (Dodson, 1975; Dressler, 1981; Ackerman 1983a,b;

Feinsinger, 1983). The evidence from phenology, distributions, pollination biology and chemical ecology support their views that the orchids have capitalized on the pre-existing fragrance-collecting behavior of bees and that the orchids have little effect on the evolution of the bees. The orchids do display numerous adaptations to utilize bees, but most of the adaptations are broad, applying to groups or size classes of euglossines. Examples of unique adaptations to a single euglossine species are doubtful, and exist only at the biochemical level as fragrance forms. Gongora tricolor, which attracts only one pollinator by its production of p-cresol or ipsdienol, is one possible example. However, the pollinator can and does obtain these compounds from other sources and probably is not dependent on the orchid for its fragrance requirements. 
Although the broad outline of the coevolutionary relationship seems clear, there are several aspects of the relationship which deserve further discussion and speculation. These are: 1 . How does the orchid/euglossine system compare with other pollination systems in terms of rewards and efficiency?; 2 . What is the major source of fragrances for male bees-- orchids or other plants?; 3. Are the orchid fragrances actually utilized by the bees, or are they mimics of other compounds that the bees seek and require?; 4. Why is fragrance production by orchids and fragrance collecting by bees largely restricted to the morning hours? Each topic is discussed below.

1. Comparison with other pollination systems.

Most pollination systems are based upon a trophic (i.e., nectar, pollen or oil) reward produced by the plant which maintains the services of the pollinators. Floral fragrance serves as a signal that the reward may be present. The ecological and evolutionary interactions between plants and pollinators are mediated largely by the production of these rewards. The orchid/euglossine system is different because no energetic reward is produced; instead, the fragrance is the reward.

Southwick (1984) showed that the energetic cost of floral nectar production is not insignificant. Estimates for milkweeds and alfalfa flowers range from 4-37\% of daily photosynthate. Is the cost of fragrance production in 
orchids also high? No data are available, but the quantities and rate of fragrance production could be measured easily using Tenax traps and GC analysis. Most male euglossine-pollinated orchid flowers have a discrete osmophore area of the lip that is rich in starch, and this starch probably serves as a substrate for fragrance biosynthesis. I predict that the energetic cost of fragrance synthesis is as high or higher than nectar rewards, and that energetic costs probably are a minor factor affection the evolution of fragrance-reward flowers. Dressler (1981) recognized the high frequency of nontrophic pollination systems in the orchidaceae. Systems such as nectar or pollen deceit, pseudo-copulation, pseudoantagonism, and euglossine pollination find their highest development in orchids. He lists five possible advantages of non-trophic systems over trophic systems. They include better reproductive isolation, greater fidelity, pollination over greater distances, greater outcrossing, and Ionger pollinator visits. Pollination by male euglossines provides all these advantages, and it is especially suited to orchids that exist at low population densities. Dressler states that euglossine pollination offers maximum opportunities for speciation; however, it is not certain whether changes in fragrance cause speciation or whether lability of fragrance composition simply facilitates the reproductive isolation of interfertile 
species whose ranges overlap (the wallace effect; Grant, 1971).

2. Major sources of fragrances for bees.

It is clear that male euglossines collect volatiles as a normal part of their biology. They possess numerous morphological and behavioral specializations for fragrance collection, suggesting that fragrances are somehow critical to their life cycle. However, the utility of the compounds to the bees is far from clear. Identification of bee mandibular gland compounds do not support the hypothesis of williams and Whitten (1983) that the fragrances serve as precursors of sex or territorial pheromones (Whitten, unpubl.). Regardless of the fate of the chemicals, fragrances are an important resource for male bees. They collect fragrances from orchids, other flowers, rotting wood and fruits, and abraded bark and roots. What proportion of a bee's fragrance needs are obtained from orchids? Are orchids a major or minor source?

Ackerman $(1983 a, b)$ examined the phenology of orchids and euglossines in central panama and concluded that the bees are not heavily dependent on the orchids for fragrances. He showed that many euglossine species are active even when their orchid hosts are not in flower and that one-third of the euglossine fauna of central Panama is not known to visit orchids for fragrances. In general, orchids do appear to be minor fragrance sources, although 
it is possible that the dependency may vary depending on the flora, bee fauna, and habitat. A direct measure of the relative importance of orchid sources vs. other sources seems impossible; both orchids and dicot sources are c-3 plants and carbon isotope ratios cannot distinguish between their fragrance compounds.

The production of a unique or rare fragrance compound (such as methyl-p-methoxycinnamate or ipsdienol) could be considered as evidence that at least some orchids are the sole source of a bee's chemical needs. However, the cornucopia of terpenoids and aromatics available in a tropical forest is so poorly studied that the term "rare compound" has little meaning at present.

It is not clear whether euglossine-pollinated orchids provide a real reward or whether they are actually deceit flowers. Two aspects have been ignored. First, do orchids produce enough sufficient fragrance for euglossine bees to collect and store as a "fragrance profit"? Some orchids (e.g., female catasetum, some Gongora) produce abundant oily droplets or crystals on the lip. Most others produce no visible accumulations of fragrances that could be mopped up by the bee's tarsal brushes. Other orchids, such as Stanhopea, restrict fragrance production to a recessed cavity of the lip that is inaccessible to the bees. It is likely that many orchids produce sufficient fragrance to entice the bees to the flowers, but not enough to allow the bees to become satiated. The longer flower visits increase 
the probability of pollination, which is necessary for the bizarre pollination mechanisms to function. Such orchids would be a form of deceit flower, since they promise a reward but provide none (at considerable energetic cost to the bee). Obviously, a gradient exists between reward quanitities of fragrance and deceit quantities. It is probable that the bees have the ability to gague their intake of fragrances, but experimental demonstrations of satiation are lacking. Schemske and Lande (1985) caged Euglossa imperialis and gave them daily access to cineole. The bees collected cineole intensely on the first day but spent much less time at the blotter pad on succeeding days. These results suggest that the bees may become satiated with a fragrance compound.

Another line of evidence supports the view that orchids are minor sources of fragrance for bees. If orchids were the major fragrance source, we would expect the bees to display evidence of a visual search image for fragrant flowers, similar to the search image demonstrated for nectar seeking bees. However, fragrance-collecting euglossines seem oblivious to the shape, size, and coloration of the fragrance source; the same brushing and transfer behavior is displayed at flowers, logs, or chemical-soaked blotter pads. This remarkable insensitivity to visual and tactile cues supports the hypothesis that bees collect fragrances from many varied sources and not just flowers. Such a lack of search image 
might also explain the great variation (both inter- and intraspecific) in flower shape and coloration found in some orchid species. The bees probably exert little selection pressure on floral shape and color except for critical shapes of the lip and column that guide the bee's position and contact with the visicidium. Indeed, in genera such as Catasetum, Stanhopea, and Coryanthes the sepals and petals are becoming vestigial. These parts are often thintextured, and they wither quickly and appear to function mainly as protection for the lip and column while in bud. Floral colors are highly variable in some species of these genera, and low selection pressure might account for Dressler's (1966) observation that flower color is a treacherous taxonomic character in these groups. A similar example occurs in orchis galilea (Bino et al., 1982). Male Halictus marginatus are attracted primarily by the scent of the orchid and not by visual cues. The orchid exists in three sympatric color forms, and the pollinator visits all three indiscriminately.

Dressler (1981) also noted that generic boundaries in orchids pollinated by male euglossines are often correlated with different placements of pollinaria on the bees. It is possible that relaxed selection on floral morphology could result in greater overall variability in morphology, and that such variation might foster radiation into new pollination mechanisms resulting in new genera.

3. Chemical mimicry. 
Do orchids provide the compounds actually sought and used by the bees, or are the bees deceived into collecting similar-smelling compounds that they cannot utilize? A non-floral example is provided by Eufriesea purpurata, which is strongly attracted to synthetic DDT (Roberts et al. 1983). The pesticide must mimic some natural product sought by the bee. It is possible that some orchid fragrance compounds (and some synthetic baits for euglossines) are mimics of other compounds naturally sought and utilized by the bees. Orchids producing such fragrances would also be deceit flowers, since they fail to provide a legitimate reward to the pollinator. An analogy in nectar flowers would be a hummingbird flower that produces aspartame instead of sugar.

Investigation of these two aspects of deceit (fragrance quantity and chemical mimicry) is feasible but difficult. The first would require quanitification of fragrance production and of the efficieny of fragrance collection by the bees, using GC/MS analysis and labelling of compounds. The second could be tested only by studying the metabolic fate of compounds and their influence on bee behavior.

4. Diurnal rhythms of fragrance production and collection.

The diurnal rhythm of the orchid/bee interaction might be interpreted as evidence of diffuse coevolution. 
Euglossine-pollinated orchids produce fragrance most strongly during the morning and early afternoon, and production ceases in the afternoon and evening. Euglossine bees collect fragrances most intensely during the morning, and fewer bees are attracted to baits in the afternoon. Their wariness also increases during the day. In the morning, fragrance-collecting bees seem oblivious to other stimuli and are easily captured, but in the afternoon they become quite wary and are difficult to approach. Are the bees adapted to some innate diurnal rhythm of orchid fragrance secretion, or have the orchids tailored their fragrance production to fit the bee's behavior? Have both adapted in a coevolutionary manner? The answer depends upon whether orchids are a major source of fragrance for bees. If we assume that orchids are not, then the orchids are probably altering their fragrance production pattern to fit the bee's behavior.

This hypothesis leads us to question why bees collect fragrances only in the morning. One possible answer is that the hours spend fragrance-foraging are governed by nectar resources. Euglossines must divert time from nectar foraging in order to collect fragrances. If nectar sources are abundant in the morning, a bee could fill its crop and then spend time collecting fragrances. If nectar resources are scarce in the afternoon, energetic constraints might prevent the bee from diverting time to fragrance-foraging. Frankie and Haber (1983) showed that nectar production and 
nectar volumes are higher during the morning in several Costa Rican tree species that are pollinated by nectarforaging euglossines.

A second hypothesis to explain morning fragrance collection is that collection of fragrances is more efficient during the morning because air temperature is lower and the compounds are less volatile. The process of brushing fragrances from the source, hovering, and transfer to the hind tibial organ must involve some loss of fragrance via volatilization, but the efficiency is unknown (and would vary with each compound and mixture). Since the rate of volatilization increases with temperature, the bee's efficiency of collection might be unprofitable during the afternoon when temperatures are higher.

Both hypotheses appear difficult to test, and they are not mutually exclusive. The former hypothesis (nectar availability) could be strengthened by measuring crop nectar volumes of bees caught at baits and at food plants at various times of the day. The latter hypothesis (temperature) could be tested only by using GC/MS to measure bees' efficiency of collection of a labelled compound at various temperatures.

\section{Recommendations for Future Research}

The greatest gaps in our knowlege of orchids and euglossines involve the chemical ecology and behavior of the bees. We need to know what male euglossines do with 
the compounds that they collect and what role the compounds have in the bees' life cycle. Such studies will require use of GC/MS analysis to study the distribution and metabolism of labelled compounds in bee bodies. Equally important are controlled experiments on captive bees to elucidate the effect of fragrances on male bee behavior. The results of these studies should provide needed direction for other studies of the interaction.

Even without answers to these questions, there are fruitful lines of research. We have some evidence that the fragrance preferences of euglossine species may vary geographically, but rigorous sampling is needed to test for such variation. We do not know how many chemicals constitute the fragrance "diet" of any bee species, nor do we know how a species' "diet" varies seasonally and geographically. Such data could be obtained by analysis of hind tibial extracts of large sample sizes of bees. We have no estimate of the total number of compounds involved in the orchid/euglossine interaction, and a survey of orchid fragrances and bee tibial contents is the only way to provide even a rough estimate. Even less data exists on the fragrances of orchids that are not pollinated by male euglossines, and we cannot predict whether a given orchid fragrance will attract male euglossines or other pollinators.

The utility of orchid fragrances as taxonomic characters above the species level is uncertain, but more 
data are required before their utility can be evaluated. Many fragrance compounds remain unidentified (especially sesquiterpenes). As more compounds are identified, the potential usefulness of the compounds in cladistic studies may increase. Studies of the biosynthetic pathways of fragrance compounds would be of great utility in determining character state polarities for cladistic studies, but such studies await the interest of biochemists.

The most important areas of study of Gongora are a survey of fragrances and pollinators of all the species, coupled with a study of geographic variation in the wideranging species of the $\mathrm{G}$. quinquenervis complex. No monograph of the genus exists, and many species are poorly represented in herbaria and are lost to cultivation. Interesting problems of floral homologies need to be solved before cladistic analyses can be used. A survey of the fragrances of species in cultivation is underway, but field work is essential for pollination studies and to resolve taxonomic problems. 


\section{LITERATURE CITED}

Ackerman, J.D. 1981. The phenological relationships of male euglossine bees (Hymenoptera: Apidae) and their orchid fragrance hosts. Doctoral dissertation, Florida state University, Tallahassee, Florida.

- 1983a. Diversity and seasonality of male euglossine bees (Hymenoptera: Apidae) in central Panama. Ecology $64: 274-283$.

- 1983b. Specificity and mutual dependency of the orchid-euglossine bee interaction. Biol. J. Linn. Soc. $20: 301-314$.

Adams, R.P. 1972. Numerical analyses of some common errors in chemosystematics. Brittonia 24:9-2l.

Adams, R.P. and L. Hogge. 1983. Chemosystematic studies of the Caribbean Junipers based on their volatile oils. Biochem. Syst. Ecol. 11:85-89.

Adams, R.P., E. von Rudloff and L. Hogge. 1983. Chemosystematic studies of the western North American Junipers based on their volatile oils. Biochem. Syst. Ecol. 11:189-193.

Adams, R.P., T.A. Zanoni and I. Hogge. 1984. Analyses of the volatile leaf oils of Juniperus deppeana and its infraspecific taxa: Chemosystematic implications. Biochem. Syst. Ecol. 12:23-27.

Allen, P.H. 1949. Flora of Panama (Orchidaceae). Part III. Fascicle 4. Ann. Missouri Bot. Gard. 36:1-132.

- 1950. Pollination in Coryanthes speciosa. Amer. orchid Soc. Bull. 19:528-536. 
1954. Pollination in Gongora maculata. Ceiba 4:121125 .

Armbruster, W.S. 1984. The role of resin in angiosperm pollination: ecological and chemical considerations. Amer. J. Bot. 71:1149-1160.

Armbruster, W.S. and G.I. Webster. 1979. Pollination of two species of Dalechampia (Euphorbiaceae) in Mexico by euglossine bees. Biotropica 11:278-283.

Baum, B.R., T. Duncan, and R.B. Phillips. 1984. A bibliography of numerical phenetic studies in systematic botany. Ann. Missouri Bot. Gard. 71:1044-1060.

Baum, B.R., A.P. Tulloch, and L.G. Bailey. 1980. A survey of epicuticular waxes among genera of Triticeae. I. Ultrastructure of glumes and some leaves as observed with the scanning electron microscope. Can. J. Bot. 58:2467-2480.

Bino, R.J., A. Dafni, and A.D.J. Meeuse. 1982. The pollination ecology of orchis galilea (Bornm. et Schulze) Schltr. (Orchidaceae). New Phytologist 90:315319 .

Bowman, R.N. 1980. Phylogenetic implications from cuticular wax analyses in Epilobium sect. Zauschneria

(Onagraceae). Amer. J. Bot. 67:671-685.

- 1983. Intraspecific variability of leaf cuticle alkanes in Sedum lanceolatum along an elevational gradient. Biochem. Syst. Ecol. 11:195-198.

Croat, T.B. 1980. Flowering behavior of the neotropical genus Anthurium (Araceae). Amer. J. Bot. 67:888-904.

Dodson, C.H. 1962. The importance of pollination in the evolution of the orchids of tropical American. Amer. orchid Soc. Bull. 31:525-534, 641-649, 731-735.

- 1970. The role of chemical attractants in orchid pollination. pp.83-107. In K.L. Chambers (ed.), 
Biochemical Coevolution. Oregon State Univ. Press, Corvallis.

- 1978. Three new South American species of Catasetum (Orchidaceae). Selbyana 2:159-168.

Dodson, C.H., R.L. Dressler, H.G. Hills, R. M. Adams, and N.H. Williams. 1969. Biologically active compounds in orchid fragrances. Science 164:1243-1249.

Dodson, C.H. and G.P. Frymire. 1961. Natural pollination of orchids. Missouri Bot. Gard. Bull. 49:133-152.

Dodson, C.H. and A.H. Gentry. 1978. Flora of the Rio Palenque Science Center. Selbyana 4:1-628.

Dodson, C.H. and H.G. Hills. 1966. Gas chromatography of orchid fragrances. Amer. Orchid Soc. Bull. 35:720-725.

Dressler, R.L. 1966. Some observations on Gongora. Orchid Digest $30: 220-223$.

- 1967. Why do euglossine bees visit orchid flowers?

Atas do Simpósio sobre a Biota Amazonica 5:171-180.

- 1968a. Pollination by euglossine bees. Evolution $22: 202-210$.

- 1968b. Observations on orchids and euglossine bees in Panama and Costa Rica. Rev. Biol. Trop. 15:143-183.

- 1972. Dos especies nuevas de Gongora. Orquideologia $7: 71-77$.

1981. The orchids: Natural History and Classification. Harvard University Press, Cambridge. $332 \mathrm{pp}$.

- 1982. Biology of the orchid bees (Euglossini). Ann. Rev. Ecol. Syst. 13:373-394. 
Dunsterville, G.C.K. and I.A. Garay. 1959. Venezuelan Orchids Illustrated. Vol. I. Andre Deutsch, London. $448 \mathrm{pp}$.

Feinsinger, P. 1983. Coevolution and pollination. Pp. 282310 in D.J. Futuyma and M. Slatkin (eds.) Coevolution. Sinauer Assoc., Inc., Sunderland, Mass.

Gregg, K.B. 1983. Variation in floral fragrances and morphology: incipient speciation in Cycnoches? Bot. Gaz. $144: 566-576$.

Hayashi, N., M. Masuoka, K. Maeshima, T. Sakao, M. Tabata and H. Komae. 1983. Phenol ethers and terpenes of six Heterotropa species distributed in the Ryukyu Islands and Formosa. Agr. Biol. Chem. 47:1397-1399.

Hills, H.G., N.H. Williams, and C.H. Dodson. 1968. Identification of some orchid fragrance components. Amer. Orchid Soc. Bull. 37:967-971.

- 1972. Floral fragrances and isolating mechanisms in the genus Catasetum (Orchidaceae). Biotropica 4:61-76.

Janzen, D.H. 1977. Promising directions of study in tropical animal-plant interactions. Ann. Missouri Bot. Gard. 64:706-736.

Janzen, D.H., P.J. DeVries, M.I. Higgins, and I.S. Kimsey. 1982. Seasonal and site variation in Costa Rican euglossine bees at chemical baits in lowland deciduous and evergreen forests. Ecology 63:66-74.

Jenny, R. 1983. Die Gongorinae, 6. Gongora Teil VI: Gongora gibba, Gongora aromatica, Gongora grossa, Gongora fulva. Die Orchidee 34:147-157.

Konoshima, T. and T. Sawada. 1984. Studies on the constituents of leguminous plants. VI. The structure elucidations of monoterpene glycosides from fruits of Gymnocladus chinensis Baillon. Chem. Pharm. Bull. $32: 2617-2621$. 
Lassak, E.V. and I.A. Southwell. 1974. Occurrence of some unusual compounds in the leaf oils of Eriostemon obovalis and Phebalium glandulosum subsp. glandulosum. Aust. J. Chem. 27:2703-2705.

Iight, D.M. and M.C. Birch. 1982. Bark beetle enantiomeric chemoreception: Greater sensitivity to allomone than pheromone. Naturwissenschaften 69:243-244.

Mohacsi, E. 1982. A convenient preparation of methyl esters from carboxylic acids. Synthetic Communications 12:453456 .

Okada, Y., K. Koyama, K. Takahashi, T. Okuyama and S. Shibata. 1980. Gleditsia saponins. I. Structures of monoterpene moieties of Gleditsia saponin C. Planta Medica 40:185-192.

Pollack, J.C. and B.P. Dancik. 1985. Monoterpene and morphological variation and hybridization of pinus contorta and $\underline{P}$. banksiana in Alberta. Can. J. Bot. $63: 201-210$.

Rao, Y.S. and R. Filler. 1976. Trans- to cis-isomerization of cinnamic acids and related carbonyl compounds. Chem. Comm. : $471-472$.

Schilling, E.E., Jr., and C.B. Heiser Jr. 1976. Reexamination of a numerical taxonomic study of Solanum species and hybrids. Taxon 25:451-462.

Smith, A.B., A.M. Belcher, G. Epple, P.C. Jurs and B. Lavine. 1985. Computerized pattern recognition: A new technique for the analysis of chemical communication. Science 228:175-177.

Sneath, P.H.A. 1976. Phenetic taxonomy at the species level and above. Taxon 25:437-450.

Sneath, P.H.A. and R.R. Sokal. 1973. Numerical taxonomy. W.H. Freeman and Co., San Francisco, CA.

Southwood, T.R.W. 1978. Ecological Methods. Chapman and Hall, London. 
Southwick, E.E. 1984. Photosynthate allocation to floral nectar: A neglected energy investment. Ecology $65: 1775-1779$.

Stone, D.E., G.A. Adrouny and R.H. Flake. 1969. New World Juglandaceae. II. Hickory nut oils, phenetic similarities, and evolutionary implications in the genus Carya. Amer. J. Bot. 56:928-935.

Thien, L.B., W.H. Heimermann and R.T. Holman. 1975. Floral odors and quantitative taxonomy of Magnolia and Liriodendron. Taxon 24:557-568.

Tulloch, A.P., B. R. Baum and L.L. Hoffman. 1980. A survey of epicuticular waxes among genera of Triticeae. 2 . Chemistry. Can. J. Bot. 58:2602-2615.

Whiffin, T. 1977a. Volatile oils and the study of natural hybridization between Correa aemula and $\subseteq$. reflexa (Rutaceae). Austral. J. Bot. 25:291-298.

- 1977b. Geographic variation in tropical tree species. Pp. 31-54. In P.B. Tomlinson and M.H. Zimmermann (eds.) Tropical Trees as Living Systems. Cambridge Univ. Press. London. $675 \mathrm{pp}$.

- 1981. Analysis of hybridization between Eucalyptus pauciflora Sieber ex Spreng. and $\underline{E}$. radiata Sieber ex DC. (Myrtaceae). Bot. J. Iinn. Soc. 83:237-250.

Whitten, W.M., N.H. Williams, W.S. Armbruster, M.A. Battiste, L. Strekowski and $N$. Lindquist. Carvone oxide: an example of convergent evolution in euglossine-polinnated orchids. Systematic Botany. In press.

Wiehler, H. 1976. A report on the classification of Achimenes, Eucodonia, Gloxinia, Goyazia, and Anetanthus (Gesneriaceae). Selbyana 1:374-404.

Williams, N.H. 1982. The biology of orchids and euglossine bees. Pp. 119-171 In J. Arditti (ed.). Orchid Biology: Reviews and Perspectives, II. Cornell Univ. Press, Ithaca, N.Y. 
- 1983. Floral fragrances as cues in animal behavior. Pp. 50-72 In C.E. Jones and R.J. Little (eds.). Handbook of Experimental Pollination Biology. Van Nostrand Reinhold Company, New York.

Williams, N.H. and C.H. Dodson. 1972. Selective attraction of male euglossine bees to orchid floral fragrances and its importance in long-distance pollen flow. Evolution $26: 84-95$.

Williams, N.H. and R.L. Dressler. 1976. Euglossine pollination of Spathiphyllum (Araceae). Selbyana 1:349356.

Williams, N.H. and W.M. Whitten. 1983. Orchid floral fragrances and male euglossine bees: Methods and advances in the last sesquidecade. Biol. Bull. 164:355395.

Williams, N.H., W.M. Whitten and L. Pedrosa. 1985. Crystalline production of fragrance in Gongora quinquenervis. Amer. Orchid Soc. Bull. 54:598-603.

Wishart, D. 1978. CLUSTAN users manual. Third edition. Edinburgh Univ., Edinburgh. 


\section{BIOGRAPHICAL SKETCH}

William Mark Whitten was born October 20, 1954, in Memphis, Tennessee. He attended Bishop Byrne High School in Memphis and was graduated in 1972. He attended Thomas More College in Covington, Kentucky, and was graduated with a B.A. in biology in 1976. While in college, he worked for various environmental consulting firms on the phytoplankton of the Ohio River. He obtained a M.S. in botany from the University of Tennessee at Knoxville in 1979, working on plant taxonomy, pollination ecology, and range extensions of the moss Bryoxiphium norvegicum. In 1979, he enrolled in a doctoral program at Florida state University under the direction of Norris williams. He transferred to the University of FIorida in 1980 to continue studies on orchid taxonomy and biology, and he spent a summer as an intern at the orchid Identification Center of the Marie Selby Botanical Gardens. His research interests have involved field work in the southern Appalachians, Ecuador, and Panama. 
I certify that I have read this study and that in my opinion it conforms to acceptable standards of scholarly presentation and is fully adequate, in scope and quality, as a dissertation for the degree of Doctor of Philosophy.

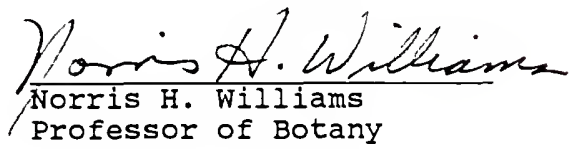

I certify that I have read this study and that in my opinion it conforms to acceptable standards of scholarly presentation and is fully adequate, in scope and quality, as a dissertation for the degree of Doctor of Philosophy.

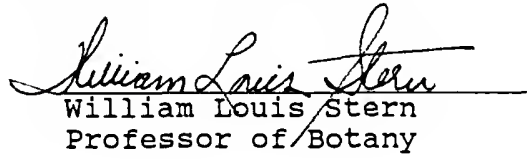

I certify that I have read this study and that in my opinion it conforms to acceptable standards of scholarly presentation and is fully adequate, in scope and quality, as a dissertation for the degree of Doctor of Philosophy.

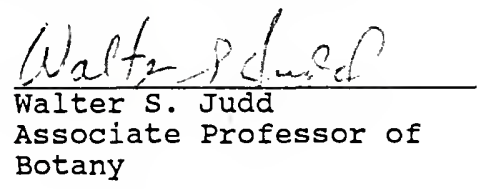

I certify that I have read this study and that in my opinion it conforms to acceptable standards of scholarly presentation and is fully adequate, in scope and quality, as a dissertation for the degree of Doctor of Philosophy.

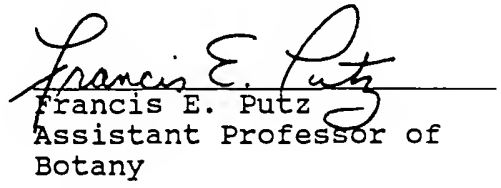

I certify that I have read this study and that in my opinion it conforms to acceptable standards of scholarly presentation and is fully adequate, in scope and quality, as a dissertation for the degree of Doctor of Philosophy.

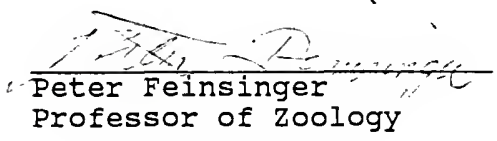


This dissertation was submitted to the Graduate Faculty of the Department of Botany in the College of Liberal Arts and Sciences and to the Graduate School and was accepted as partial fulfillment of the requirements for the degree of Doctor of Philosophy.

August, 1985

Dean, Graduate School 
UNIVERSITY OF FLORIDA

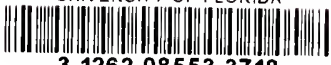

$\begin{array}{lll}31262 & 08553 & 3718\end{array}$ 